\title{
SISTEMA AUTOMÁTICO PARA OBTENÇÃO DE PARÂMETROS DO TRÁFEGO VEICULAR A PARTIR DE IMAGENS DE VÍDEO USANDO OPENCV
}

Tese apresentada à Escola de Engenharia de São Carlos, da Universidade de São Paulo, como parte dos requisitos para a obtenção do título de Doutor em Ciências, Programa de Pós-graduação em Engenharia de Transportes, área de concentração: Planejamento e Operação de Transportes.

Orientador: Prof. Dr. José Reynaldo Anselmo Setti 
AUTORIZO A REPRODUÇÃO TOTAL OU PARCIAL DESTE TRABALHO, POR QUALQUER MEIO CONVENCIONAL OU ELETRÔNICO, PARA FINS DE ESTUDO E PESQUISA, DESDE QUE CITADA A FONTE.

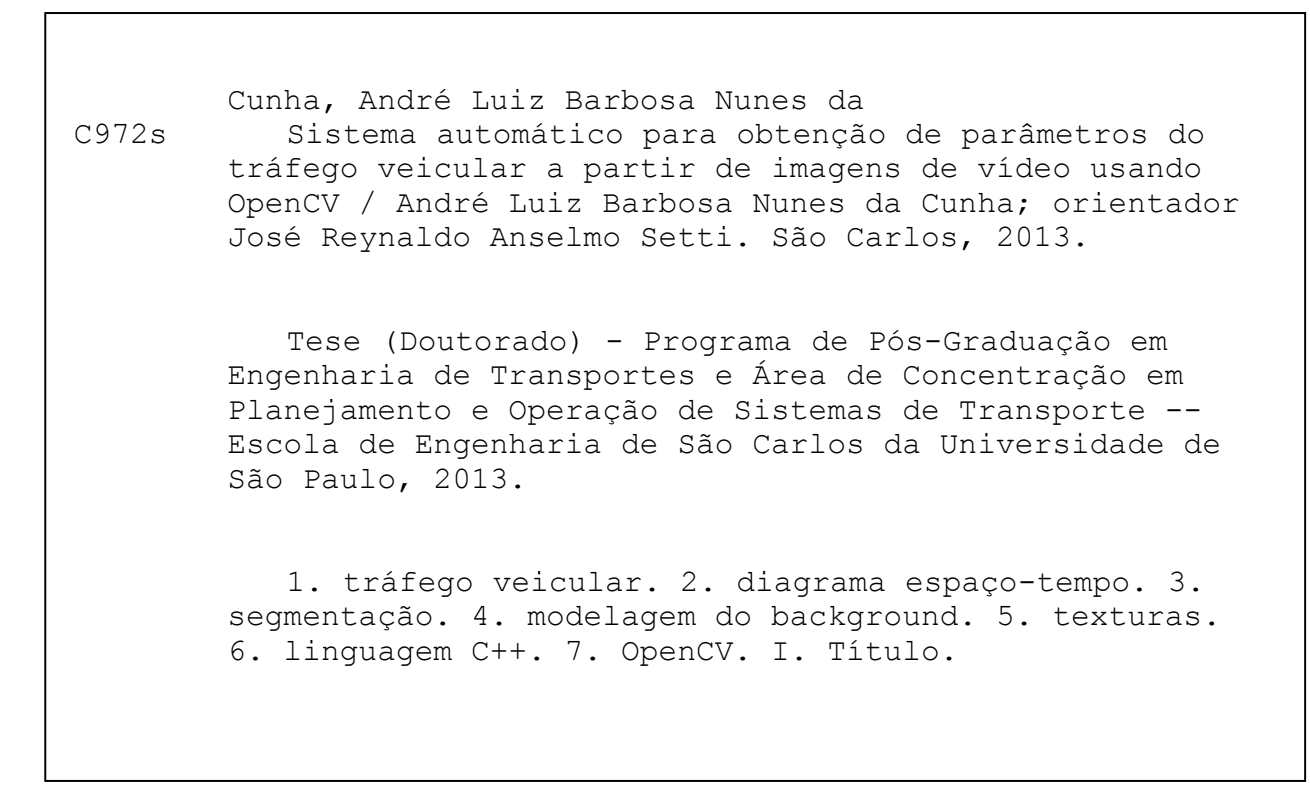




\section{FOLHA DE JULGAMENTO}

\section{Candidato: Engenheiro ANDRÉ LUIZ BARBOSA NUNES DA CUNHA}

Título da tese: "Sistema automático para obtenção de parâmetros do tráfego veicular a partir de imagens de vídeo usando OpenCV"

Data da defesa: 08/11/2013

\section{Comissão Julgadora:}

Prof. Titular José Reynaldo Anselmo Setti (Orientador)

(Escola de Engenharia de São Carlos/USP)

Prof. Titular João Alexandre Widmer

(Escola de Engenharia de São Carlos/USP)

Prof. Associado Adilson Gonzaga

(Escola de Engenharia de São Carlos/USP)

Prof. Dr. Werner Kraus Junior

(Universidade Federal de Santa Catarina/UFSC)

Prof. Dr. Luiz Henrique de Figueiredo

(Instituto Nacional de Matemática Pura e Aplicada/IMPA-RJ)
Resultado:

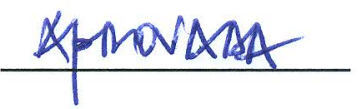

APROVADA

APROVADA

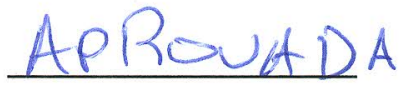

APROVADA

Coordenador do Programa de Pós-Graduação em Engenharia de Transportes:

Prof. Associado Antônio Nélson Rodrigues da Silva

Presidente da Comissão de Pós-Graduação:

Prof. Titular Denis Vinicius Coury 
Dedico este trabalho aos meus pais, José Carlos e Miriam. 


\section{AGRADECIMENTOS}

Agradeço a Deus.

A toda minha família, meus pais José Carlos e Miriam e meus irmãos, Zé Carlos e João Paulo, por estarem sempre ao meu lado, me apoiando e incentivando em todas as ocasiões. Sou muito grato também aos meus padrinhos, Gerson e Laude, e minhas primas, Cláudia e Kátia, por acreditarem no meu esforço e me confortarem com palavras de incentivo todas as vezes que voltava a Campo Grande, MS.

Em especial a Ana Elisa Jorge pelo carinho e companheirismo demonstrados em todos os momentos, além da paciência durante esta etapa. Agradeço também a toda a família Jorge.

Ao CNPq pela bolsa de estudos concedida.

Ao professor Dr. José Reynaldo A. Setti pelo aceite na orientação e, principalmente, pela confiança depositada na realização deste trabalho. Suas sugestões, opiniões e ensinamentos foram fundamentais para que este trabalho fosse, pouco a pouco, sendo moldado.

Ao professor Dr. Adilson Gonzaga (SEL-EESC) pelas muitas conversas e ideias lançadas, abrindo-se um leque maior aos conhecimentos de reconhecimento de padrões, usando descritores de texturas. Ao professor Dr. Marcelo Gattass (PUC-Rio) e ao Maurício Ferreira do grupo TecGraf pelos conselhos e dicas de uso da biblioteca OpenCV.

Aos professores e funcionários do Departamento de Transportes (STT) da EESC-USP pelo apoio, convívio e amizade.

Aos amigos do grupo de pesquisa: José Elievam, Fernando Piva, Artur Paiva e Felipe pela amizade e ótima convivência. As conversas e sugestões foram essenciais para o andamento deste trabalho. Ao Diogo Colella pela amizade e principalmente pela ajuda nas coletas em campo. Aos grandes amigos do STT, especialmente, Bruno Bertoncini, David Alex e Luis Miguel Klinsy.

Agradeço também ao Gustavo Riente, amigo e integrante do grupo de pesquisa, que me ofereceu a oportunidade de trabalhar no grupo TECTRAN, de onde vivenciei e agreguei enorme conhecimento em consultorias na área de transportes, principalmente em programação 
em Banco de Dados e em equipamentos de coleta de dados. Agradeço também aos amigos da empresa: Ana Paula Magalhães, Bruna Braga, Daniel Caetano, Jorge Duran, Karla Cristina, Leandro Piassi, Letícia Faria, Lígia Gesteira, Marcelo Mancini, Marcus Ferreira, Patrícia Alves, Raíssa Sena, Racquel Gonçalves, Robert El-Hage, Sammer Suellen, Thaisa Fraga e todos os demais amigos da empresa. Agradeço também ao Fernando Resende e toda a sua família pela acolhida durante o tempo morando em Belo Horizonte.

Aos amigos do São Carlos Clube, especialmente a equipe de maratonas aquáticas. 
"Às vezes, Deus nos leva a nosso limite, pois Ele tem mais fé em nós do que nós mesmos.”

"Existem pessoas que trabalham duro, pessoas que trabalham muito duro e você, André!" Axel Mitbauer ex-técnico de natação da equipe de Karlsruhe, Alemanha 


\section{RESUMO}

\section{CUNHA, A. L. B. N. Sistema automático para obtenção de parâmetros do tráfego}

veicular a partir de imagens de vídeo usando OpenCV. 2013. 128 p. Tese (Doutorado) Escola de Engenharia de São Carlos, Universidade de São Paulo, São Carlos, 2013.

Esta pesquisa apresenta um sistema automático para extrair dados de tráfego veicular a partir do pós-processamento de vídeos. Os parâmetros macroscópicos e microscópicos do tráfego são derivados do diagrama espaço-tempo, que é obtido pelo processamento das imagens de tráfego. A pesquisa fundamentou-se nos conceitos de Visão Computacional, programação em linguagem $\mathrm{C}++$ e a biblioteca OpenCV para o desenvolvimento do sistema. Para a detecção dos veículos, duas etapas foram propostas: modelagem do background e segmentação dos veículos. Uma imagem sem objetos (background) pode ser determinada a partir das imagens do vídeo através de vários modelos estatísticos disponíveis na literatura especializada. A avaliação de seis modelos estatísticos indicou o Scoreboard (combinação de média e moda) como o melhor método de geração do background atualizado, por apresentar eficiente tempo de processamento de $18 \mathrm{~ms} /$ frame e 95,7\% de taxa de exatidão. A segunda etapa investigou seis métodos de segmentação, desde a subtração de fundo até métodos de segmentação por textura. Dentre os descritores de textura, é apresentado o $L F P$, que generaliza os demais descritores. Da análise do desempenho desses métodos em vídeos coletados em campo, conclui-se que o tradicional método Background Subtraction foi o mais adequado, por apresentar o melhor tempo de processamento (34,4 ms/frame) e a melhor taxa de acertos totais com 95,1\% de média. Definido o método de segmentação, foi desenvolvido um método para se definir as trajetórias dos veículos a partir do diagrama espaço-tempo. Comparando-se os parâmetros de tráfego obtidos pelo sistema proposto com medidas obtidas em campo, a estimativa da velocidade obteve uma taxa de acerto de 92,7\%, comparado com medidas de velocidade feitas por um radar; por outro lado, a estimativa da taxa de fluxo de tráfego foi prejudicada por falhas na identificação da trajetória do veículo, apresentando valores ora acima, ora abaixo dos obtidos nas coletas manuais.

Palavras-chave: tráfego veicular; diagrama espaço-tempo; segmentação; modelagem do background; texturas; linguagem $\mathrm{C}++$; OpenCV. 


\section{ABSTRACT}

CUNHA, A. L. B. N. Automatic system to obtain traffic parameters from video images based on OpenCV. 2013. 128 p. Tese (Doutorado) - Escola de Engenharia de São Carlos, Universidade de São Paulo, São Carlos, 2013.

This research presents an automatic system to collect vehicular traffic data from video postprocessing. The macroscopic and microscopic traffic parameters are derived from a spacetime diagram, which is obtained by traffic image processing. The research was based on the concepts of Computer Vision, programming in $\mathrm{C}++$, and OpenCV library to develop the system. Vehicle detection was divided in two steps: background modeling and vehicle segmentation. A background image can be determined from the video sequence through several statistical models available in literature. The evaluation of six statistical models indicated Scoreboard (combining mean and mode) as the best method to obtain an updated background, achieving a processing time of $18 \mathrm{~ms} /$ frame and $95.7 \%$ accuracy rate. The second step investigated six segmentation methods, from background subtraction to texture segmentation. Among texture descriptors, LFP is presented, which generalizes other descriptors. Video images collected on highways were used to analyze the performance of these methods. The traditional background subtraction method was found to be the best, achieving a processing time of $34.4 \mathrm{~ms} /$ frame and $95.1 \%$ accuracy rate. Once the segmentation process was chosen, a method to determine vehicle trajectories from the spacetime diagram was developed. Comparing the traffic parameters obtained by the proposed system to data collected in the field, the estimates for speed were found to be very good, with 92.7\% accuracy, when compared with radar-measured speeds. On the other hand, flow rate estimates were affected by failures to identify vehicle trajectories, which produced values above or below manually collected data.

Palavras-chave: traffic surveillance; space-time diagram; segmentation; background modeling; textures; C++ language; OpenCV. 



\section{SUMÁRIO}

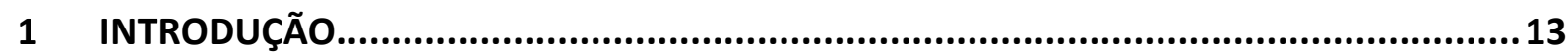

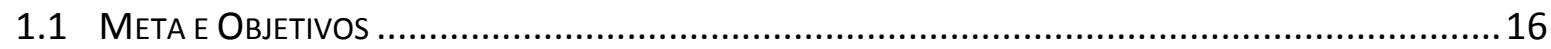

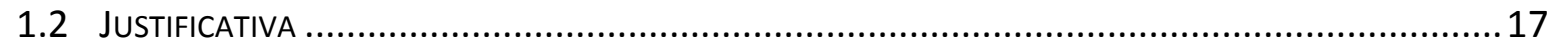

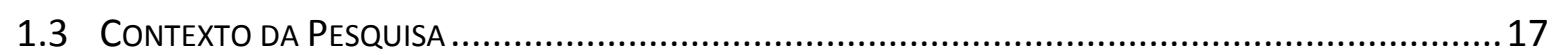

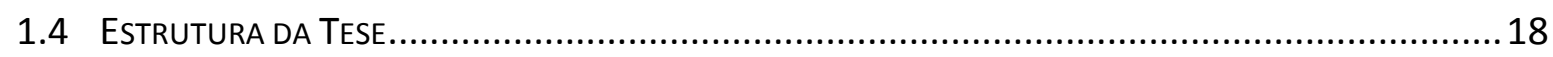

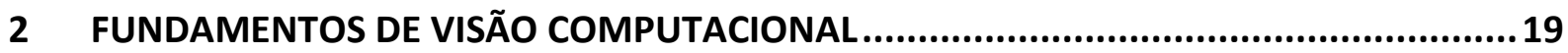

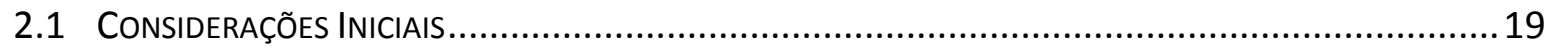

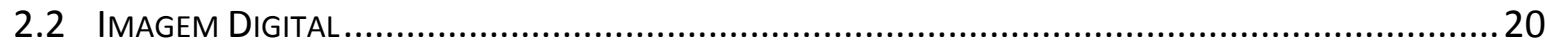

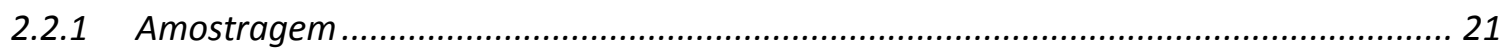

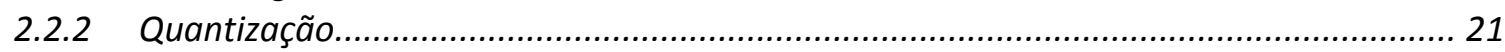

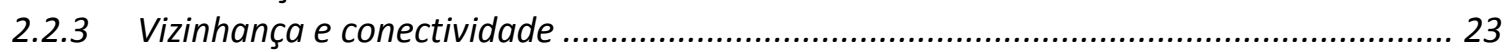

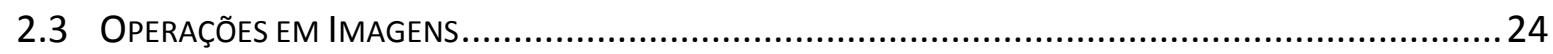

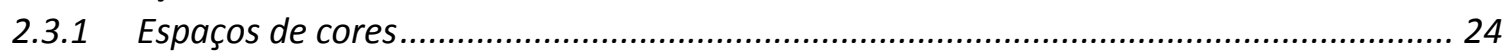

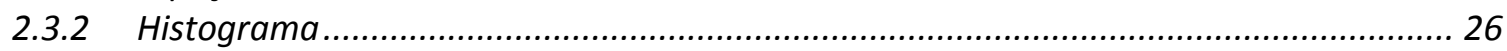

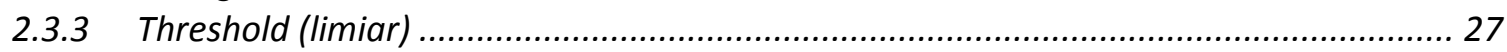

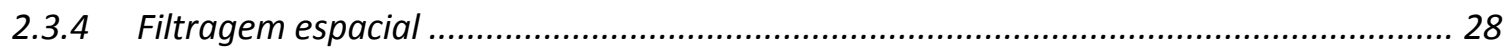

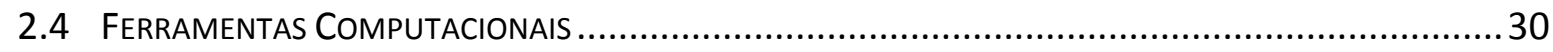

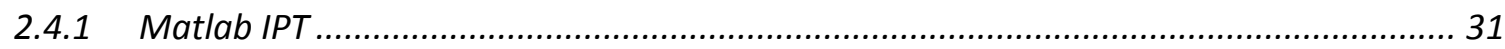

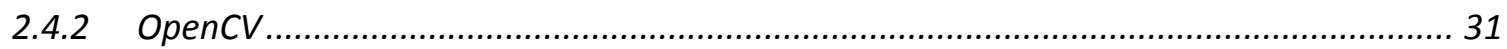

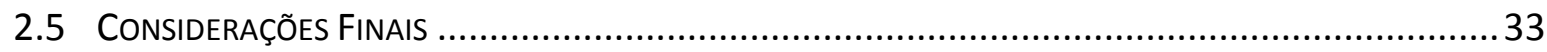

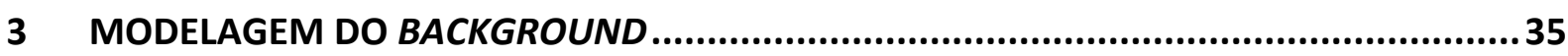

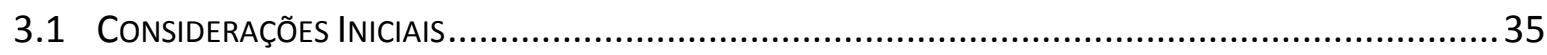

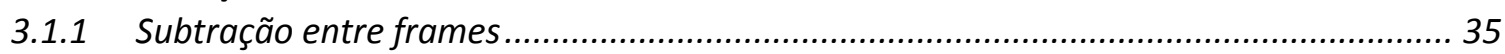

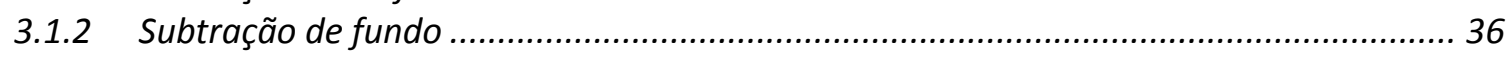

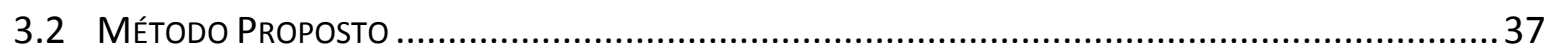

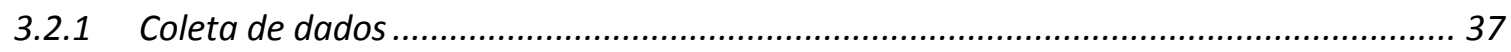

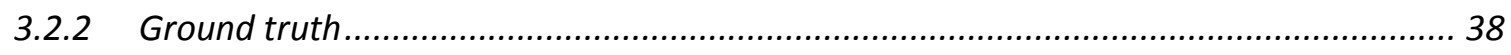

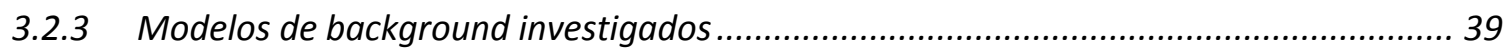

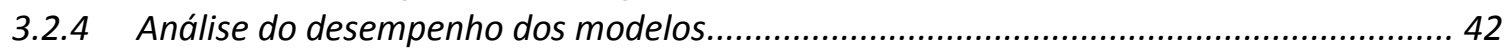

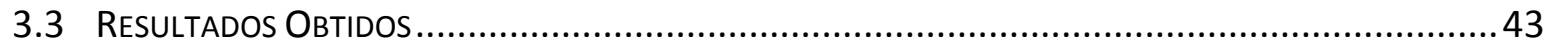

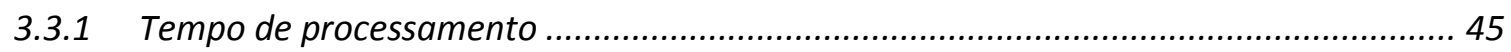

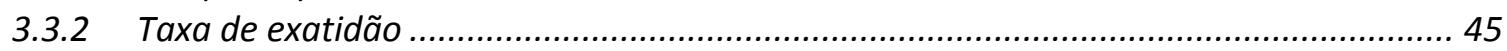

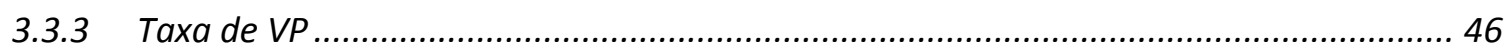

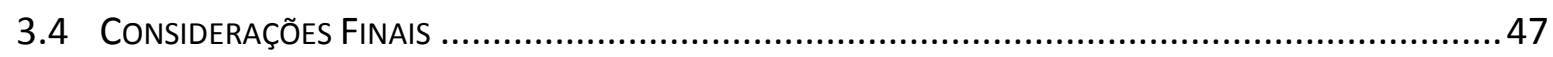

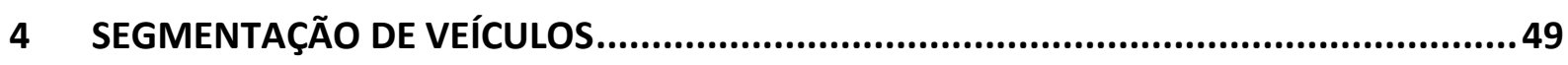

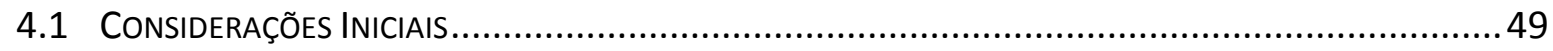

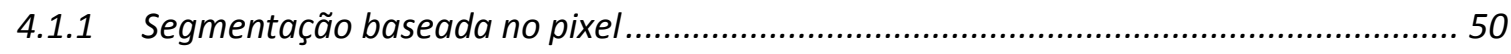

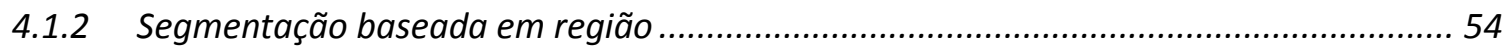

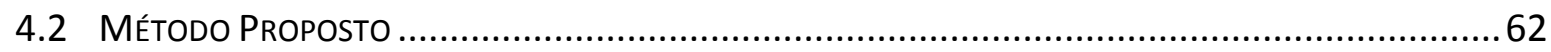

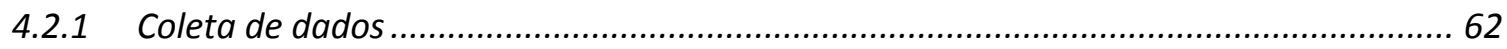

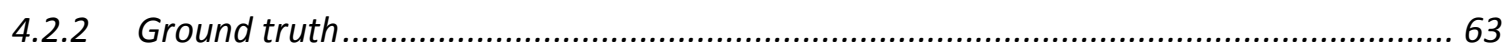

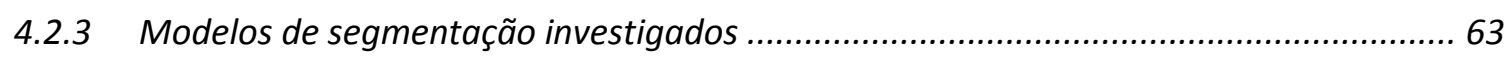

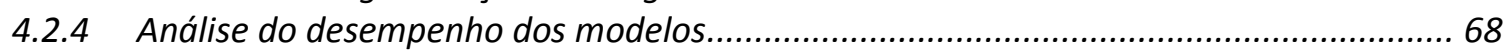




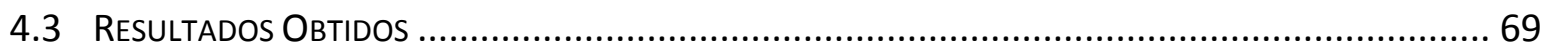

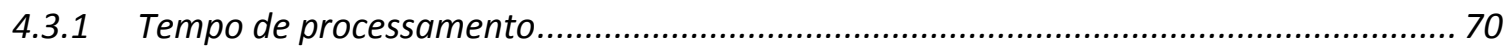

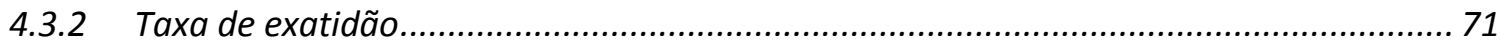

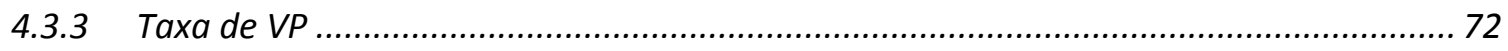

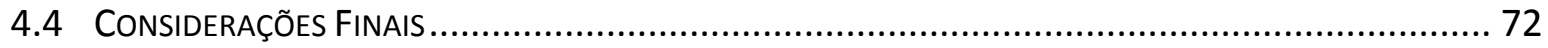

5 SISTEMA AUTOMÁTICO DE COLETA DE DADOS DE TRÁFEGO ................................ 75

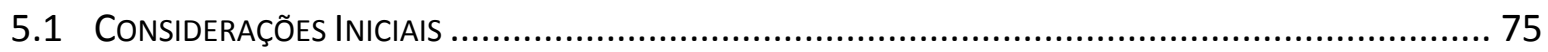

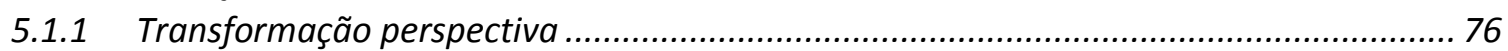

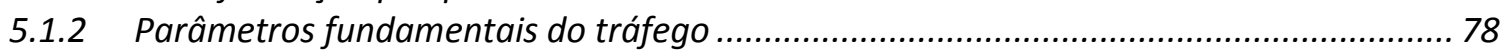

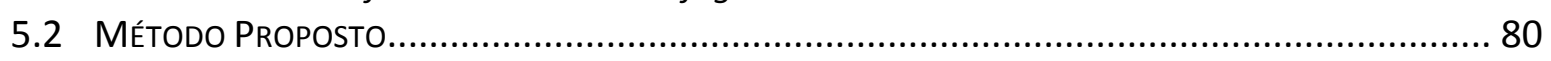

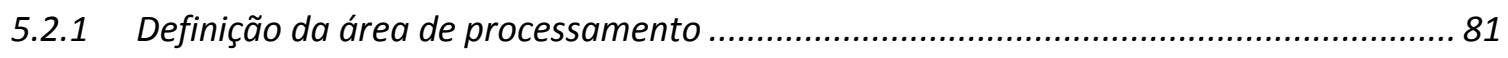

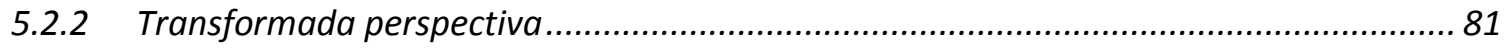

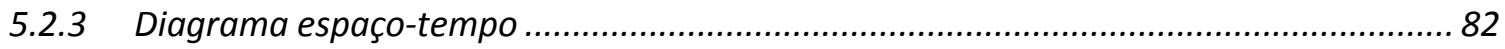

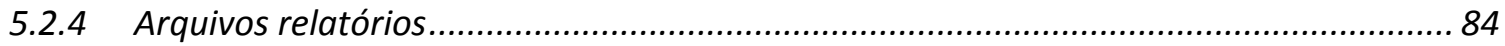

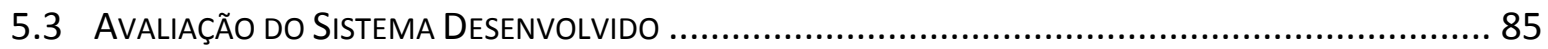

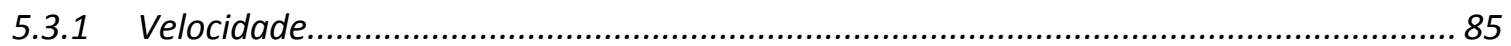

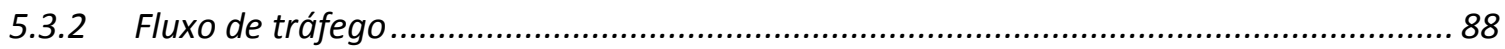

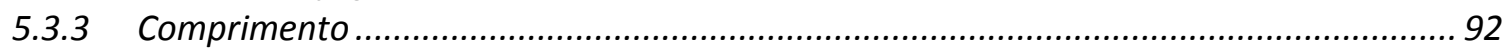

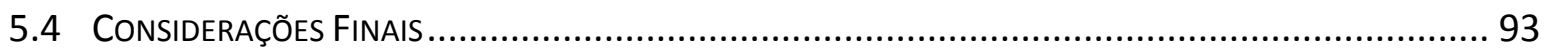

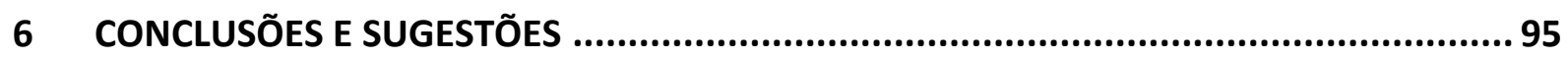

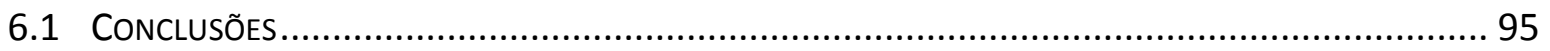

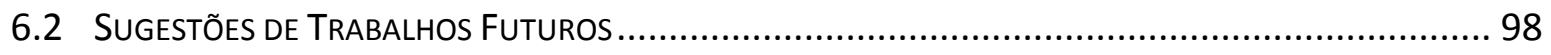

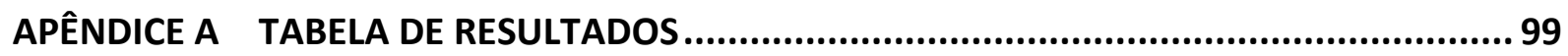

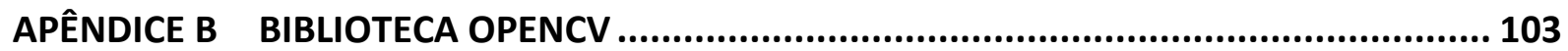

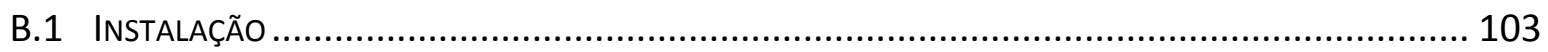

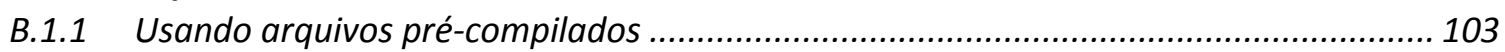

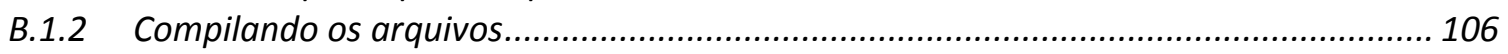

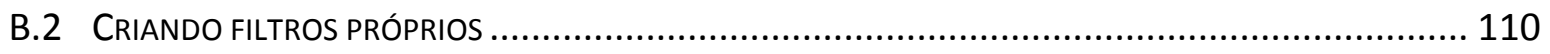

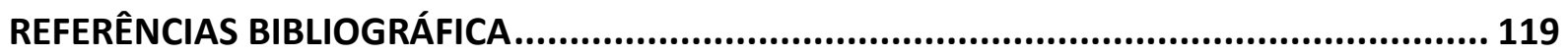




\section{INTRODUÇÃO}

O estudo de tráfego é etapa essencial em Engenharia de Transportes, seja no planejamento, no desenvolvimento de projetos ou na operação de sistemas de transportes rodoviários. Essa etapa tem como propósito obter parâmetros que descrevam o comportamento do tráfego e a composição da frota de veículos.

Um dos parâmetros essenciais para descrever o tráfego é o volume, definido como a taxa de fluxo de tráfego, expressa em veículos por unidade de tempo. A contagem do tráfego visa determinar a quantidade, o sentido e a composição do fluxo de veículos que passam por um determinado ponto da via durante um certo período de tempo. As informações do volume de tráfego são usadas em diversos estudos tanto na análise de capacidade viária, como na avaliação das causas de congestionamento e de índices de acidentes, no dimensionamento do pavimento, nos projetos de canalização do tráfego e outras melhorias [DNIT, 2006]. Permitem ainda a análise de tendência de crescimento de tráfego e de variação do volume quando comparada com dados de séries históricas, obtidos em diferentes períodos.

Além do volume, outros parâmetros de tráfego são necessários para complementar as análises dos estudos citados. Em geral, esses parâmetros são obtidos de acordo com o seu nível de representação: microscópico ou macroscópico. No nível microscópico, cada veículo é considerado único na corrente de tráfego, o que permite descrever o modo como os diferentes tipos de veículos se distribuem ao longo do tempo e espaço. Headway, espaçamento, tempo de viagem e movimentos de conversão são alguns dos parâmetros microscópicos. Por outro lado, o nível macroscópico tem interesse no movimento de grupos de veículos que constituem a corrente, permitindo a avaliação da fluidez do movimento geral dos veículos. Os parâmetros macroscópicos a citar são: a taxa de fluxo, a velocidade média e a densidade da corrente de tráfego.

A precisão e a confiabilidade dos métodos de coletas de dados de tráfego são extremamente importantes, pois fornecem a base para muitas das tomadas de decisões em relação à infraestrutura dos sistemas de transportes [VERSAVEL; LEMAIRE; VAN DER STEDE, 1989; FHWA, 1997]. Além disso, a fidelidade dos dados afeta diretamente as 
prioridades de financiamento, elaboração de projetos de melhorias de transportes e gerenciamento do tráfego.

Os dados de tráfego são obtidos a partir de pesquisas em campo, as quais podem ser manuais ou automáticas. Os procedimentos normalmente usados para o levantamento manual em campo são pesquisas por observação direta, ou seja, os fenômenos do tráfego são registrados em fichas e/ou contadores manuais tal como são. Desse modo, a coleta manual depende essencialmente da experiência do observador que pode contar e classificar por tipo de veículo um volume da ordem de 350 veíc/(h.sentido) [DNIT, 2006]. Além disso, vários observadores são necessários em longos períodos de coletas, devido à incapacidade do ser humano se manter atento durante muito tempo [MOEN et al., 1993]. O tempo de pósprocessamento dos dados é outro aspecto negativo desse tipo de coleta.

Por outro lado, os procedimentos automáticos dispensam observadores e podem ser baseados em diversos tipos de sensores [KLEIN, 2001]. As tecnologias dos sensores podem ser classificadas em duas categorias: intrusivas e não-intrusivas. Sensores intrusivos são embutidos no pavimento, como tubo pneumático, sensor piezelétrico e laço indutivo, e necessitam a interrupção do tráfego para sua instalação e manutenção. Os sensores nãointrusivos são baseados em observações remotas que podem ser por sensor infravermelho, radar de microondas, radar sonoro ou processamento de imagens [LEDUC, 2008], geralmente são instalados ao lado ou acima da via, em pórticos, por exemplo. A maioria desses sensores pode contar, classificar (em função do comprimento) e estimar a velocidade. Todavia, esses dispositivos têm custo elevado de instalação e manutenção; além disso, erros de falsas detecções de veículos podem ocorrer.

Dentre os dispositivos automáticos, o laço indutivo é o método de detecção veicular mais usado para contagem de tráfego, desde a sua introdução em 1960 [KLEIN; MILLS; GIBSON, 2006]. Embora sua tecnologia seja bem compreendida [DOURADO, 2007], os problemas documentados com esse dispositivo têm levado a utilização de sensores nãointrusivos que superam muitas das falhas dos laços indutivos [MIDDLETON; GOPALAKRISHNA; RAMAN, 2002]. Nesse contexto, uma tecnologia nascente tem sido o processamento de imagens de vídeo.

A instalação de câmeras de vídeo em diversos pontos da via e o uso de circuitos 
fechados de televisão (CFTV) tornaram-se comuns no monitoramento de tráfego viário, principalmente com a disseminação de Sistemas Inteligentes de Transportes (ITS - Intelligent Transportation Systems). Inicialmente, o monitoramento do tráfego era feito por operadores que assistiam às imagens de cada câmera. Desse processo, surgiu a análise automática de imagens, uma eficiente ferramenta para o controle de tráfego, que procura não apenas substituir olhos humanos por câmeras, mas automatizar o monitoramento [GONZALES; WOODS, 2007].

Desde que o primeiro sensor de detecção de veículos foi introduzido em 1928 em uma interseção semaforizada nos EUA [MIDDLETON; GOPALAKRISHNA; RAMAN, 2002], várias pesquisas surgiram com o propósito de aprimorar e criar sistemas de monitoramento de veículos nas vias. Segundo Michalopoulos [1991], pesquisas de processamento de imagens de tráfego veicular iniciaram em meados dos anos 1970. Um dos primeiros sistemas de detecção de veículos por imagem, denominado Autoscope, foi iniciado na Universidade de Minnesota em 1984 [MICHALOPOULOS et al., 1989]. Desde então, conceitos de visão computacional foram introduzidos e novas técnicas de processamento de imagens estão sendo desenvolvidas em diversos países, como Alemanha, EUA, Finlândia, França, Inglaterra, Japão, Suécia e Brasil [MARTIN; FENG; WANG, 2003].

O processamento de imagens consiste em procedimentos computacionais para extrair alto nível de informações de uma imagem digital [SETCHELL, 1997]. A detecção de objetos e o rastreamento (tracking) são os tópicos mais estudados na área de visão computacional, pois são as etapas principais de qualquer sistema de monitoramento automático por imagens. A detecção de veículos tem se desenvolvido muito nos últimos anos [WANG; XIAO; GU, 2008; PIETIKÄINEN, 2011], pois se, na análise de imagens estáticas, vários objetos podem ser confundidos com veículos, na análise de imagens de vídeos é possível maior precisão, visto que o movimento é uma característica inerente aos veículos [HU et al., 2004]. O rastreamento de veículos permite obter parâmetros de tráfego como fluxo, velocidade, mudanças de faixa e as trajetórias dos veículos [COIFMAN et al., 1998].

Um dos maiores desafios das pesquisas em visão computacional tem sido a execução em tempo real com baixo custo de equipamento [BADENAS et al., 2001]. Nas pesquisas aplicadas no monitoramento do tráfego veicular, o foco tem sido na melhoria da precisão dos dados de tráfego veicular [KYTE; KHAN; KAGOLANU, 1993]. Entretanto, além da qualidade dos dados, os engenheiros de transportes almejam obter outros parâmetros do 
tráfego, como o comportamento dos motoristas, explorando ainda mais essa nova tecnologia.

Sabe-se que alguns dispositivos já estão disponíveis no mercado, entretanto os seus algoritmos ainda não são robustos o suficiente para suprir as principais dificuldades encontradas nas imagens de tráfego veicular, tais como: operar em qualquer condição climática, variação de iluminação, oclusão de objetos, sombras, detecção de objetos que param ou iniciam o movimento na imagem, entre outros [FHWA, 1997]. O posicionamento da câmera também é decisivo para o desempenho favorável do dispositivo de detecção [TSAI, 1987; WORRAL; SULLIVAN; BAKER, 1994] . Esses fatores revelam a complexidade que os dispositivos de detecção por vídeo têm frente aos outros dispositivos e que ainda existem limitações, o que faz a coleta de dados automática um desafio. Os pontos favoráveis desse método são a simplicidade de instalação e a mínima interrupção nas operações do tráfego, reduzindo a interferência no comportamento da corrente de tráfego.

\subsection{META E OBJETIVOS}

A tese defendida nesta pesquisa baseia-se na hipótese de que é possível obter parâmetros de correntes de tráfego usando visão computacional. Em função disso, a meta desta pesquisa de doutorado foi desenvolver um sistema de coleta automática de dados do tráfego veicular a partir do pós-processamento de imagens de vídeos em rodovias. Para tanto, foram propostos os seguintes objetivos:

- A partir do estado da técnica, definir o melhor método para detecção e segmentação de veículos em imagens de rodovias;

- Estabelecer, a partir do estado da técnica, o melhor processo para rastreamento de veículos em imagens de vídeo de rodovias; e

- Desenvolver uma ferramenta de software que permita a coleta automática de parâmetros da corrente de tráfego, a partir de imagens de vídeos em rodovias, usando as técnicas de segmentação e rastreamento desenvolvidas nas etapas anteriores.

Assim, o método proposto para se atingir a meta e os objetivos consiste nas seguintes etapas: 
- Definir um método para gerar imagens atualizadas de background em tempo de execução do vídeo;

- Definir um método de segmentação de veículos; e

- Extrair os parâmetros de tráfego a partir dos veículos segmentados nas imagens.

\subsection{JUSTIFICATIVA}

A aplicação do processamento de imagens em estudos de tráfego veicular desperta especial interesse, tanto no monitoramento do tráfego como em automação. O maior interesse é o desafio inerente das imagens de tráfego veicular, pois são imagens com nenhum controle de iluminação, o que dificulta acentuadamente o seu processamento. A justificativa desta pesquisa baseia-se nos seguintes fatores:

- A necessidade de se obter maior quantidade de dados de tráfego veicular, de forma fácil e barata, para subsidiar estudos de tráfego como, por exemplo, simulações e a calibração dos modelos de simulação;

- O baixo custo de equipamentos de captura de vídeo e de computadores, além do avanço na tecnologia de processamentos;

- A disponibilidade de bibliotecas de funções para o processamento de imagens, com código aberto e uso livre.

\subsection{CONTEXTO DA PESQUISA}

Este trabalho se insere em uma linha de pesquisa desenvolvida no Departamento de Engenharia de Transportes da Escola de Engenharia de São Carlos (EESC-USP), pelo professor Doutor José Reynaldo A. Setti, com o propósito de simular o tráfego veicular com modelos microscópicos, tais como CORSIM, VISSIM e AIMSUN, que devem, entretanto, ser recalibrados para melhor representar as condições observadas em rodovias brasileiras. Para tanto, coletas de dados em campo são necessárias como relatam as pesquisas realizadas no grupo de pesquisa [EGAMI, 2006; ARAÚJO, 2007; CUNHA, 2007; MON-MA, 2008; BESSA JR., 2009]. No entanto, esses estudos usaram coletas manuais, que demandam um grande número de pesquisadores e um intenso esforço para extração e classificação dos dados. 
Para aprimorar as calibrações da linha de pesquisa e, principalmente, obter dados de campo de forma automática, esta pesquisa de doutorado buscou a integração entre as áreas de Engenharia de Tráfego, Computação e Processamento de Imagens. Essa multidisciplinaridade só foi possível com o suporte do Laboratório de Visão Computacional (LAVI-SEL-EESC), do Instituto de Ciências Matemáticas e da Computação (ICMC), na USP, e do Instituto TecGraf (PUC-Rio).

\subsection{ESTRUTURA DA TESE}

Esta tese está dividida em seis capítulos, incluindo este primeiro capítulo introdutório o qual apresenta a proposta da pesquisa. No Capítulo 2 são apresentados os fundamentos básicos do processamento de imagens e são apresentados alguns pacotes de bibliotecas de funções para utilização em pesquisas da área.

O Capítulo 3 descreve a modelagem do fundo estático das imagens do tráfego veicular. Diversos modelos foram testados para se identificar o que melhor atende às condições de vídeos do tráfego em rodovias.

O Capítulo 4 relata a segmentação dos objetos na imagem de vídeo através da apresentação de modelos que utilizam a textura dos pixels da imagem como parâmetro de identificação. São apresentados modelos consagrados na literatura e é testado um novo identificador de microtextura, o LFP (Local Fuzzy Pattern).

O Capítulo 5 apresenta algumas ferramentas práticas desenvolvidas para a área de Engenharia de Tráfego, a fim de se obter parâmetros do tráfego veicular.

Por fim, o Capítulo 6 traz as conclusões desta pesquisa e sugestões para pesquisas futuras. Como produtos desta pesquisa, o Apêndice A apresenta os resultados da comparação entre as velocidades obtida em campo e pelo sistema automático. O Apêndice B descreve um tutorial passo-a-passo do OpenCV, tratando a instalação e a criação de filtros próprios usando a ferramenta otimizada BaseFilter. 


\section{Fundamentos de Visão Computacional}

Este capítulo tem o objetivo de introduzir os conceitos básicos relacionados à Visão Computacional, campo esse que vem se desenvolvendo rapidamente nos últimos anos. No mundo digital atual, imagens e vídeos estão em toda parte e com o advento de dispositivos computacionais poderosos, criar aplicações com imagens está cada vez mais acessível. Como esta pesquisa é multidisciplinar, os conceitos de Visão Computacional são essenciais para o desenvolvimento e compreensão deste trabalho.

\subsection{CONSIDERAÇÕES INICIAIS}

A visão é o sentido mais desenvolvido dos vertebrados, sendo o mais eficiente mecanismo, aprimorado pela natureza durante o processo evolutivo, para captar as informações do mundo externo [BRUNO; CARVALHO, 2008]. Diferentemente dos outros sentidos, a visão tem a capacidade de obter imensa quantidade de informações quase em tempo real, apesar de limitada a apenas uma banda estreita do espectro de energia eletromagnética, a chamada banda visível [GONZALEZ; WOODS, 2007]. A Figura 2.1 ilustra esta fatia de comprimentos de ondas de luz visível a olho nu.

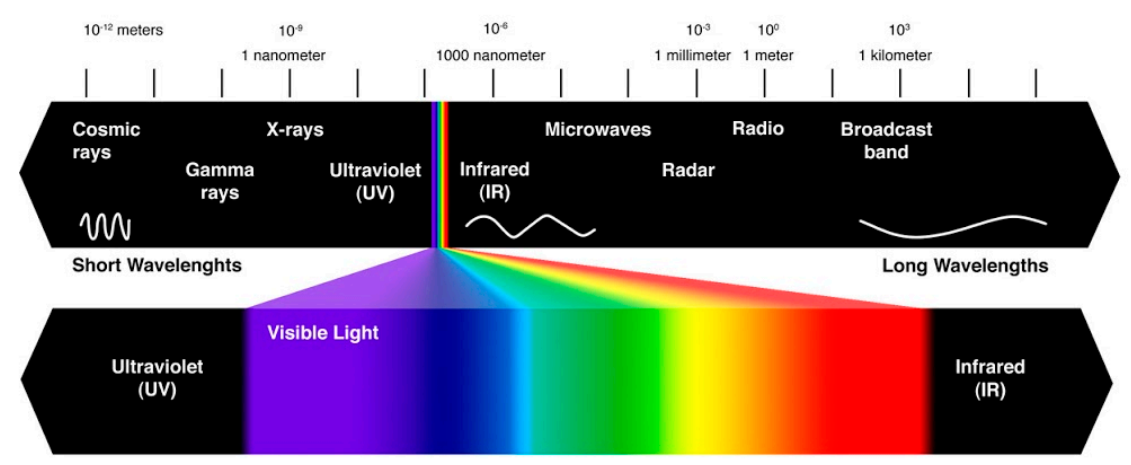

Figura 2.1. Comprimentos de ondas eletromagnéticas e espectro de luz visível [Fonte: Google Imagens]

Segundo Bruno e Carvalho [2008], entender a visão implica compreender detalhes da natureza da luz e suas leis, bem como os fenômenos fisiológicos e neuronais. Desse modo, o estudo da visão é um exemplo de multidisciplinaridade, pois vai além da integração de áreas da ciência como física e biologia; entender a visão acarreta num dos mais importantes desafios científicos: conhecer o funcionamento do cérebro [BRUNO; CARVALHO, 2008]. 
Da tentativa de compreender essa complexidade da visão natural, através de modelagem e simulação, surgiu um novo campo científico denominado Visão Artificial ou Visão Computacional.

Crowley e Christensen [1995] definem Visão Computacional como sendo a área de análise de imagens para a coleta de informações baseada na visão humana. Gonzalez e Woods [2007] descrevem como um conjunto de técnicas que tem como objetivo auxiliar o observador a interpretar o conteúdo da imagem. Szeliski [2011] complementa dizendo que a Visão Computacional é a transformação do dado da imagem em uma nova representação, ou seja, busca-se descrever o mundo a partir de imagens e reconstruí-lo em suas propriedades, como forma, iluminação e distribuição de cores. É interessante como o ser humano faz isso sem esforço, enquanto que os algoritmos de visão computacional ainda são precários [SZELISKI, 2011].

A fim de tentar simular a visão natural, a Visão Computacional também recorre às teorias de diversas áreas da ciência para encontrar soluções em potencial, tais como: os conceitos da visão humana em Biologia, a teoria de Óptica em Física, a Matemática com a Álgebra Linear e a Estatística e, também, a compreensão de Algoritmos para a programação do Processamento de Imagens.

É interessante notar que, mesmo com toda a complexidade desse assunto, o campo da Visão Computacional vem se desenvolvendo rapidamente nos últimos anos [GONZALEZ; WOODS; EDDINS, 2004; GONZALEZ; WOODS, 2007; PARKER, 2011; SZELISKI, 2011], parte como resultado da redução do custo de aquisição de câmeras de alta definição e parte pelo desenvolvimento de novas tecnologias de processamento computacional, o que resulta no amadurecimento dos algoritmos [BRADSKI; KAEHLER, 2008].

\subsection{IMAGEM DIGITAL}

O termo imagem digital, ou simplesmente imagem, refere-se à função bidimensional de intensidade da luz $f(x, y)$, em que $x$ e $y$ denotam as coordenadas espaciais e o valor de $f$ em qualquer ponto $(x, y)$ é proporcional ao brilho (ou nível de cinza) da imagem naquele ponto (GONZALES; WOODS, 2007). A Figura 2.2 ilustra a convenção dos eixos utilizada na representação de uma imagem digital monocromática para o processamento e sua respectiva 
representação matricial.

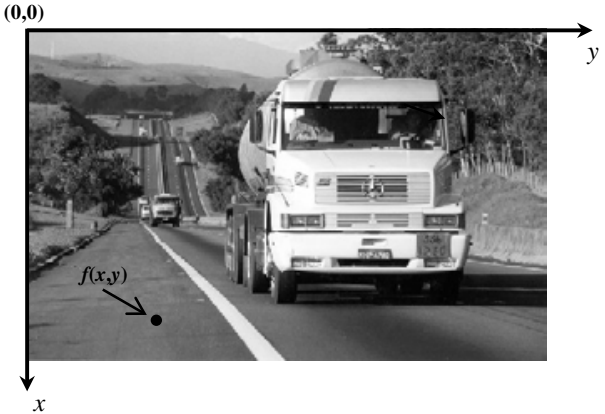

(a)

$$
f(x, y)=\left[\begin{array}{cccc}
f(0,0) & f(0,1) & \ldots & f(0, N-1) \\
f(1,0) & f(1,1) & \ldots & f(1, N-1) \\
\vdots & \vdots & \ddots & \vdots \\
f(M-1,0) & f(M-1,1) & \ldots & f(M-1, N-1)
\end{array}\right]
$$

(b)

Figura 2.2. Representação de uma imagem digital: (a) convenção de eixos e (b) matriz de pixels

Cada ponto $(x, y)$ dessa matriz digital é denominado “elemento da imagem” ou pixel abreviação de Picture Element. A intensidade luminosa $f(x, y)$ de cada pixel é quantizada em uma escala de acordo com a resolução da imagem. Para se adequar ao processamento computacional, a função $f(x, y)$ deve ser digitalizada tanto no espaço quanto em amplitude.

\subsubsection{Amostragem}

A amostragem é a digitalização das coordenadas espaciais $(x, y)$ em valores discretos inteiros e positivos [GONZALES; WOODS, 2007]. O dispositivo de captura da imagem recebe um sinal contínuo (onda eletromagnética) e faz a sua digitalização transformando o sinal em pequenas partes com valores discretos. A amostragem representa o tamanho da imagem nos eixos $x$ e $y$, representado por $M$ linhas e $N$ colunas. A Figura 2.3 ilustra um exemplo de amostragem de uma imagem.

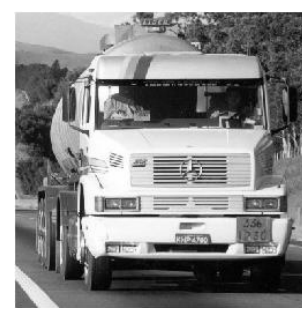

(a) $256 \times 256$

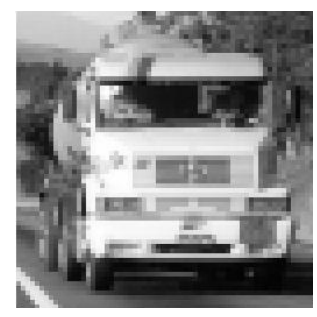

(b) $64 \times 64$

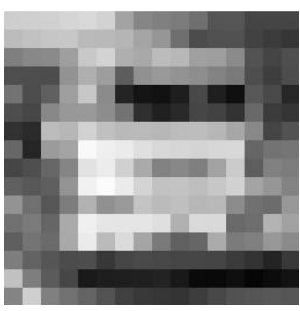

(c) $16 \times 16$

Figura 2.3. Exemplo de amostragem de uma imagem

\subsubsection{Quantização}

A quantização é a digitalização da amplitude, ou escala de variação da intensidade luminosa, representado por valores reais e positivos [GONZALEZ; WOODS, 2007]. A quantização está diretamente ligada ao espaço de memória de armazenamento da imagem, a 
prática comum em processamento de imagens digitais assume a quantização como potências inteiras de dois, por exemplo:

- A imagem com resolução de 8 bits fornece $\left(2^{8}\right) 256$ níveis de cinza diferentes variando do branco ao preto (Figura 2.4a);

- A imagem com resolução de 2 bits fornece $\left(2^{2}\right) 4$ níveis de cinza diferentes, o branco, o cinza claro, o cinza escuro e o preto (Figura 2.4b); e

- A imagem com 1 bit de resolução apresenta $\left(2^{1}\right)$ dois níveis de cinza, o branco e o preto, denominada imagem binária (Figura 2.4c).

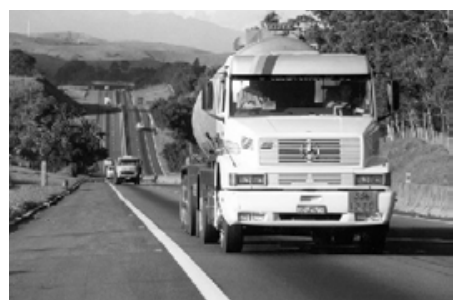

(a) 8 bits $=256$ níveis de cinza

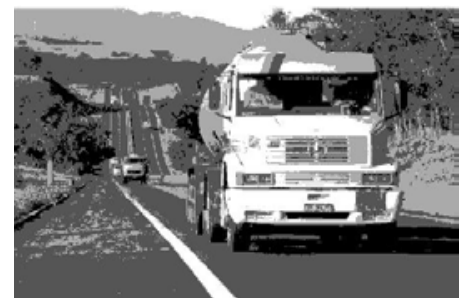

(b) 2 bits $=4$ níveis de cinza

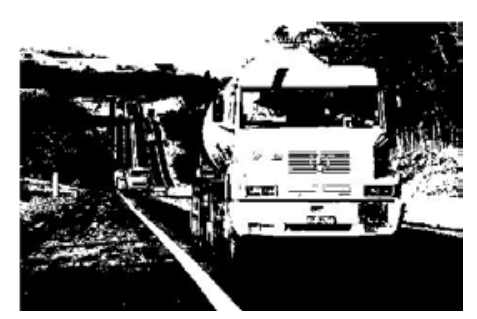

(c) 1 bit = 2 níveis de cinza

Figura 2.4. Exemplo de quantização de uma imagem

A Figura 2.4 exemplifica a quantização de uma imagem monocromática. Vale ressaltar que uma pessoa é capaz de discernir não mais do que 30 tons de cinzas diferentes, segundo estudos relatados em Gonzalez e Woods [2007]; por outro lado, em processamento de imagens, a quantização em 256 níveis traz muita informação que pode ser usada para diferenciar objetos.

Em imagens coloridas, ao invés da intensidade de luz ser representada por um único valor, cada pixel armazena três valores de intensidade de luz, um para cada plano de cor, representado por: $f(x, y)=(R, G, B)$. Assim, imagens coloridas tem 24 bits (três planos de 8 bits), totalizando mais de 16 milhões de cores diferentes. No caso das cores, o olho humano é capaz de discernir milhares de tons e intensidades de cores [GONZALEZ; WOODS, 2007]. A Figura 2.5 ilustra os valores observados nos pixels de uma região da imagem. 


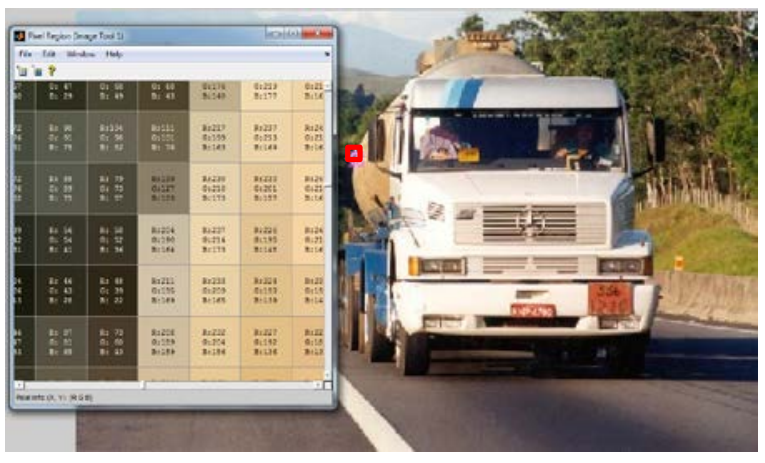

(a)

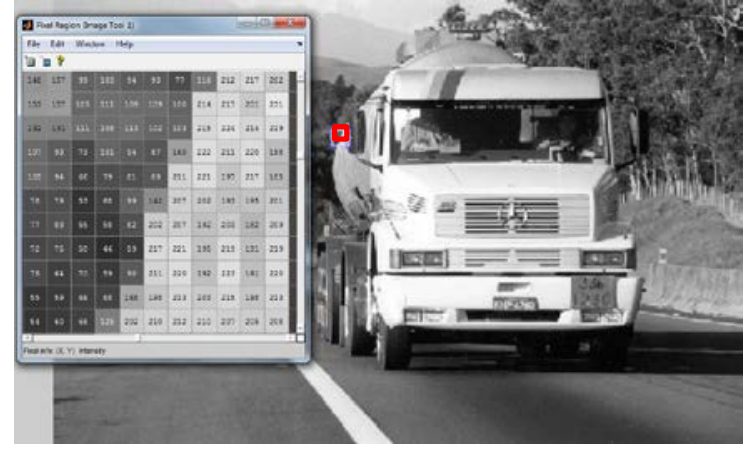

(b)

Figura 2.5. Intensidades dos pixels na região destacada em imagem: (a) colorida e (b) monocromática

É importante notar também que a combinação de amostragem e quantização representa o espaço de memória necessário para armazenamento da imagem. Por exemplo, sabendo que 1 byte de memória representa 8 bits, logo uma imagem monocromática de 320x240 pixels com 8 bits de resolução ocupa 75 Kbytes de memória, enquanto que esta mesma imagem sendo colorida (24 bits) ocupa 225 Kbytes.

\subsubsection{Vizinhança e conectividade}

Como visto, o pixel é o elemento básico de uma imagem e a sua forma mais comum de representação é a quadrada, o que, segundo Albuquerque e Albuquerque [2000], facilita a implementação eletrônica, seja dos sistemas de aquisição ou dos sistemas de visualização de imagens. No entanto, é importante destacar que este tipo de representação implica em dois problemas inerentes às técnicas de processamento. O primeiro problema considera que o pixel é anisotrópico, isto é, um pixel não apresenta as mesmas propriedades em todas as direções, [ALBUQUERQUE; ALBUQUERQUE, 2000]. Esta propriedade faz com que um pixel tenha 4 vizinhos de borda (Figura 2.6a) e 4 vizinhos de diagonal (Figura 2.6b). As vizinhanças de um pixel $p$ são definidas por [GONZALEZ; WOODS, 2007]:

- Vizinhança de $4 N_{4}(p)$ é o conjunto de pixels que são adjacentes de borda, ou 4adjacentes (Figura 2.6a);

- Vizinhança diagonal $N_{D}(p)$ é o conjunto de pixels que compartilham o vértice (Figura 2.6b); e

- Vizinhança de $8 N_{8}(p)$ é o conjunto de pixels de todos os pixels de borda ou vértice, denominada 8-adjacentes (Figura 2.6c). 


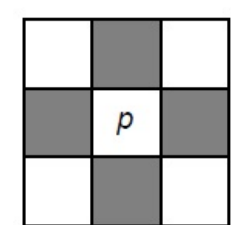

(a) $\mathrm{N}_{4}(p)$

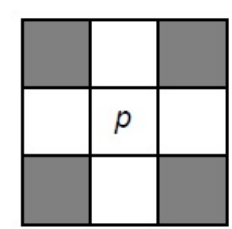

(b) $\mathrm{N}_{\mathrm{D}}(\mathrm{p})$

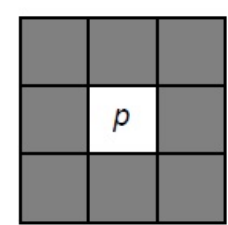

(c) $\mathrm{N}_{8}(p)$

Figura 2.6. Vizinhanças de um pixel

O segundo problema é consequência direta do primeiro, ou seja, as distâncias entre o pixel central e seus vizinhos não são as mesmas. Matematicamente, a distância entre pixels adjacentes de borda é igual a 1, enquanto a distância entre vizinhos na diagonal é $\sqrt{2}$.

A conectividade entre pixels é um conceito usado para estabelecer bordas de objetos e componentes de regiões em uma imagem [GONZALEZ; WOODS, 2007]. Dois pixels são considerados conectados se: (i) são adjacentes em uma vizinhança de 4 ou 8; e (ii) seus níveis de cinza satisfazem a um certo critério de similaridade.

\subsection{OPERAÇÕES EM IMAGENS}

A imagem digital é representada no processamento como uma matriz, logo todas as operações matriciais são válidas, tanto operadores aritméticos (soma, subtração, multiplicação e divisão) como operadores lógicos (E, OU, XOU e NÃO). Além disso, é possível realizar operações entre uma matriz e um valor escalar, assim como entre duas matrizes. Para exemplificar algumas dessas operações, os itens a seguir descrevem brevemente as operações mais usuais em processamento de imagens.

\subsubsection{Espaços de cores}

Em análise automática de imagens, a cor pode ser um descritor poderoso e que pode simplificar a identificação de objetos na cena. Embora a percepção das cores seja um fenômeno fisiopsicológico ainda não completamente compreendido, a natureza física das cores pode ser expressa numa base formal suportada por resultados experimentais e teóricos [GONZALEZ; WOODS, 2007]. Esses resultados definiram espaços de cores os quais facilitam a especificação das cores em um determinado padrão. Existem vários espaços de cores, os mais comuns em processamentos de imagens são o RGB, o HSV e o YCrCb. 
O conceito fundamental é que uma cor pode ser expressa pela combinação de cores primárias ou ainda pelas características de brilho, matiz e saturação. De modo geral, o brilho representa a intensidade de luz; a matiz representa a cor dominante como percebido por um observador; e a saturação refere-se a pureza relativa ou quantidade de luz branca misturada a matiz [GONZALEZ; WOODS, 2007].

No modelo RGB (red, green, blue), cada cor é derivada da combinação de seus componentes espectrais primários: vermelho, verde e azul. Este modelo é baseado em um sistema de coordenadas cartesianas, conhecido como cubo RGB (Figura 2.7). Nos vértices do cubo estão as cores primárias (vermelho, verde e azul) e as cores secundárias (ciano, magenta e amarelo). O preto está localizado na origem e o branco na extremidade oposto, sendo a diagonal a escala de cinza. É o modelo mais usado em câmeras e monitores de vídeos.
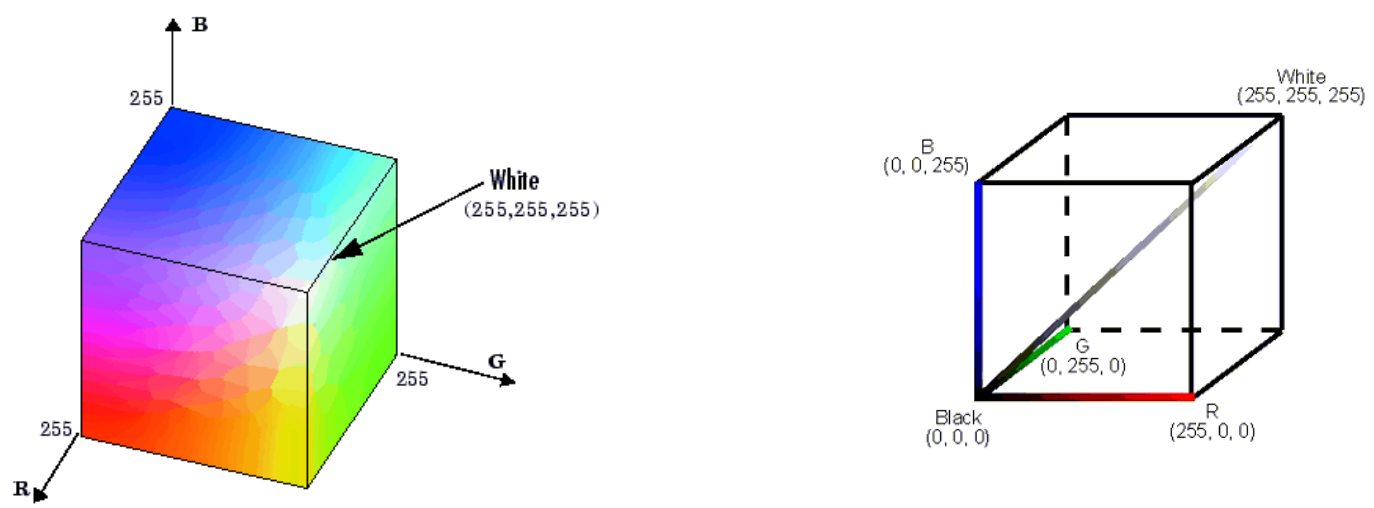

Figura 2.7. Modelo de cores RGB [MATHWORKS, 2012]

O espaço HSV é representado pela combinação de matiz (H), saturação (S) e valor (V) ou intensidade de luz. O componente $\mathrm{V}$ é desagregado da informação de cor, enquanto o $\mathrm{H}$ e o S estão intimamente relacionados à percepção humana de cores. Este espaço é baseado em estudos de como as pessoas selecionam cores [GONZALEZ; WOODS, 2007]. O espaço HSV é representado por coordenadas cilíndricas, como apresentada na Figura 2.8.
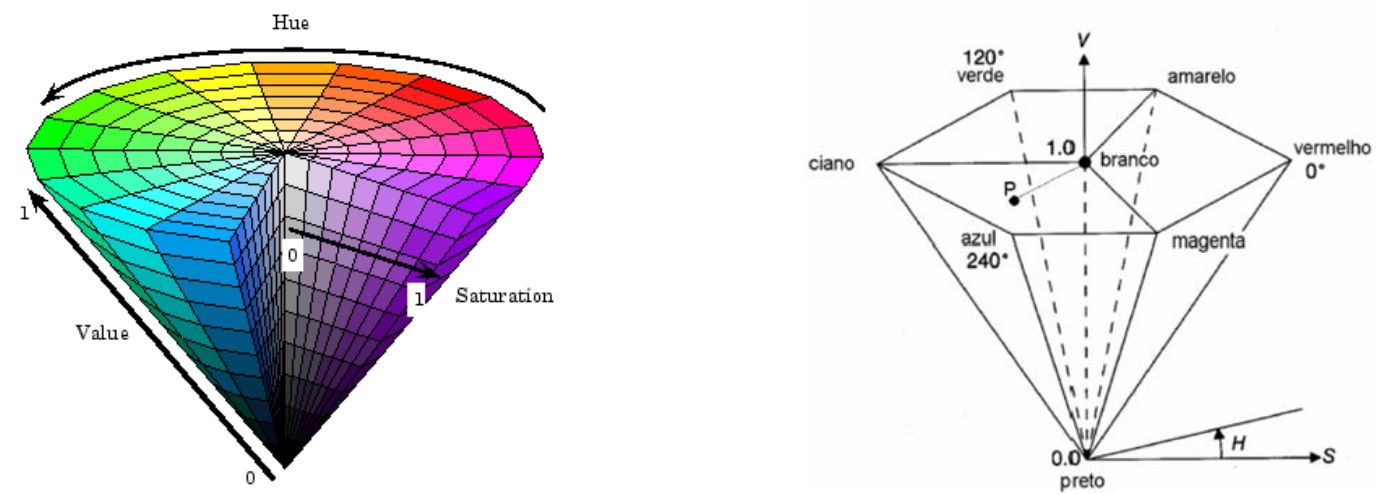

Figura 2.8. Espaços de cores HSV [MATHWORKS, 2012] 
O espaço de cores YCbCr é descrito pela luminância (Y) e pela crominância que é separada em duas componentes de cores: o Cb é a diferença do componente azul para um valor de referência; e o Cr é a diferença do componente vermelho para um valor de referência [JIN et al., 2011]. O espaço YCbCr pode ser obtido do modelo RGB de acordo com a expressão:

$$
\left[\begin{array}{c}
Y \\
C b \\
C r
\end{array}\right]=\left[\begin{array}{c}
16 \\
128 \\
128
\end{array}\right]+\left[\begin{array}{ccc}
65,481 & 128,553 & 24,966 \\
-37,797 & -74,203 & 112,000 \\
112,000 & -93,786 & -18,214
\end{array}\right] \cdot\left[\begin{array}{c}
R \\
G \\
B
\end{array}\right]
$$

O modelo YCbCr é amplamente usado em vídeos digitais, pois separa a luminância das informações de cores [MATHWORKS, 2012].
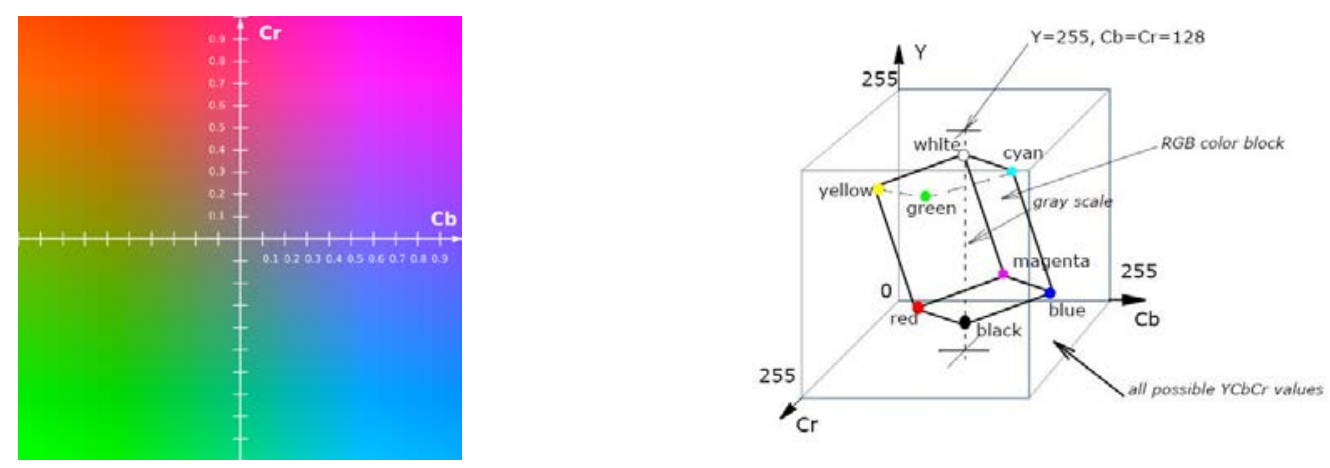

Figura 2.9. Espaços de cores $\mathrm{YCbCr}$ [Google Image]

\subsubsection{Histograma}

O histograma descreve graficamente a distribuição de frequências das intensidades luminosas. É uma ferramenta muito popular e normalmente utilizada para representar a quantidade que cada intensidade de cor se repete na imagem. O histograma proporciona um melhor entendimento da imagem, pois é mais fácil visualizar parâmetros para a avaliação da imagem, como contraste e luminosidade. Porém, como ponto negativo, o histograma não traz informações da posição dos pixels na imagem. A Figura 2.10 ilustra uma imagem monocromática e seu respectivo histograma de níveis de cinza. A quantidade de níveis de cinza representado em um histograma é denominada de bins e, neste caso, são apresentados 256 níveis variando de 0 a 255. 

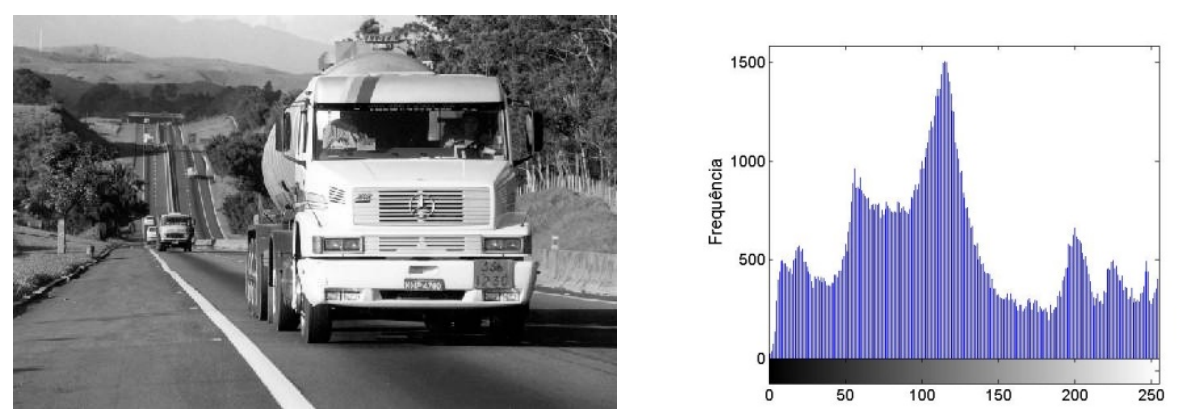

Figura 2.10. Exemplo de imagem monocromática e seu respectivo histograma

\subsubsection{Threshold (limiar)}

A função thresholding ou limiarização é um operador fundamental na identificação de objetos em imagens. O objetivo desta operação é rotular os pixels na imagem comparandoos a um valor threshold (limiar), de acordo com a expressão:

$$
T(x, y)=\left\{\begin{array}{lll}
0, & \text { se } & f(x, y)<\tau \\
1, & \text { se } & f(x, y) \geq \tau
\end{array}\right.
$$

Cada pixel da imagem $f(x, y)$ é comparado ao valor limiar $\tau$, caso o valor do pixel seja menor que o limiar, a imagem resultante $T(x, y)$ é rotulada com zero (preto); e caso o pixel tenha valor maior ou igual a $\tau$, o pixel da imagem $T(x, y)$ recebe o valor 1 (branco). $\mathrm{O}$ resultado da função threshold é uma imagem binária, como apresenta a Figura 2.11.

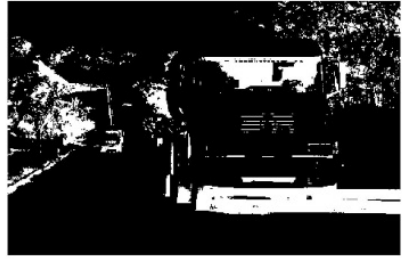

(a) $f(x, y)<50$

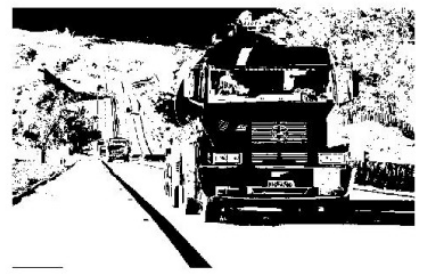

(b) $50 \leq f(x, y) \leq 150$

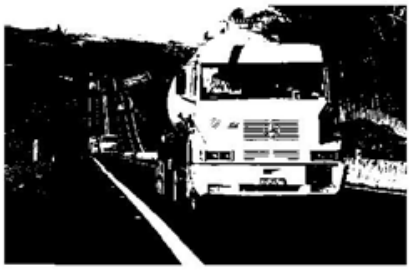

(c) $f(x, y)>150$

Figura 2.11. Exemplos de aplicações de threshold na imagem

A Figura 2.11 exemplifica a aplicação do threshold para diferentes valores do nível de cinza, de acordo com o histograma obtido na Figura 2.10. A Figura 2.11a destaca os pixels onde os valores são inferiores a 50, valores mais escuros e sombras. Já na Figura 2.11c foi aplicado um limiar de 150, destacando os pixels mais claros, principalmente os objetos (veículos). Por fim, a Figura 2.11b representa os pixels com intensidades entre 50 e 150, os quais representam a maioria dos pixels da imagem, como havia sido identificado no histograma (Figura 2.10). 
A determinação de um bom limiar é essencial para que o processo de identificação de objetos tenha êxito. Em virtude das variações de brilho e contraste que as imagens possuem a definição de um valor de threshold não é tarefa simples. Além disso, o uso de um valor limiar fixo em um vídeo (sequência de imagens) pode acarretar erros na segmentação. Uma variação desta técnica é o threshold adaptativo que considera a variação da iluminação durante a sequencia de imagens, mesmo assim não resolve completamente o problema de falsas detecções de sombras ou perdas de parte de um veículo com intensidade similar ao fundo [YEN et al., 1995; PARK, 2001].

\subsubsection{Filtragem espacial}

A filtragem espacial envolve o conceito de vizinhança do pixel ao realizar qualquer operação, permitindo uma variedade de funções de processamento [GONZALEZ; WOODS, 2007]. Ao contrário das operações anteriores, em que cada pixel era tratado individualmente levando apenas a informação do próprio pixel, a filtragem espacial considera também a vizinhança do pixel durante o processamento, levando informações importantes dos seus vizinhos. Para tanto, a formulação da filtragem espacial é baseada no uso de máscaras (ou também denominado janelas, kernel, templates ou filtros). Basicamente, uma máscara é uma matriz bidimensional, na qual seus valores determinam a natureza do processo, representado por pesos em cada pixel. A Figura 2.12 esquematiza o processo da filtragem espacial utilizando uma vizinhança 3x3 como exemplo.

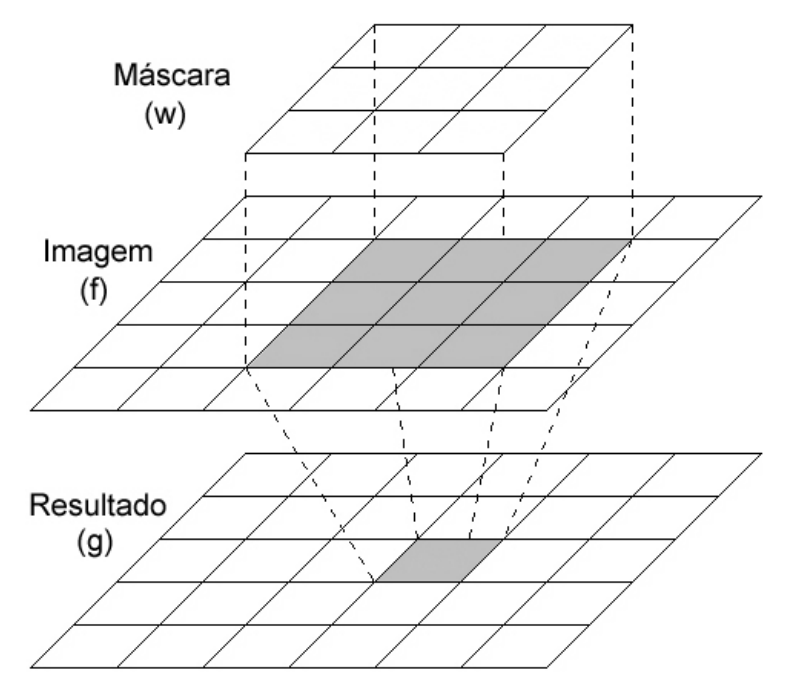

Figura 2.12. Representação da aplicação de filtro espacial 
Matematicamente, a filtragem espacial de uma imagem $f(x, y)$ de dimensões $M \times N$ com um filtro $w(u, v)$ de dimensões $m \times n$ é dada pela expressão [SZELISK, 2011]:

$$
g(x, y)=\sum_{u=0}^{m-1} \sum_{v=0}^{n-1} w(u, v) \cdot f\left(x+u-\frac{m}{2}, y+v-\frac{n}{2}\right)
$$

Dessa forma, a filtragem espacial cria um novo pixel $g(x, y)$, com coordenadas iguais às coordenadas do pixel da imagem $f(x, y)$, e cujo o valor é o resultado da Equação 2.3, ou seja, o somatório de pesos da região da imagem $f(x, y)$ e a máscara $w(u, v)$. Se a operação realizada sobre os pixels da imagem for linear, o filtro é chamado de filtragem espacial linear; caso contrário, é chamado de filtragem espacial não linear.

A parte fundamental dessa operação é a definição da máscara para que corresponda ao processamento desejado. As principais funcionalidades encontradas na literatura são a suavização (filtros passa baixa) e o aguçamento (filtros passa alta) [GONZALEZ; WOODS 2007]. A suavização da imagem é obtida pela média da vizinhança o que resulta em uma imagem borrada. A máscara geralmente é retangular e composta por valores unitários, divido pela soma total dos pesos. A Figura 2.13 ilustra os valores para as máscaras 5x5 e 9x9, assim como os resultados obtidos após a sua aplicação na imagem.
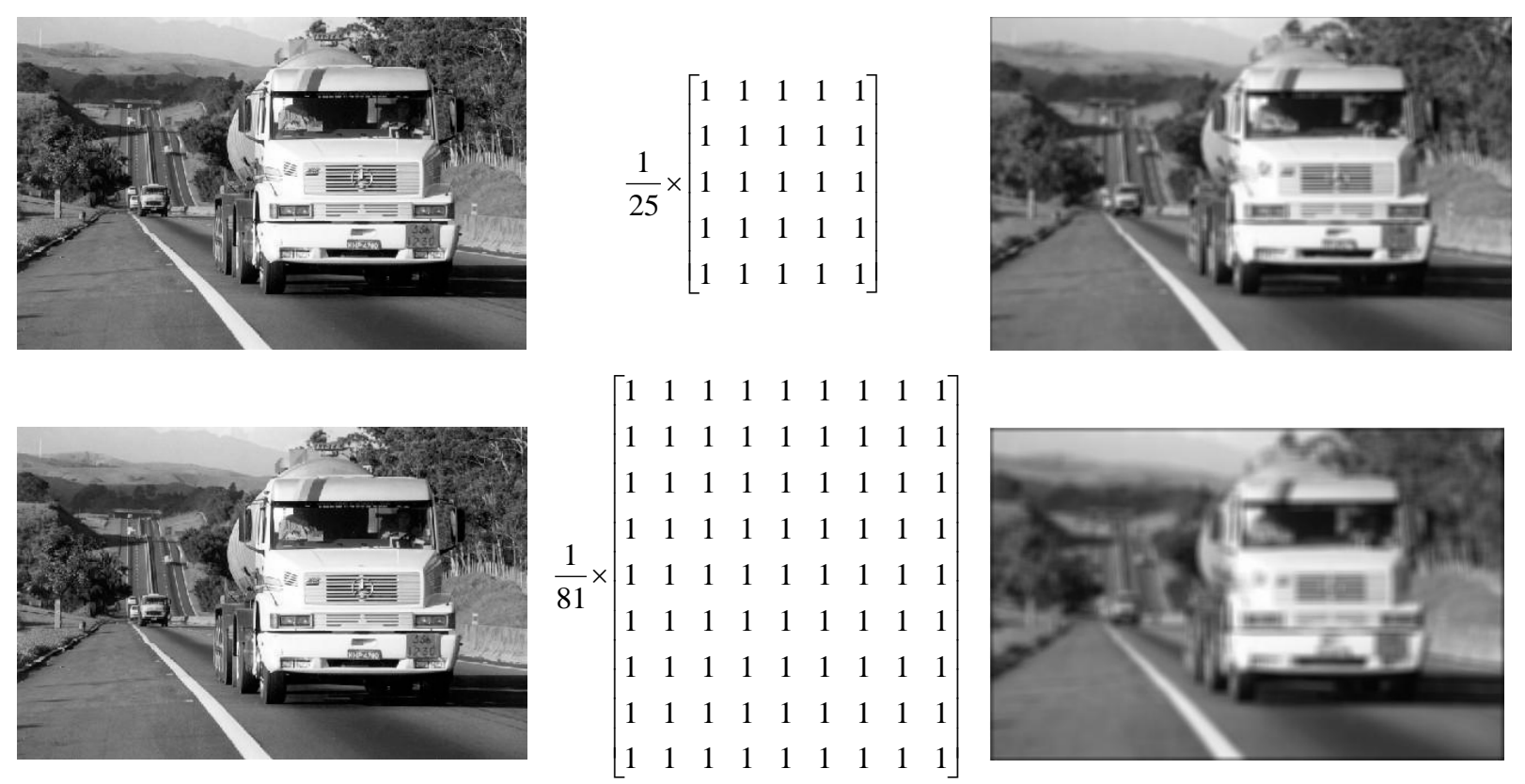

(a) Imagem

(b) Máscara

(c) Resultado

Figura 2.13. Exemplo de filtragem passa baixa - suavização

Outra principal funcionalidade é o aguçamento da imagem que tem como objetivo enfatizar detalhes finos na imagem ou realçar detalhes que tenham sido borrados. $\mathrm{O}$ formato 
da máscara para descrever um filtro passa alta (aguçamento) deve ter coeficientes positivos no centro e coeficientes negativos na periferia. Além disso, a soma dos coeficientes deve ser zero, para que a resposta seja mínima caso a janela esteja em uma área constante. A Figura 2.14 ilustra o exemplo deste filtro.

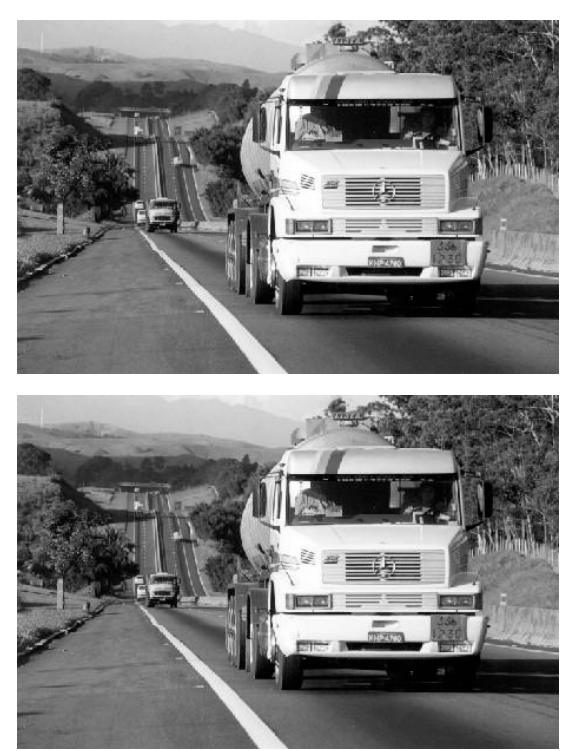

(a) Imagem

$$
\frac{1}{9} \times\left[\begin{array}{ccc}
-1 & -1 & -1 \\
-1 & 8 & -1 \\
-1 & -1 & -1
\end{array}\right]
$$$$
\frac{1}{25} \times\left[\begin{array}{rrrrr}
-1 & -1 & -1 & -1 & -1 \\
-1 & -1 & -1 & -1 & -1 \\
-1 & -1 & 24 & -1 & -1 \\
-1 & -1 & -1 & -1 & -1 \\
-1 & -1 & -1 & -1 & -1
\end{array}\right]
$$

(b) Máscara
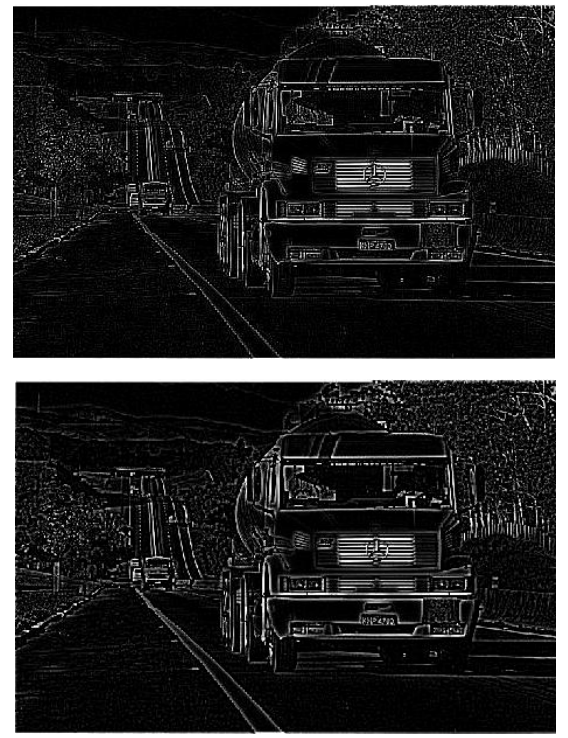

(c) Resultado

Figura 2.14. Exemplo de filtragem passa alta - aguçamento

Existem diversos outros tipos de máscaras, as quais utilizam representações de Gaussianas ou derivadas, cada uma podendo executar determinada finalidade. Toda a teoria de filtragem espacial é derivada do processamento de sinais digitais que utilizam conceitos de convolução e correlação no domínio de frequência. Entretanto, o objetivo deste capítulo é dar uma introdução ao assunto; mais detalhes de filtragens e operações em imagens podem ser encontrados na literatura especializada [GONZALEZ; WOODS, 2007; SZELISKI, 2011; NIXON; AGUADO, 2012].

\subsection{FERRAMENTAS COMPUTACIONAIS}

Várias ferramentas computacionais estão disponíveis para o processamento de imagens, em várias linguagens de programação. Algumas dessas ferramentas são adquiridas por licença e outras distribuídas gratuitamente. Uma parte delas é mantida por universidades e pesquisadores, enquanto outra parte é mantida por empresas especializadas em computação. Todas as ferramentas oferecem pelo menos o pacote básico para a leitura e a gravação de imagens e vídeos, o processamento no domínio de frequência e o processamento no domínio 
espacial. A seguir, são apresentados detalhes de dois pacotes utilizados nesta pesquisa.

\subsubsection{Matlab IPT}

O Matlab (Matrix Laboratory) é um software interativo que se destina a cálculos numéricos e gráficos científicos. Seu ponto forte é a manipulação e cálculos matriciais, como por exemplo, resolução de sistemas lineares, cálculos de autovalores e autovetores, fatoração de matrizes, entre outros. A maioria das funções de cálculos já estão implementadas, de modo que o usuário, em muitos casos, não necessita construir muito código. Uma característica marcante do Matlab é a sua linguagem de programação fácil de aprender, ao contrário das muitas linguagens padrões, como C, Fortran e outras. Entretanto, quanto maior e mais complexa a codificação, pior fica o desempenho do Matlab comparado com as outras linguagens.

O Matlab é um software proprietário mantido pela empresa MathWorks e recebe apoio de diversas universidades para a atualização dos seus pacotes adicionais. O pacote básico do Matlab contém toda a estrutura de cálculo, programação e gráficos. O pacote de processamento de imagens (IPT - Image Processing Toolbox) é vendido separadamente e traz toda a estrutura necessária para se manipular imagens e vídeos. A partir da versão R2012a, a estrutura de manipulação de vídeos melhorou significativamente; entretanto, ainda fica atrás de alguns de outras ferramentas, como o OpenCV.

O Matlab é conhecido por ser um software de protótipo e sua programação fácil e intuitiva, ajuda a acelerar o desenvolvimento de protótipos. No processamento de imagens, a facilidade de se manipular e visualizar a imagem são os pontos positivos.

\subsubsection{OpenCV}

Open Source Computer Vision Library (OpenCV) é uma biblioteca de funções de visão computacional e aprendizado de máquinas com código aberto, disponível no site http://opencv.org. OpenCV foi desenvolvido para fornecer uma infraestrutura comum em aplicações de visão computacional e acelerar o uso da percepção de máquinas em produtos comerciais. O pacote OpenCV possui licença BSD (Berkeley Source Distribution), ou seja software de licença gratuita, o que faz dele fácil de se utilizar e modificar os seus códigos.

Esta biblioteca tem mais de 2.500 algoritmos otimizados, que incluem um extenso 
conjunto de algoritmos, tanto clássicos como no estado da arte de visão computacional e inteligência artificial. Esses algoritmos podem ser usados para detectar e reconhecer faces, identificar objetos, extrair modelos de objetos em 3-D, produzir nuvens de pontos 3-D em câmeras estéreo, unir imagens para produzir uma única imagem de alta resolução, encontrar imagens semelhantes em um banco de dados, remover olhos vermelhos de imagens capturadas com flash, acompanhar o movimento dos olhos, reconhecer cenários e estabelecer marcadores para aplicação de realidade aumentada, entre outros. OpenCV tem mais de 47 mil pessoas como usuários na comunidade e um número estimado de downloads da biblioteca que superam os 5 milhões ${ }^{1}$. Este pacote é extensamente utilizado em empresas, grupos de pesquisas e órgãos governamentais.

Dentre as empresas mais conhecidas que fazem uso desta biblioteca, podemos citar: Google, Yahoo, Microsoft, Intel, IBM, Sony, Honda, Toyota, além de muitas outras que estão entrando no mercado [BRADSKI; KAHELER, 2008]. Existe uma vasta aplicação da biblioteca OpenCV, como na união de imagens das ruas para detecção de intrusos em vídeos de monitoramento em Israel, equipamentos de monitoramento de minas na China, suporte em robôs na navegação e em pegar objeto no Willow Garage, detecção de acidentes de afogamentos em piscinas na Europa, execução de arte interativa na Espanha e Nova York, verificação de buracos em rodovias na Turquia, inspeção de rótulos de produtos nas fábricas ao redor do mundo e a detecção rápida da face humana no Japão ${ }^{1}$.

O OpenCV tem interface com linguagens $\mathrm{C}++, \mathrm{C}$, Python, Java e pode rodar em sistemas Windows, Linux, Android e Mac OS. A biblioteca tem se especializado em aplicações em tempo real e tira proveito de computação paralela quando disponível. O OpenCV é escrito nativamente em $\mathrm{C}++$ e tem uma interface de modelos que funcionam perfeitamente com contêiner STL (Standard Template Library), muito usado em programação orientada a objetos.

Um dos objetivos do OpenCV é fornecer uma infraestrutura de visão computacional fácil de usar que ajude as pessoas a desenvolverem rapidamente sofisticadas aplicações de visão [BRADSKI; KAHELER, 2008]. Desde sua introdução em 1999, tem sido amplamente adotada como a principal ferramenta de desenvolvimento pela sua comunidade de

\footnotetext{
${ }^{1}$ Informações obtidas no site: http://opencv.org.
} 
pesquisadores e desenvolvedores em visão computacional. O OpenCV foi originalmente desenvolvido pela Intel, pela equipe liderada por Gary Bradski com a iniciativa de avançar em pesquisas em visão e promover o desenvolvimento de aplicações computacionais baseadas em visão. Após uma série de versões beta, a versão 1.0 foi lançada em 2006. A segunda maior atualização ocorreu em 2009 com o lançamento do OpenCV 2.0 que propôs importantes mudanças, especialmente na nova interface C++ [LAGANIÈRE, 2011].

O ponto negativo do OpenCV é a necessidade de conhecimento avançado de programação em $\mathrm{C}$ ou $\mathrm{C}++$. O conhecimento de $\mathrm{C}++$ traz maiores vantagens do uso das ferramentas disponíveis em programação orientada a objeto, como aproveitamento de códigos, menor preocupação com a manipulação da memória usada e menor quantidade de linhas de código.

A Tabela 2.1 compara um programa simples para abrir e exibir uma imagem, escrito em linguagem $\mathrm{C}$ e $\mathrm{C}++$. Note a menor quantidade de linhas de código, mesmo neste simples exemplo, além da facilidade do $\mathrm{C}++$ fazer automaticamente para o usuário a limpeza da memória usada no programa, ao contrário do código em C.

Tabela 2.1. Exemplos de códigos em linguagem $\mathrm{C}$ e $\mathrm{C}++$

\begin{tabular}{|c|c|}
\hline Algoritmo 1. Código escrito em C & Algoritmo 2. Código escrito em C++ \\
\hline $\begin{array}{l}\text { int main } \\
\text { \{ } \\
\text { IplImage* img = cvLoadImage(“img.jpg”); } \\
\text { cvNamedWindow(“Imagem”, 1); } \\
\text { cvShowImage(“Imagem”, img); } \\
\text { cvWaitKey( }(0) \text {; } \\
\text { cvReleaseImage( img ); } \\
\text { cvDestroyWindow(“Imagem”); }\end{array}$ & 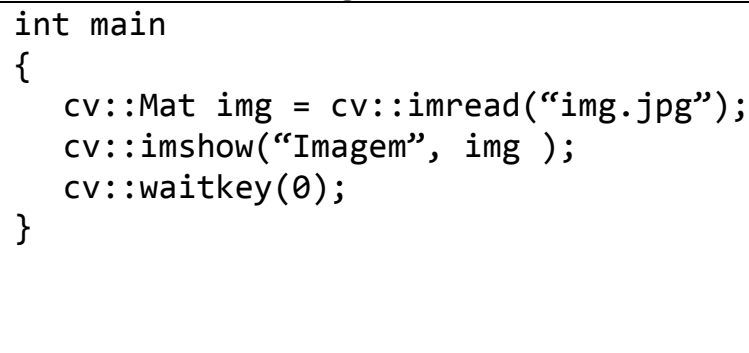 \\
\hline
\end{tabular}

\subsection{CONSIDERAÇÕES FINAIS}

Este capítulo apresentou uma introdução sobre o tema Visão Computacional. Descreveu sua origem, baseada na tentativa de simular a Visão Natural, e descreveu os princípios fundamentais da imagem digital e suas operações básicas. Com base nestes conhecimentos, o capítulo a seguir relata como modelar o fundo estático de uma sequência de imagens para manter uma imagem de fundo sem objeto (background) sempre atualizada. 


\section{Modelagem do Background}

O objetivo deste capítulo é investigar os modelos de construção de background comumente usados na literatura e definir o modelo mais adequado para análise de imagens de vídeo de tráfego rodoviário. Em uma cena de vídeo, a obtenção de uma imagem sem objetos móveis (background) dá suporte à próxima etapa, a segmentação de veículos nas imagens.

\subsection{CONSIDERAÇÕES INICIAIS}

A detecção de objetos em uma imagem é a primeira etapa em qualquer sistema automático de processamento de imagens [WANG; XIAO; GU, 2008; LI; ZHU; HUANG, 2009; CHEN; LIU; HUANG, 2011]. Para essa função, a técnica tradicional e consagrada na literatura é a subtração de imagens, na qual duas figuras são subtraídas pixel-a-pixel resultando em uma imagem que identifica os pixels com as maiores diferenças como foreground (objetos em movimento) e os pixels com valores baixo como background (fundo estático) [ELHABIAN; EL-SAYED; AHMED, 2008]. Na literatura, esse processamento pode ser realizado através de duas técnicas: subtração entre frames ou subtração de fundo.

\subsubsection{Subtração entre frames}

Nesse caso, dois ou mais frames consecutivos (imagens de um vídeo) são subtraídos o que resulta numa imagem com os pixels onde houve alguma movimentação, contorno dos objetos, como mostra a Figura 3.1. Esse processo é altamente dependente da velocidade dos objetos na imagem, ou seja, objetos parados tendem a ficar na mesma posição entre frames, logo a subtração entre os frames será nula, pois apresentam o mesmo valor.

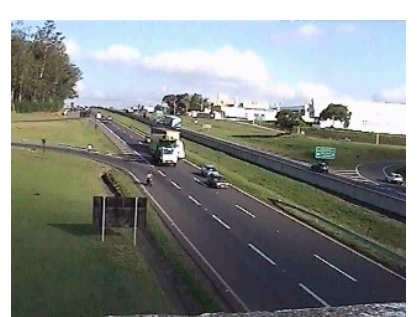

Frame \#144

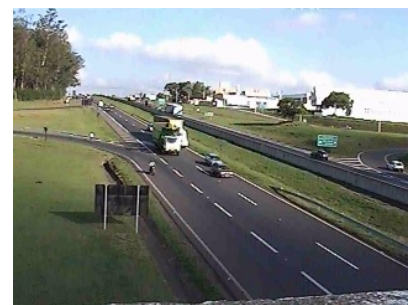

Frame \#164

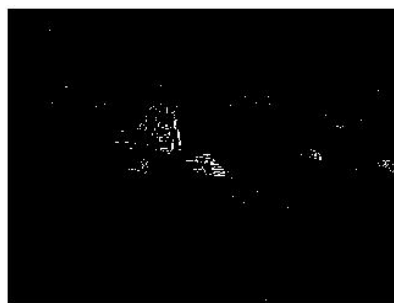

Diferença entre frames

Figura 3.1. Exemplo de subtração entre frames 
Essa técnica é conhecida na literatura como Frame Difference e seu processamento é simples e rápido, no entanto a maioria dos trabalhos usou variações desta técnica para melhor detectar os objetos. Tang, Miao e Wan [2007] usaram a subtração entre frames combinada com subtração de fundo para extrair os objetos, enquanto Hu et al. [2010] acrescentaram também a detecção de borda. Chen e Zhang [2012] propuseram a combinação da diferença de três frames consecutivos.

\subsubsection{Subtração de fundo}

O princípio da subtração de fundo (background subtraction) envolve a comparação de uma imagem com objetos e outra de referência (real ou modelada) que não contenha objetos de interesse. A imagem de referência do fundo pode ser real, obtida em campo na própria sequência de imagens do vídeo, porém no monitoramento de tráfego é pouco provável que se tenha uma imagem sem veículos constantemente atualizada [ZHENG et al., 2006]. Por outro lado, pode-se obter uma imagem do fundo confiável construída a partir de modelos de geração de background. Uma diferença significativa de pixels entre as imagens real e estimada indicam a localização dos objetos, como representado na Figura 3.2.

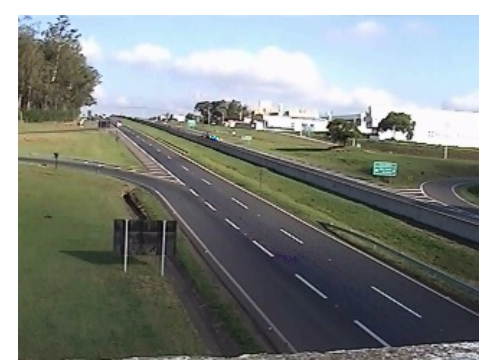

(a) Background

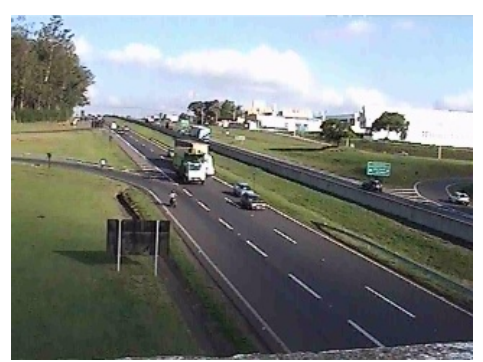

(b) Frame \#144

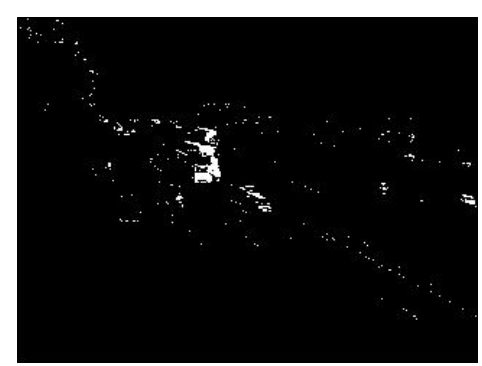

(c) Subtração de fundo

Figura 3.2. Exemplo de subtração de fundo

Modelar o background é a parte mais importante de algoritmos de subtração de fundo. O objetivo é construir e manter uma representação estatística da cena que a câmera captura. Na maioria dos estudos, a câmera é suposta como fixa e estática (sem qualquer movimentação). Cada pixel do background é modelado identicamente, o que permite uma implementação paralela de alta velocidade [PIETIKÄINEN et al., 2011].

Pesquisas nesse assunto investigaram diferentes modelos estatísticos para gerar o background, como os apresentados a seguir. A sequência de imagens do mundo real apresentam ruídos que afetam a precisão da extração do background, incluindo a variação dos 
objetos e mudanças de iluminação. Para um desempenho confiável e robusto, o modelo de construção do fundo estático deve ser capaz de suprir essas variações [CHIU; KU, 2009].

Assim, o desempenho da subtração de fundo depende diretamente da técnica de modelagem do background utilizada. A imagem resultante da subtração de fundo muitas vezes é usada como entrada em um procedimento de alto nível, como rastreamento e identificação de objetos [HEIKKILÄ; PIETIKÄINEN, 2006].

\subsection{MÉTODO PROPOSTO}

O método proposto consiste em avaliar os modelos de geração do background a partir de sequências de imagens de vídeo. Os modelos de geração analisados foram os comumente utilizados na literatura. Cabe ressaltar que, na literatura, esses modelos têm como propósito serem eficientes em diversos tipos de vídeos. No entanto, este trabalho foca apenas em imagens do tráfego veicular rodoviário.

Os códigos foram escritos em linguagem C++ e compilados no software Microsoft Visual Studio 2012. Para auxiliar o processamento das imagens, foi utilizada a biblioteca de funções OpenCV versão 2.4.5, disponível no site http://opencv.org. O computador usado foi um Core i7 3,4 GHz com 8 Gb de memória RAM.

\subsubsection{Coleta de dados}

Os vídeos analisados nesta etapa foram obtidos na SP-310, Rodovia Washington Luís, km 235 - entrada da cidade de São Carlos, SP. O tráfego veicular rodoviário foi capturado por duas câmeras digitais, sendo posicionadas: uma frontalmente ao tráfego, e outra em perspectiva, como ilustram as imagens da Figura 3.3. A resolução dos vídeos foi de 320x240 pixels e imagens coloridas. 


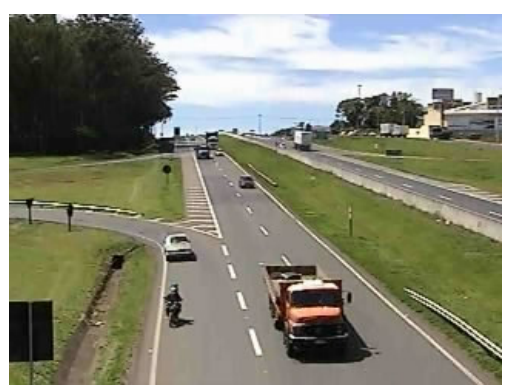

(a) Frontal - manhã

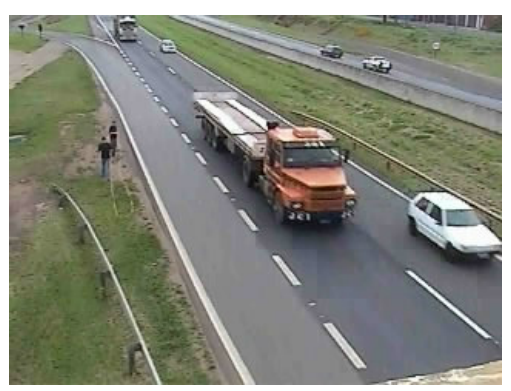

(d) Perspectiva - manhã

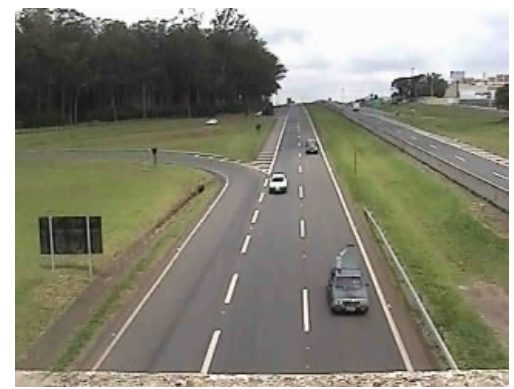

(b) Frontal - meio-dia

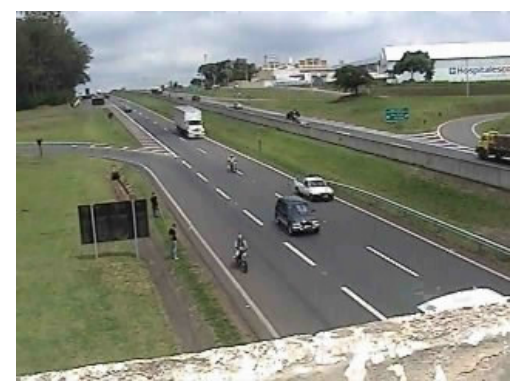

(e) Perspectiva - meio-dia

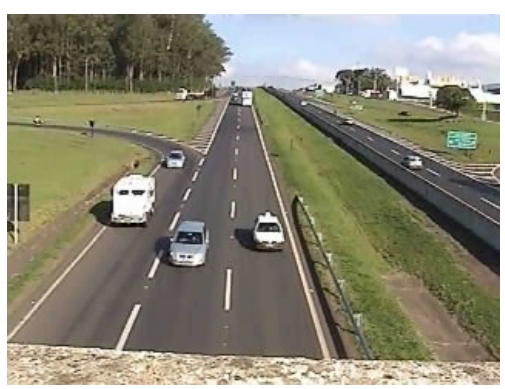

(c) Frontal - tarde

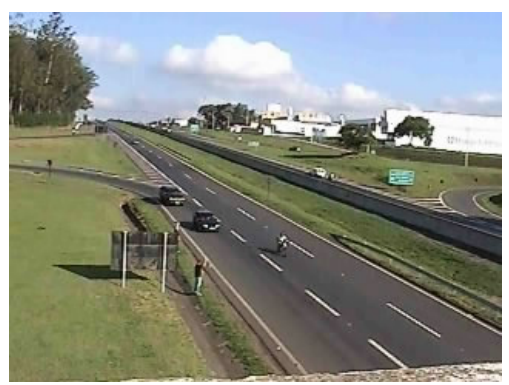

(f) Perspectiva - tarde

Figura 3.3. Frames selecionados para a comparação nos vídeos coletados em campo

As coletas foram realizadas em três períodos do dia: manhã (7h), meio-dia (12h) e tarde (17h), por um período de 1 hora, com o propósito de avaliar os algoritmos em diferentes condições de iluminação e sombra, fatores comumente observados em longos períodos de coletas de dados de tráfego. Vídeos noturnos não foram testados neste estudo.

\subsubsection{Ground truth}

O ground truth representa uma imagem da segmentação ideal, em que os pixels em destaque representam os veículos corretamente segmentados. Para se determinar o ground truth, um quadro (frame) foi aleatoriamente selecionado em cada um dos vídeos e os veículos contidos na imagem (Figura 3.3) foram segmentados manualmente. Desta forma, foi construído um conjunto de imagens ideais para se comparar com a segmentação obtida após o processamento dos modelos de background.

Para todos os vídeos, a imagem selecionada aleatoriamente foi definida como um frame a partir de 1 minuto (>1800 frames) da sequência de imagens de modo que os modelos investigados tenham tempo de gerar um background suficiente para análise. 


\subsubsection{Modelos de background investigados}

Quando uma câmera fixa observa uma cena, o background permanece a maior parte do tempo invariável. Nesse caso, os elementos de interesse são objetos se movendo dentro da cena. Assim, para se extrair os objetos (foreground), é necessário construir um modelo de background para então comparar este modelo com o frame atual e detectar os objetos na imagem.

$\mathrm{Na}$ construção da imagem do fundo estático, considera-se a normalidade da distribuição dos pixels e a probabilidade é usada para modelar o background. Os modelos investigados estão descritos a seguir.

\subsubsection{Média Ponderada}

O algoritmo Running Average executa a média ponderada dos pixels, como detalhado em Laganière [2011]. Para cada frame, o algoritmo calcula a média dos valores no tempo considerando os últimos valores observados em cada pixel. A atualização da média é feita em tempo de execução, sem a necessidade de armazenamento de frames, de acordo com a seguinte expressão:

$$
B_{(x, y, t)}=\alpha \cdot I_{(x, y, t)}+(1-\alpha) \cdot B_{(x, y, t-1)}
$$

em que: $\quad B_{(x, y, t)}$ : $\quad$ pixel $(x, y)$ no instante $t$ na imagem do modelo background; $B_{(x, y, t-1)}$ : $\quad$ pixel $(x, y)$ no instante $t-1$ na imagem do modelo background; $I_{(x, y, t)}: \quad$ pixel $(x, y)$ no instante $t$ na imagem do frame do vídeo; e $\alpha: \quad$ taxa de aprendizado $(0,01)$.

A taxa de aprendizado varia de 0 a 1 e define a influência dos valores do frame atual na composição da estimativa do background. Quanto maior este valor, mais rapidamente as mudanças ocorridas nas novas imagens são atualizadas no background. Não existe um consenso sobre o melhor valor para este parâmetro, mas a literatura recomenda não utilizar valores muito altos para evitar que os objetos sejam incorporados ao background [HEIKKILA; SILVÉN, 1999]. Neste trabalho, o valor de $\alpha$ adotado foi 0,01 de acordo com resultados de testes realizados com as imagens coletadas.

\subsubsection{Mediana}

Este modelo consiste em obter a imagem de background a partir da mediana dos valores observados num certo intervalo de tempo. Teoricamente, a mediana representa o valor 
que separa a distribuição em duas partes, neste caso background e objeto. Para tanto, é necessário armazenar uma quantidade $N$ de frames para se calcular a mediana desses frames:

$$
B_{(x, y, t)}=\operatorname{Med}\left\{I_{(x, y, t-1)}, I_{(x, y, t-2)}, \ldots, I_{(x, y, t-N)}\right\} .
$$

O cálculo da mediana envolve ordenação de dados para obter o valor que representa a metade do intervalo da sequência de dados. Em programação, essa operação é de alto custo computacional [HUNG; PAN; HSIEH, 2010], pois envolve várias operações, além da necessidade de armazenar os $N$ últimos frames na memória. Para otimizar essa operação, Hung, Pan e Hsieh [2010] apresentaram um algoritmo que acelera o processo de determinação da mediana, usando operações simples com histogramas. Esse algoritmo foi codificado para melhorar o desempenho da obtenção do background.

\subsubsection{Moda}

Este método determina a imagem de fundo a partir do valor da moda de um histórico de $N$ frames. Li, Zhu e Huang [2009] observaram em certa quantidade de tempo (100 frames) que a intensidade dos pixels do background variam muito pouco; por outro lado, nos objetos a intensidade dos pixels varia para cada veículo, além do mais, a intensidade pode não ser a mesma em diferentes partes de um mesmo veículo. Desta forma, Li, Zhu e Huang [2009] concluíram que os objetos apresentam valores de intensidades bem distribuídos, enquanto que o background apresenta a intensidade de luz concentrada em certos valores. Logo, a hipótese deste modelo considera que o background pode ser estimado pelos valores de intensidades mais frequentes, representado pela moda:

$$
B_{(x, y, t)}=\operatorname{Mod}\left\{I_{(x, y, t-1)}, I_{(x, y, t-2)}, \ldots, I_{(x, y, t-N)}\right\} .
$$

Assim como no método da mediana, a moda também apresenta como ponto negativo o custo computacional, pois necessita contabilizar a frequência dos valores dos pixels e armazenar certa quantidade de frames na memória.

\subsubsection{Mistura de Gaussianas}

O modelo de mistura de Gaussianas (MoG - Mixture of Gaussian, ou GMM Gaussian Mixture Model) é o modelo mais usual em processamento de imagens para modelagem do fundo em imagens de vídeo. Em linhas gerais, o modelo considera $k$ 
distribuições normais para representar o comportamento do pixel no tempo. Ao contrário dos modelos anteriores que obtiveram apenas um parâmetro do histórico dos valores, na MoG é possível especificar uma combinação de distribuições Gaussianas. Cada pixel pode ter valores para objetos, fundo estático ou até sombra. Assim, a hipótese deste modelo considera que cada distribuição represente uma dessas classes.

No OpenCV, o modelo de MoG descrito por Zivkovi [2004] está implementado de forma otimizada. Assim, o código escrito para este algoritmo chama a função ajustando os parâmetros necessários:

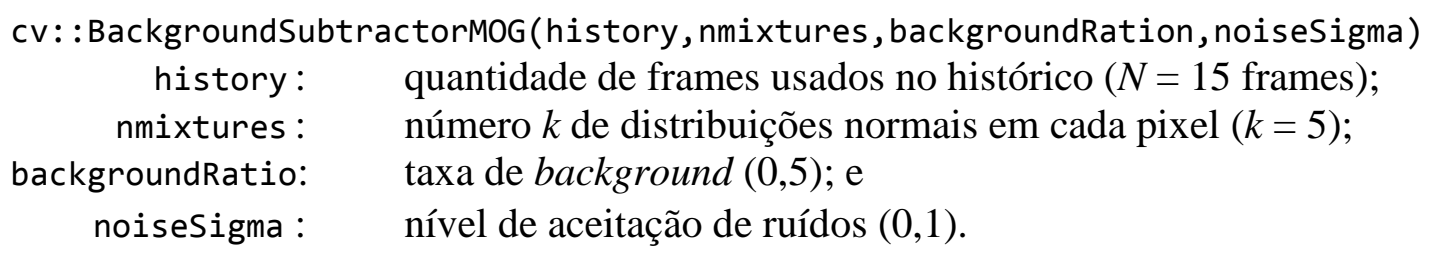

Os parâmetros quantidade de frames e números de distribuições foram definidos a partir de resultados dos experimentos deste trabalho. Para os demais parâmetros, backgroundRatio e noiseSigma, foram mantidos os valores padrões da função [ZIVKOVI, 2004].

\subsubsection{Probabilidades}

O método de probabilidade desenvolvido por Godbehere, Matsukawa e Goldberg [2012], denominado GMG (iniciais dos autores), está disponível na versão 2.4.5 da biblioteca OpenCV. Esse modelo é uma derivação do MoG. Esse método utiliza regras de inferência Bayesiana para calcular a verossimilhança de cada pixel ser classificado como background ou foreground. O método cria, para cada pixel, um vetor que armazena os valores de intensidade de cada plano de cor, este vetor é quantizado de forma a representar um histograma otimizado. Após $N$ frames iniciais de treinamento, uma função densidade de probabilidades é obtida em cada pixel, representando a probabilidade do pixel ser objeto ou fundo estático. Os parâmetros que diferenciam o pixel como background e foreground são atualizados automaticamente a cada frame e são obtidos por estatística não paramétrica.

\subsubsection{Scoreboard}

Lai e Yung [1998] apresentaram um método que mescla os modelos da Média Ponderada e a Moda em um único modelo. Em linhas gerais, esse método verifica a cada 
novo frame quais os pixels que apresentam as maiores variações do valor da intensidade. Caso haja uma grande variação, utiliza-se o método da moda que prioriza a qualidade; por outro lado, caso a variação seja menor, utiliza-se a média ponderada que é mais rápida. De modo geral, os pixels apresentam pequena variação na sequência de imagens, portanto o Scoreboard tende a mesclar precisão e velocidade de processamento [LAI; YUNG, 1998].

A decisão entre usar o modelo da moda ou da média ponderada é definida por:

$$
d_{(x, y, t)}=1-\frac{\left|I_{(x, y, t)}-B_{(x, y, t-1)}\right|}{T}
$$

Sendo que $T$ representa um valor limiar para considerar pequenas variações de intensidades, no qual Lai e Yung [1998] recomendam um valor entre 10 e 20 na escala de 256 níveis de cinza. Este trabalho definiu como 10 este valor. A diferença do frame atual $I_{(x, y, t)}$ e a estimativa do background anterior $B_{(x, y, t-1)}$ resulta na imagem $d_{(x, y, t)}$, a qual define que os pixels com diferença menor ou igual a zero são atualizados pela moda; enquanto os valores maiores que zero são avaliados pelo método da média ponderada.

\subsubsection{Análise do desempenho dos modelos}

O desempenho dos modelos investigados foi aferido pela sua representatividade em identificar os objetos na imagem. Para isso, após a geração da imagem de background de cada modelo, foi realizada uma subtração do frame atual com o background modelado. Esta imagem de diferença, denominada de fgmask (abreviação de foreground mask, ou máscara de foreground) representa os objetos encontrados pelo sistema de detecção.

A partir das imagens de fgmask, o desempenho dos modelos foi avaliado por dois quesitos: tempo de processamento e taxa de acerto. O tempo de processamento foi determinado durante a execução de cada modelo, a cada frame, uma função contabilizava o tempo gasto para se processar cada novo frame. A taxa de acerto foi calculada segundo as medidas de desempenho apresentadas na Tabela 3.1, obtidas ao comparar a imagem ground truth e a fgmask. 
Tabela 3.1. Tabela de contingência e cálculo das métricas comuns de desempenho

\begin{tabular}{l|l|l|l}
\hline \multirow{2}{*}{$\begin{array}{l}\text { Referência } \\
\text { (ground truth) }\end{array}$} & \multicolumn{2}{|l|}{ Resultado (fgmask) } & \multirow{2}{*}{ Total } \\
\cline { 2 - 3 } & Positivo (foreground) & Negativo (background) & \\
\hline Positivo (foreground) & Verdadeiro Positivo (VP) & Falso Negativo (FN) & Positivos $(P)$ \\
\hline Negativo (background) & Falso Positivo (FP) & Verdadeiro Negativo (VN) & Negativos $(N)$ \\
\hline Taxa de Verdadeiro Positivo $=\frac{V P}{P}$ & Precisão $=\frac{V P}{V P+F P}$ & \\
Taxa de Falso Positivo $=\frac{F P}{N}$ & Exatidão $=\frac{V P+V N}{P+N}$ & \\
\hline
\end{tabular}

A Tabela 3.1 apresenta a tabela de contingência e suas métricas de desempenho [METZ, 1978; FAWCETT, 2005], comumente usada na literatura para verificar a detecção de objetos em imagens. Para se obter esses parâmetros é necessário comparar as duas imagens e contar a quantidade de pixels de acordo com as seguintes definições:

- VP (verdadeiro positivo): objetos do ground truth que foram corretamente classificados no fgmask como objetos;

- VN (verdadeiro negativo): background do ground truth corretamente classificado no fgmask como background;

- $\quad$ FP (falso positivo): pixels de objetos no fgmask classificados erroneamente, pois representam background no ground truth;

- FN (falso negativo): pixels de background no fgmask classificados de forma errada, pois são objetos no ground truth;

\subsection{RESULTADOS OBTIDOS}

A Tabela 3.2 traz em detalhes as imagens dos frames selecionados para a avaliação, dos ground truth obtidos manualmente, além dos resultados das imagens (fgmask) após o processamento de cada modelo avaliado e em cada um dos vídeos.

Os pixels na cor branca representam os objetos identificados após a subtração do frame atual com o background modelado. A partir das imagens da Tabela 3.2, fica evidente a presença de vários pixels como falso positivo, ou seja, pixels do background classificados como objeto. Da mesma forma, outra parcela dos pixels são falso negativo, objetos que foram classificados como background - resultando objetos incompletos com vazios no seu interior. 
O método da Probabilidade foi o que apresentou a maior concentração de falsos positivos, como apresentado nas imagens da Tabela 3.2.

Tabela 3.2. Resultados das imagens processadas

\begin{tabular}{|c|c|c|c|c|c|c|}
\hline & \multicolumn{6}{|c|}{ Vídeos coletados } \\
\hline & $\begin{array}{l}\text { Frontal } \\
\text { manhã }\end{array}$ & $\begin{array}{l}\text { Frontal } \\
\text { meio-dia }\end{array}$ & $\begin{array}{l}\text { Frontal } \\
\text { tarde }\end{array}$ & $\begin{array}{l}\text { Perspectiva } \\
\text { manhã }\end{array}$ & $\begin{array}{l}\text { Perspectiva } \\
\text { meio-dia }\end{array}$ & $\begin{array}{l}\text { Perspectiva } \\
\text { tarde }\end{array}$ \\
\hline Frame & & & & & int & \\
\hline Ground Truth & & & $0^{\circ}$ & & & \\
\hline Média & & & & & & \\
\hline Mediana & & & & & & \\
\hline Moda & & $8^{*}$ & $\Delta_{0}^{2}$ & & & \\
\hline MoG & & 8 & $=0$ & & 15 & 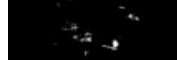 \\
\hline Probabilidad & & & & & & \\
\hline Scoreboard & & $a^{2}$ & $a_{0}^{*}$ & & & $=$ \\
\hline
\end{tabular}

Visualmente, a Tabela 3.2 revela que o Scoreboard parece ter as melhores identificações dos veículos. Além da detecção dos objetos em movimento, vale destacar que, de todos os modelos investigados, o Scoreboard foi o que determinou o fundo estático em menor tempo de processamento. Em menos de 160 frames (menos de 6 segundos de vídeo), já é possível ter um background como retrata a sequência de frames do vídeo na Tabela 3.3. 
Tabela 3.3. Exemplo do processamento do modelo Scoreboard

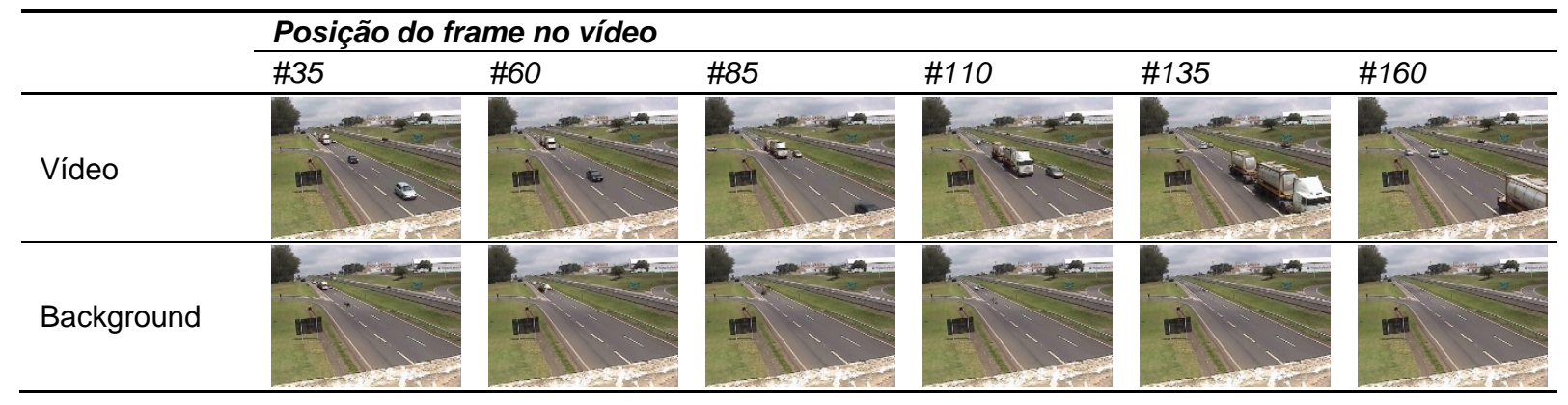

\subsubsection{Tempo de processamento}

Nesta etapa foi determinado o tempo médio em segundos para se processar um único frame. Como parâmetro de referência, vale ressaltar que os vídeos geralmente são capturados a uma taxa de $30 \mathrm{fps}$ (frames por segundo), o que resulta em 0,0333 s/frame.

Tabela 3.4. Resultados dos tempos médios de processamento em s/frame

\begin{tabular}{lllllll}
\hline \multirow{2}{*}{ Vídeo } & \multicolumn{7}{l}{ Modelos avaliados } & & & \\
\cline { 2 - 7 } & Média & Mediana & Moda & MoG & Probabilidade & Scoreboard \\
\hline Frontal - manhã & 0,0130 & 0,1425 & 1,9916 & 0,0508 & 0,0226 & 0,0184 \\
Frontal - meio-dia & 0,0123 & 0,0639 & 1,1693 & 0,0506 & 0,0218 & 0,0198 \\
Frontal - tarde & 0,0123 & 0,1176 & 1,1210 & 0,0501 & 0,0219 & 0,0201 \\
Perspectiva - manhã & 0,0125 & 0,1539 & 1,2063 & 0,0507 & 0,0233 & 0,0180 \\
Perspectiva - meio-dia & 0,0122 & 0,1683 & 1,1091 & 0,0506 & 0,0231 & 0,0168 \\
Perspectiva - tarde & 0,0124 & $\mathbf{0 , 1 2 6 9}$ & $\mathbf{1 , 1 2 2 5}$ & 0,0503 & 0,0239 & 0,0200 \\
\hline Tempo médio (s/frame) & $\mathbf{0 , 0 1 2 4}$ & $\mathbf{0 , 1 2 8 9}$ & $\mathbf{1 , 2 8 6 6}$ & $\mathbf{0 , 0 5 0 5}$ & $\mathbf{0 , 0 2 2 7}$ & $\mathbf{0 , 0 1 8 9}$ \\
\hline
\end{tabular}

De fato, o modelo da Média corroborou o que a literatura relata, sendo o método mais rápido de processamento com 12,4 ms/frame (milissegundos), seguido pelo Scoreboard com 18,9 ms/frame e pelo modelo de Probabilidade (GMG) com 22,7 ms/frames. Esses três modelos foram os únicos com taxa de processamento menor que 33,3 ms/frame (30 fps), ou seja, tão rápidos quanto a execução normal de um vídeo.

Os modelos mais lentos foram a Moda (mais de $1 \mathrm{~s} /$ frame) e a Mediana (128,9 ms/frame), como era de se esperar, pois esses modelos necessitam de armazenamento dos frames na memória e tem custo computacional elevado para executar as operações matemáticas. Vale lembrar que foram usadas imagens coloridas (3 planos) em todos os modelos; caso se utilizem imagens monocromáticas (1 plano), os tempos de processamento tendem a ser menores.

\subsubsection{Taxa de exatidão}

A taxa de exatidão (accuracy) dos modelos expressa a razão dos pixels corretamente 
identificados $(\mathrm{VP}+\mathrm{VN})$ pela total de pixels do ground truth $(\mathrm{P}+\mathrm{N})$. Este parâmetro fornece um valor de taxa de acerto total, ou seja, o quanto o modelo consegue classificar objetos e background comparando-se com o ground truth. A Tabela 3.5 apresenta os valores calculados em cada modelo.

Tabela 3.5. Resultados da taxa de exatidão

\begin{tabular}{lllllll}
\hline \multirow{2}{*}{ Vídeo } & \multicolumn{7}{l}{ Modelos avaliados } \\
\cline { 2 - 7 } & Média & Mediana & MoG & Moda & Probabilidade & Scoreboard \\
\hline Frontal - manhã & $94,6 \%$ & $95,5 \%$ & $95,7 \%$ & $93,1 \%$ & $89,8 \%$ & $96,5 \%$ \\
Frontal - meio-dia & $98,1 \%$ & $98,1 \%$ & $98,1 \%$ & $97,6 \%$ & $95,9 \%$ & $98,2 \%$ \\
Frontal - tarde & $94,9 \%$ & $94,7 \%$ & $94,5 \%$ & $93,2 \%$ & $91,4 \%$ & $95,0 \%$ \\
Perspectiva - manhã & $91,1 \%$ & $91,7 \%$ & $92,1 \%$ & $86,5 \%$ & $84,0 \%$ & $92,8 \%$ \\
Perspectiva - meio-dia & $92,6 \%$ & $92,6 \%$ & $93,5 \%$ & $94,2 \%$ & $86,8 \%$ & $94,6 \%$ \\
Perspectiva - tarde & $97,9 \%$ & $97,8 \%$ & $98,0 \%$ & $97,7 \%$ & $91,4 \%$ & $97,0 \%$ \\
\hline Exatidão média & $\mathbf{9 4 , 9 \%}$ & $\mathbf{9 5 , 1 \%}$ & $\mathbf{9 5 , 3 \%}$ & $\mathbf{9 3 , 7 \%}$ & $\mathbf{8 9 , 9 \%}$ & $\mathbf{9 5 , 7 \%}$ \\
\hline
\end{tabular}

O Scoreboard foi o modelo com maior média de taxa de acertos totais (95,7\%), seguido pela MoG (95,3\%) e pela Mediana (95,1\%). Esta tabela mostra também que, independentemente do modelo, a taxa de accuracy é superior a 84\%. Outro fato de destaque é que o vídeo Perspectiva - manhã teve os piores índices de accuracy em todos os modelos. Isso pode ser explicado pelas constantes variações de iluminação do sol neste vídeo.

\subsubsection{Taxa de VP}

A taxa de verdadeiros positivos representa a porcentagem dos objetos corretamente identificados pelo modelo perante o total de objetos do ground truth. Este parâmetro reflete apenas a taxa de acertos dos objetos, retratada na Tabela 3.6.

Tabela 3.6. Resultados da taxa de verdadeiro positivo (VP)

\begin{tabular}{lllllll}
\hline \multirow{2}{*}{ Vídeo } & \multicolumn{7}{l}{ Modelos avaliados } & \multicolumn{2}{l}{} \\
\cline { 2 - 7 } & Média & Mediana & MoG & Moda & Probabilidade & Scoreboard \\
\hline Frontal - manhã & $66,2 \%$ & $60,7 \%$ & $54,7 \%$ & $28,4 \%$ & $78,3 \%$ & $62,4 \%$ \\
Frontal - meio-dia & $44,6 \%$ & $35,0 \%$ & $30,0 \%$ & $27,2 \%$ & $60,7 \%$ & $36,2 \%$ \\
Frontal - tarde & $46,0 \%$ & $40,3 \%$ & $34,8 \%$ & $21,8 \%$ & $54,6 \%$ & $41,5 \%$ \\
Perspectiva - manhã & $52,7 \%$ & $63,8 \%$ & $55,4 \%$ & $34,8 \%$ & $80,8 \%$ & $63,0 \%$ \\
Perspectiva - meio-dia & $42,7 \%$ & $22,3 \%$ & $22,9 \%$ & $20,9 \%$ & $61,1 \%$ & $32,4 \%$ \\
Perspectiva - tarde & $30,8 \%$ & $\mathbf{2 8 , 5 \%}$ & $\mathbf{2 7 , 5 \%}$ & $\mathbf{1 4 , 8} \%$ & $\mathbf{4 9 , 9} \%$ & $34,9 \%$ \\
\hline Taxa VP média & $\mathbf{4 7 , 2 \%}$ & $\mathbf{4 1 , 8 \%}$ & $\mathbf{3 7 , 6 \%}$ & $\mathbf{2 4 , 6 \%}$ & $\mathbf{6 4 , 3 \%}$ & $\mathbf{4 5 , 1 \%}$ \\
\hline
\end{tabular}

Dos resultados obtidos, o modelo Probabilidades apresentou a melhor taxa de VP (64,3\%), seguido pelos modelos Média (47,2\%) e Scoreboard (45,1\%). De fato, o modelo Probabilidades reconheceu melhor os objetos no frame: nota-se, nas imagens da Tabela 3.2, que os objetos estão bem definidos e com poucos vazios. Porém, há uma grande quantidade de pixels identificados erroneamente como objetos, tanto que a medida anterior acusou o 
método da Probabilidade com o pior índice. Esse fato pode ser explicado por ter sido usado os parâmetros default do método, sem uma prévia calibração para o tipo de imagem.

\subsection{CONSIDERAÇÕES FINAIS}

A partir de uma adequada imagem de background aumenta-se a chance de uma melhor segmentação dos frames da corrente de tráfego. Assim, nesta etapa, investigaram-se seis modelos de geração de background disponíveis na literatura: Média, Mediana, Misturas de Gaussianas (MoG), Moda, Probabilidade e Scoreboard. Os testes foram realizados com vídeos obtidos em períodos diferentes do dia (manhã, meio-dia e tarde), com tempo bom.

Dentre os modelos investigados, conclui-se que o Scoreboard, modelo que combina a Moda e a Média para se determinar o background de referência, foi o mais adequado para a identificação dos objetos em imagem do tráfego. O Scoreboard apresentou a segunda melhor média do tempo de processamento (18,9 ms/frame), atrás apenas do modelo Média (12,4 ms/frame), e obteve a melhor taxa de acertos totais (accuracy) com 95,7\% de média, variando de 92,8\% a 98,2\% nos seis vídeos testados. Quanto à taxa de VP (verdadeiro positivo) o modelo obteve um índice de apenas 45,1\% de acerto dos objetos, o terceiro melhor dentre os modelos analisados. Vale ressaltar que esta detecção de objetos é a primeira etapa do sistema em desenvolvimento. A partir dessas detecções, o próximo capítulo traz o processamento para a segmentação os objetos. 


\section{Segmentação de Veículos}

O objetivo deste capítulo é investigar os modelos de segmentação de veículos em imagens de vídeo usados na literatura e definir o melhor modelo a ser incorporado no sistema automático proposto. Sabe-se que uma adequada segmentação dos veículos nas imagens de vídeos garante que os parâmetros de tráfego sejam obtidos com maior fidelidade a realidade.

\subsection{CONSIDERAÇÕES INICIAIS}

Todo sistema automático de processamento de imagens em vídeo tem início na detecção do movimento de objetos. Nesta etapa, regiões correspondentes ao movimento dos veículos são segmentadas do restante da imagem. A segmentação merece especial atenção, pois apenas os objetos segmentados na imagem são considerados nas etapas seguintes de rastreamento do veículo e classificação. Por essa razão, esta etapa deve ser cuidadosamente estudada para se melhorar as chances de uma segmentação robusta.

A segmentação automática é uma das tarefas mais difíceis em processamento de imagens [GONZALEZ; WOODS, 2007] e esse passo determina o sucesso ou o fracasso do sistema. Segundo Szeliski [2011], a segmentação é a tarefa de encontrar grupos de pixels na imagem com alguma similaridade. Em estatística, este problema é conhecido como análise de cluster e é amplamente estudada com centenas de algoritmos diferentes para realizar tal tarefa [JAIN; DUBES, 1988; KAUFMAN; ROUSSEEUW, 1990].

Existem vários métodos de segmentação na literatura, dos mais simples que consideram apenas operações pixel-a-pixel, aos mais complexos cujos procedimentos procuram compreender a imagem por modelos matemáticos. Embora haja constante evolução nos métodos de segmentação, ainda não existe um consenso do melhor método para tal tarefa [PAL; PAL, 1993; TOYAMA et al., 1999], principalmente quando se usa imagens de ambiente externo sem controle algum da iluminação, muito comum nas imagens do tráfego viário. Pal e Pal [1993] reforçam dizendo que não existe um único método que possa ser considerado bom para tratar todos os tipos de imagens, muito menos obter resultados semelhantes ao se usar diferentes métodos em uma mesma imagem. 
Em visão computacional, a segmentação é um dos problemas mais antigos e amplamente estudado [HARALICK; SHAPIRO, 1985]. A literatura em segmentação é vasta, portanto, os métodos devem ser avaliados de acordo com a aplicação em questão. Alguns trabalhos descrevem uma revisão dos principais métodos em aplicação [PAL; PAL, 1993; HU et al., 2004; BENEZETH et al., 2008; WANG; XIAO; GU, 2008].

Com base na revisão bibliográfica, os métodos de segmentação foram classificados em duas principais categorias: baseado no pixel e baseado em regiões (templates ou janelas) da imagem.

\subsubsection{Segmentação baseada no pixel}

Nesta categoria, os métodos de segmentação consideram apenas a informação do pixel na posição $(x, y)$. O procedimento mais comum e mais empregado na literatura consiste na operação da diferença absoluta entre duas imagens seguida pela aplicação da função threshold, de acordo com a equação:

$$
M_{t}(x, y)= \begin{cases}1, & \left|I_{t}(x, y)-B_{t}(x, y)\right| \geq \tau_{t} \\ 0, & \left|I_{t}(x, y)-B_{t}(x, y)\right|<\tau_{t}\end{cases}
$$

Sendo $M_{t}$ a imagem da máscara resultante identificando os objetos, $I_{t}$ o frame atual no instante $t, B_{t}$ a imagem de referência e $\tau_{t}$ o valor limiar que diferencia objetos. Como já apresentado no Capítulo 3, dependendo da imagem usada como referência, duas técnicas são conhecidas:

- A primeira é denominada diferença entre frames, do inglês Frame Difference ou Inter-frame Difference, no qual a subtração é feita entre dois ou mais frames consecutivos resultando numa imagem onde houve alguma movimentação, contorno dos objetos, como mostra a Figura 4.1. Este processo é altamente dependente da velocidade dos objetos na imagem, pois objetos parados tendem a ficar na mesma posição entre as imagens, logo a subtração entre os frames será nula. 


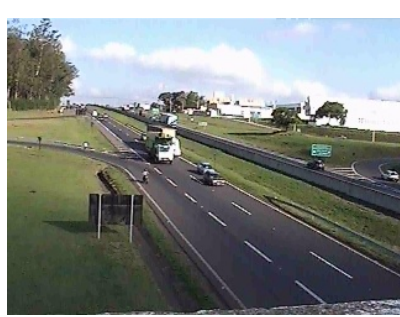

Frame \#144

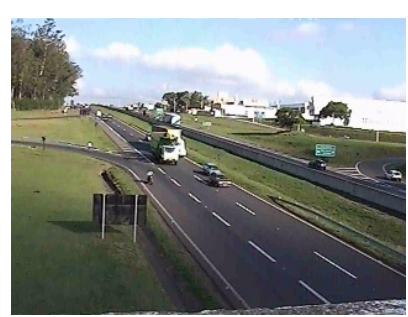

Frame \#164

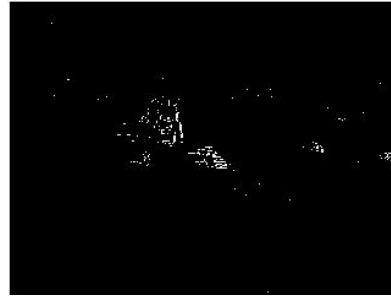

Diferença entre frames

Figura 4.1. Exemplo de subtração entre frames

- A segunda é denominada subtração de fundo (background subtraction), seu princípio envolve a diferenciação de uma imagem com objetos e outra de referência que não contenha objetos de interesse. A imagem de referência do fundo pode ser real, obtida na própria sequência de imagens do vídeo, ou pode ser obtida de uma imagem confiável do fundo construída a partir de modelos de geração de background, como apresentado no Capítulo 3. As significantes diferenças nos pixels entre as imagens real e estimada indicam a localização dos objetos (Figura 4.2).

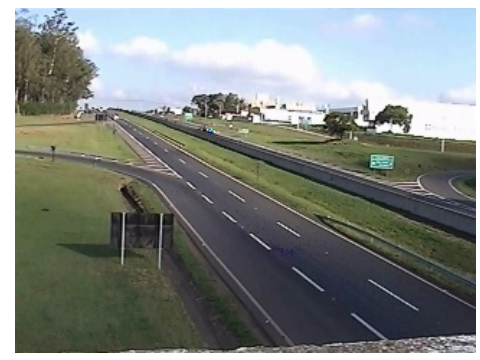

(a) Background

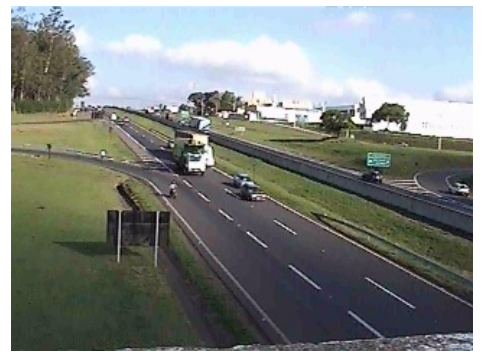

(b) Frame \#144

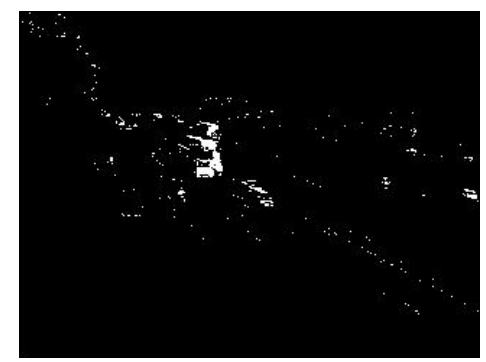

(c) Subtração de fundo

Figura 4.2. Exemplo de subtração de fundo

Na literatura, diversos trabalhos utilizaram essas técnicas e alguns até propuseram variações. A seguir uma breve explanação de alguns desses trabalhos aplicados à área de monitoramento do tráfego.

Jelača, Pižurica e Philips [2009] propuseram um algoritmo para deteç̧ão e rastreamento de veículos que trafegam em túneis, usando a diferença entre frames consecutivos. Em seguida, os autores desenvolveram uma técnica denominada scan-line a qual projeta no plano horizontal e vertical a quantidade de pixels encontrados na subtração, resultando a provável localização dos veículos em movimento. Chen e Zhang [2012] propuseram a combinação da diferença de três frames consecutivos para a detecção de veículos.

Tang, Miao e Wan [2007] usaram a subtração entre frames combinada com a 
subtração de fundo para extrair os objetos. Já Hu et al. [2010] e Yu et al. [2011] combinaram as técnicas de diferença entre frames, subtração de fundo e detectores de borda para melhorar a identificação dos veículos. A proposta de Hu et al. [2010] foi avaliar a taxa de precisão na segmentação dos veículos na imagem, enquanto Yu et al. [2011] propuseram o método para classificação dos veículos pelo comprimento.

He e Yung [2007] apresentaram um novo método para se determinar a velocidade dos veículos, no qual a imagem bidimensional é transformada na sua projeção perspectiva em 3D, para então realizar a diferença entre frames e segmentar os veículos. O trabalho apresentou bons resultados comparando as velocidades obtidas com dados de sensores no pavimento, inclusive ao se utilizar vídeos noturnos.

Em subtração de fundo, nota-se que os trabalhos enfatizam a modelagem da imagem de fundo para garantir uma segmentação satisfatória. Jung e Ho [1999] construíram o background pelo algoritmo da média e realizaram a subtração de fundo para extrair os veículos e calcular os parâmetros de tráfego. Já Batista et al. [2006] e Monteiro et al. [2008] utilizaram a média em um método multicamadas que modela três imagens de background, sendo duas para absorver as variações de iluminação e ruídos e uma para validar todo o processo. Após a modelagem, a subtração de fundo e um threshold dinâmico foram aplicados para o monitoramento do tráfego. Khorramshashi, Behrad e Kanhere [2008] também usaram a média na modelagem da imagem do fundo, porém a atualização dessa imagem era feita apenas nos pixels identificados como estático na diferença entre frames [FU et al., 2004]. Em seguida, aplicaram o background subtraction com o objetivo de identificar os veículos que ultrapassavam o limite de altura permitida nas vias.

No Brasil, Ferreira [2008] aplicou a subtração de fundo, utilizando o modelo de geração do background da mediana proposto em Haritaoglu, Harwood e Davis [2000], e complementou a segmentação com o algoritmo de remoção de sombras de Yoneyama, Yeh e Kuo [2005] para segmentar e obter a velocidade dos veículos em rodovias. Tancredi [2012] aplicou três modelos de estimativa de background, baseados na mediana, disponíveis no pacote do Matlab-Simulink e realizou a subtração de fundo para a identificação de veículos de carga em vias urbanas com restrições à circulação desses veículos.

Outros trabalhos optaram pela mistura de Gaussianas $(G M M)$ na modelagem do 
background, como Silva e Gonzaga [2006] que realizaram a subtração de fundo para segmentar os veículos da imagem de vídeo no Brasil. Em Portugal, Loureiro, Rossetti e Braga [2009] decidiram pela função GMM disponível no pacote OpenCV e calibraram um sistema de segmentação de veículos. Wang e Song [2011] utilizaram o mesmo modelo GMM e após a subtração de fundo determinaram o fluxo e velocidade dos veículos.

Alguns trabalhos optaram por usar um modelo de inferência estatística para construir a imagem background, como em Pan et al. [2002] que utilizou uma combinação dos três planos no espaço de cor YCbCr. Já Chiu, Ku e Liang [2010] usaram o histórico dos valores dos pixels em cada plano no modelo RGB. No Brasil, Oliveira e Scharcanski [2010] utilizaram uma função densidade de probabilidade para modelar a ocorrência dos níveis de cinza de cada pixel. A partir dessa função estimativa, foi possível classificar os pixels em objetos e fundo.

Outros métodos propuseram inovações, como Lai, Fung e Yung [2001] que combinaram a subtração de fundo, a partir do modelo Scoreboard [LAI; YUNG, 1998] para determinar o background, e o método de remoção de sombras proposto em Fung et al. [2000] para classificar veículos obtendo suas medidas de comprimento, largura e altura. Enquanto Porikli [2005] interpretou os conceitos de imagem intrínseca [WEISS, 2001] e propôs um modelo multiplicativo que decompõe uma imagem $\left(I_{t}\right)$ em parte estática $\left(B_{t}\right)$ e parte em movimento $\left(C_{t}\right)$, representado por: $I_{t}=B_{t} \cdot C_{t}$. No domínio logaritmo, essa equação torna-se $i_{t}$ $=b_{t}+c_{t}$, o que recai na subtração de fundo. Este método apresentou bons resultados de segmentação de veículos em rodovias (Figura 4.3).

Chiu, Ku e Wang [2010] utilizaram subtração de fundo e o background foi gerado pelo método de Chen et al. [2004], o qual propõe um modelo estatístico baseado nas informações de cada plano no espaço RGB. Após a subtração é aplicado um detector de bordas e os autores descrevem um método que contabiliza o histograma das bordas nas projeções horizontal e vertical da imagem para detectar os veículos. O sistema proposto nesse trabalho foi aplicado com bons resultados nas rodovias de Taiwan.

Em resumo, a subtração de fundo é a operação de processamento de imagem mais fundamental em aplicações em vídeos, por causa da sua simplicidade e, principalmente, pela sua aplicabilidade quando se usa câmeras em uma posição fixa [GONZALEZ; WOODS, 2007]. No entanto, este método tem como ponto fraco a sua principal consideração: tratar os 
pixels independentemente.
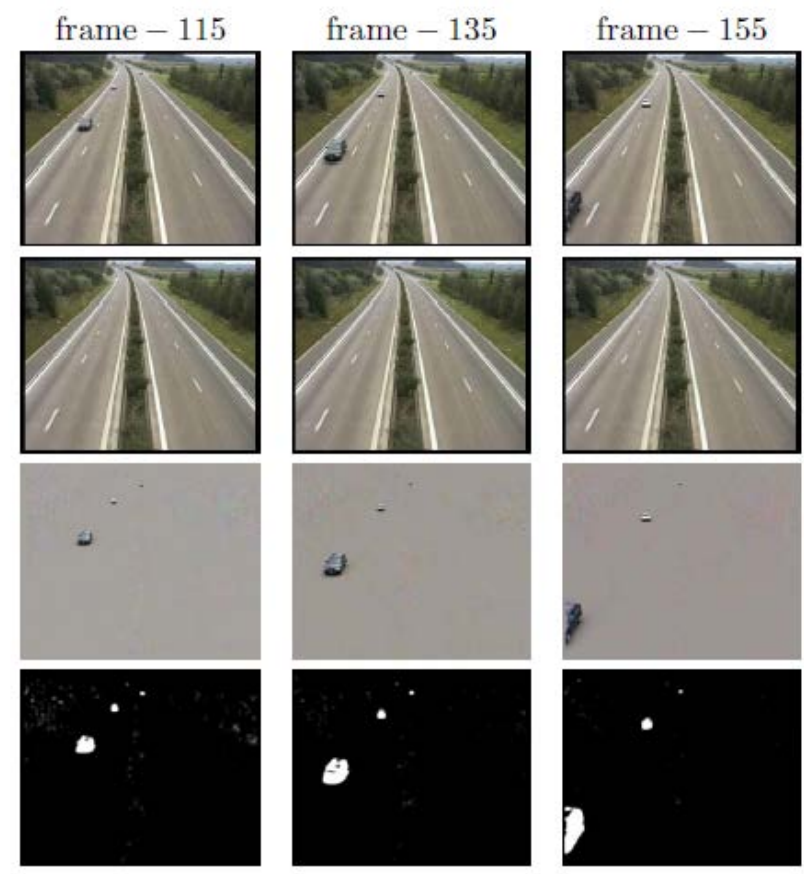

Figura 4.3. Exemplo dos resultados de segmentação de Porikli [2005]

\subsubsection{Segmentação baseada em região}

O princípio dos métodos baseados em região leva em consideração, além do pixel $(x, y)$, as informações de uma janela em volta deste pixel. Dada uma imagem $I$, cada pixel dessa imagem e sua vizinhança é transformada em uma imagem $p$ de tamanho $M x N$, dada por:

$$
p_{(x, y)}(m, n)=I\left(x+m-\frac{M}{2}, y+n-\frac{N}{2}\right)\left\{\begin{array}{c}
0 \leq m \leq M \\
0 \leq n \leq N
\end{array}\right.
$$

A partir dessa janela, é possível aplicar um operador e obter não um, mas vários parâmetros descritores dessa região, denominado vetor de características. O principal diferencial deste método está na comparação entre duas imagens que emprega medidas de similaridade para diferenciar os vetores de características de cada região. A seguir, alguns exemplos com aplicações na área de monitoramento da corrente de tráfego.

Xia et al. [2009] determinaram a estatística de correlação dos pixels em uma janela 3x3 na imagem de cinza e uma função threshold separou os veículos em imagens de vídeo na China. Zhong et al. [2011] obtiveram os veículos através da subtração de fundo, sendo que o background foi obtido a partir de um conceito de similaridade espaço-temporal aplicado em uma janela tridimensional $(N x N) x k$, ou seja, uma janela $N x N$ da imagem nos últimos $k$-frames. 
Lien et al. [2011] descreveram um método que, utilizando a imagem da diferença entre frames no espaço de cores YCbCr, percorre uma janela por toda a imagem e identifica o veículo nos pixels onde houve certa alteração nos três planos de cor simultaneamente; caso contrário é definido como sombra ou ruído. Já Gangodkar, Kumar e Mittal [2012] determinaram o movimento dos veículos comparando janelas entre frames consecutivos. Se uma janela não se encontra na mesma posição entre os dois frames, então a região está em movimento. A soma da diferença absoluta foi a métrica usada para determinar a similaridade dos blocos.

Lam, Pang e Yung [2003; 2004] descobriram que existe certa variação do valor da autocorrelação ao investigarem três janelas de uma imagem contendo: parte de um veículo, sombra e o pavimento da rodovia. Assim, propuseram um método que combina mapas de textura, luminância e crominância, usando o espaço de cor YCbCr. O resultado obtido na pesquisa mostra o veículo bem definido na segmentação (Figura 4.4).

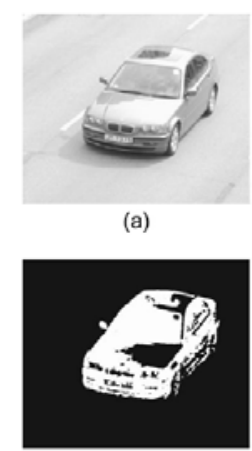

(e)

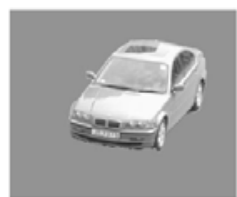

(i)

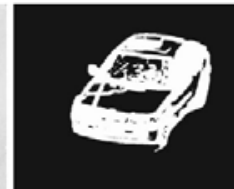

(c)

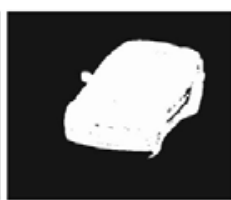

(f)

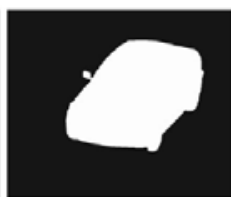

(j)

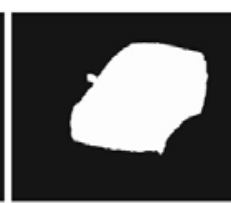

(g)

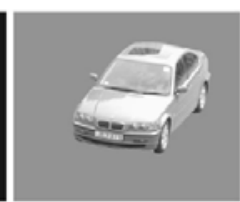

(k)

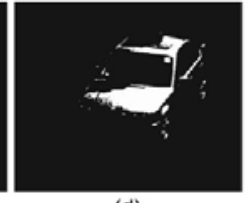

(d)

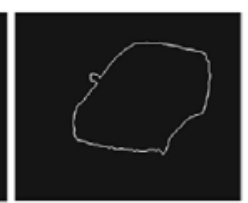

(h)

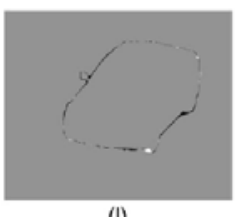

(l)

Figura 4.4. Resultado da segmentação de Lam, Pam e Yung [2004]: (a) frame; (b) background; (c) mapa de textura; (d) mapa de luminância; (e) mapa de crominância, (f) combinação de (c-d-e);

(g) morfologia em (f); (h) borda; (i) resultado segmentação; (j) máscara de referência;

(k) veículo de referência; (l) erro - diferença entre $(j-g)$

Neste contexto, a textura aparece como uma importante abordagem para a descrição de regiões. Embora não exista um consenso comum da definição de textura, esse descritor intuitivamente fornece medidas de propriedades como suavidade, rugosidade e regularidade [GONZALEZ; WOODS, 2007]. Segundo Mejia-Iñigo, Barrila-Pérez e Montes-Venegas [2008], a textura é conceituada como uma rica fonte de informação pela sua natureza e forma. Para Marteka e Strzelecki [1998], a textura consiste de padrões e sub-padrões visualmente 
complexos com propriedades singulares como brilho, cor e tamanho. Sklansky [1978] descreveu que uma região em uma imagem apresenta textura única se um conjunto de parâmetros estatísticos ou outras propriedades locais da imagem forem constantes, com pouca variação ou aproximadamente periódicas.

A análise de textura tem sido um tópico de intensas pesquisas desde 1960 e uma grande variedade de técnicas de descritores de texturas tem sido propostas desde então [PIETIKÄINEN et al., 2011]. He e Wang [1990] apresentaram uma formulação de análise de textura com operadores simples e eficientes. Após esse trabalho, outros descritores surgiram, dentre eles o $L B P$ e o $L F P$ vêm ganhando muito espaço na literatura, devido à sua facilidade de codificação e elevadas taxas de acerto nos testes em bases de imagens padrões. A seguir é apresentada uma breve conceituação desses dois descritores de texturas.

\subsubsection{LBP}

Local Binary Pattern (LBP) foi introduzido por Ojala, Pietikäinen e Harwood [1996] no Machine Vision Group da Universidade de Oulu, na Finlândia. A hipótese do LBP considera que a textura possui localmente dois aspectos complementares, um padrão e uma intensidade. Desta forma, o método $L B P$ pode ser visto como uma aproximação que unifica a estatística tradicional e a estrutura de modelos em análise de texturas [PIETIKÄINEN et al., 2011].

O LBP é considerado um operador de textura simples e muito eficiente em que codifica os pixels de uma imagem pelo thresholding da sua vizinhança e considera o resultado um número binário. Pietikäinen et al. [2011] relatam que a propriedade mais importante do operador $L B P$ em aplicações reais é a sua invariância quanto às mudanças do nível de cinza causada, por exemplo, por variações de iluminação. Outra importante característica é sua simplicidade computacional, o que o torna viável para analisar imagens em tempo real.

A versão original do operador $L B P$ trabalha em uma vizinhança $3 \times 3$ de um pixel na imagem. Os pixels nesta vizinhança são limiarizados pelo valor do pixel central (threshold), multiplicado por potência de dois e então somados para obter o código do pixel central, denominado código $L B P$, como ilustra a Figura 4.5. 


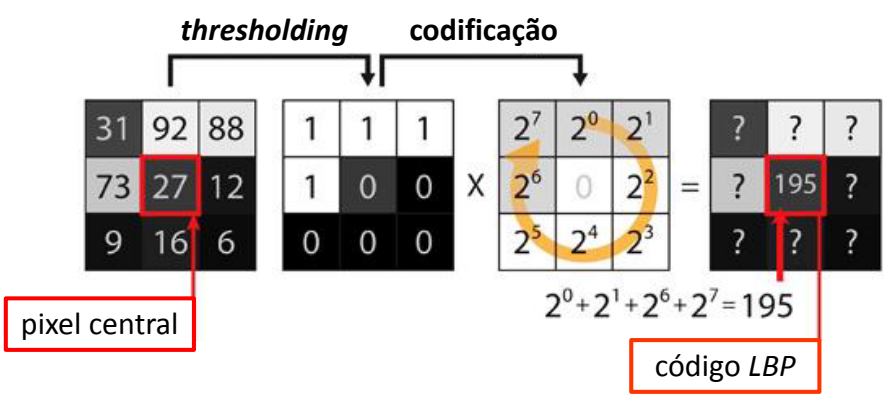

Figura 4.5. Procedimento do operador $L B P$

Como a vizinhança da janela 3x3 consiste em 8 pixels, um total de $\left(2^{8}\right) 256$ códigos diferentes podem ser obtidos pela combinação dos valores relativos do nível de cinza do pixel central e dos seus vizinhos. O operador LBP é definido por:

$$
L B P_{P, R}\left(x_{c}, y_{c}\right)=\sum_{p=0}^{P-1} s\left(g_{p}-g_{c}\right) \cdot 2^{p}, \quad s(x)=\left\{\begin{array}{lc}
1 & x \geq 0 \\
0 & x<0
\end{array}\right.
$$

Sendo: $P$ a quantidade de pixels da vizinhança, $R$ o raio da vizinhança, $g_{p}$ o valor de cinza (grayscale) do pixel na vizinhança e $g_{c}$ o valor da intensidade de cinza do pixel central. A configuração do $L B P$ original é com vizinhança $P=8$ e raio $R=1$. Como a janela do $L B P$ tem a forma circular, a posição do pixel na vizinhança $g_{p}$ pode ser calculada por:

$$
\begin{gathered}
g_{p}=I\left(x_{p}, y_{p}\right), \quad p=0, \ldots, P-1 \\
x_{p}=x+R \cdot \cos \left(\frac{2 \pi p}{P}\right) \\
y_{p}=y-R \cdot \operatorname{sen}\left(\frac{2 \pi p}{P}\right)
\end{gathered}
$$

A Figura 4.6 traz o exemplo de uma imagem, código $L B P$ dessa imagem e o histograma da distribuição dos códigos $L B P$.

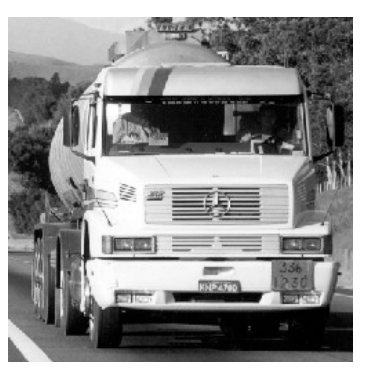

(a) Imagem

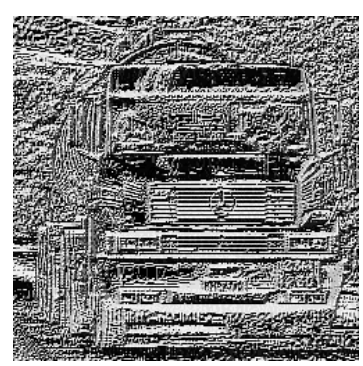

(b) Imagem $\angle B P$

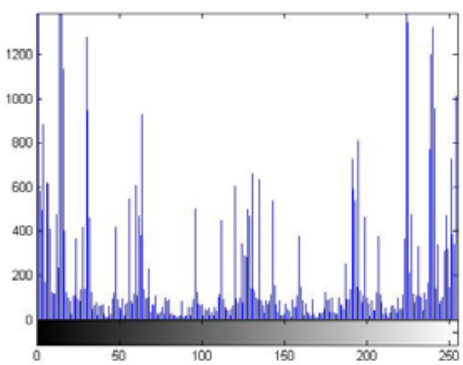

(c) Histograma $\angle B P$

Figura 4.6. Exemplo da aplicação de LBP

$\mathrm{Na}$ análise de similaridade entre duas imagens, uma técnica usada consiste em dividir 
as imagens em pequenos blocos $W x W$ e obter o histograma $L B P$ de cada parte. Em seguida, uma métrica de similaridade é usada com o propósito de identificar as partes com o mesmo padrão. Na literatura, as métricas mais usadas podem ser: distância Euclidiana, Qui-Quadrado, ou Interseção [PIETIKÄINEN et al., 2011]. A Figura 4.7 ilustra este conceito.

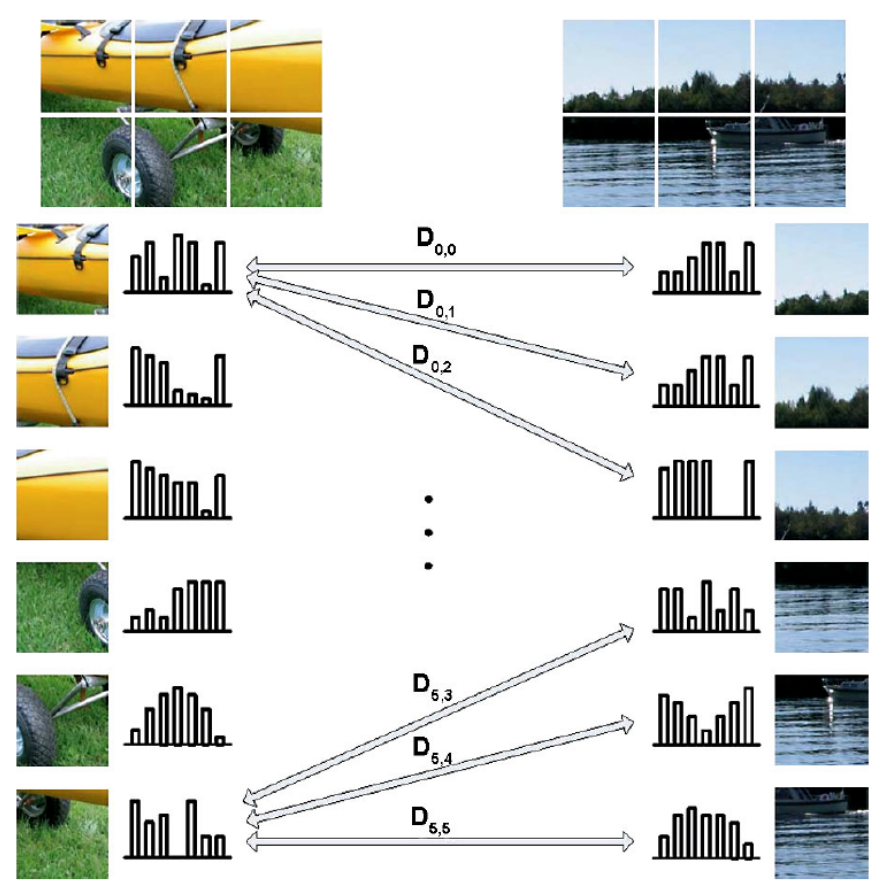

Figura 4.7. Exemplo de comparação entre imagens usando histogramas LBP [PIETIKÄINEN et al., 2011]

O LBP tem se desenvolvido rapidamente nos últimos anos, apresentando bons resultados em aplicações de reconhecimento de face [ANOHEN; HADDID; PIETIKÄINEN, 2006; HADDID; PIETIKÄINEN, 2008], detecção de movimento [ZHAO; PIETIKÄINEN, 2007], subtração de fundo [HEIKKILA; PIETIKÄINEN, 2006], dentre outras.

\subsubsection{LFP}

Local Fuzzy Pattern (LFP) é outro descritor de textura que surgiu no Laboratório de Visão Computacional (LAVI), Departamento de Engenharia Elétrica da Escola de Engenharia de São Carlos, USP. Inicialmente, Boaventura e Gonzaga [2007] identificaram um detector de bordas usando lógica fuzzy, denominado FUNED (Fuzzy Number Edge Detector). Após esse estudo, algumas reformulações matemáticas no modelo original apontaram para um potencial descritor de textura com uma característica muito particular, generalizar a maioria dos outros descritores. O LFP utiliza os conceitos de números fuzzy que procuram representar a incerteza da representação dos valores, muito comum na representação de imagens. 
As imagens digitais estão diretamente ligadas a certo grau de incerteza, desde a sua captura, no dispositivo de aquisição do sinal digital, até o mapeamento da imagem e a quantização dos pixels em $L$ níveis de cinza. Neste contexto, a lógica fuzzy se enquadra muito bem, pois permite que dados imperfeitos sejam adequadamente manipulados e quantificados [BOAVENTURA, 2010].

A teoria de conjuntos fuzzy foi introduzida por Zadeh [1965] com o objetivo de dar tratamento matemático a conceitos vagos e subjetivos existentes na comunicação humana, como os termos: "aproximadamente”, “em torno de”, e outros, os quais não podem ser tratados adequadamente com os conjuntos numéricos convencionais [BOAVENTURA, 2010]. Assim, a lógica fuzzy permite a definição de valores intermediários entre avaliações tradicionais, como verdadeiro/falso, sim/não, alto/baixo, entre outras. Estes valores intermediários podem ser matematicamente formulados e processados por computadores. A modelagem fuzzy considera o modo como a falta de exatidão e a incerteza são descritas e, fazendo isso, torna-se suficientemente adequada para manipular de maneira convincente o conhecimento [VIEIRA, 2013].

Na teoria clássica de conjuntos, é comum usar uma afirmação que um determinado elemento pertence ou não àquele conjunto. Já na teoria dos conjuntos fuzzy, a ideia da afirmação é tanto quanto flexível, pois indica que um determinado elemento pertence mais ao conjunto do que outros elementos pertencentes ao mesmo conjunto, ou seja, os elementos podem então pertencer parcialmente ao conjunto [VIEIRA, 2013]. Um conjunto fuzzy contém elementos que têm diferentes graus de pertinência ao conjunto.

Bezdek et al. [2005] relataram um exemplo que representa bem o conceito de pertinência: "Suponha que se tenha duas garrafas marcadas com A e B. No rótulo da garrafa A lê-se: 'a probabilidade desta garrafa ter líquido potável é 0,91 '. Na garrafa B, 'o grau de pertinência do conteúdo dessa garrafa em relação ao conjunto dos líquidos potáveis é 0,91'. Qual das duas garrafas seria própria para se beber? O valor da pertinência significa que o conteúdo de B tem um grau de 0,91 de similaridade com um líquido potável, o qual pode ser, por exemplo, vinho ou água. Já a probabilidade significa que, dentre um conjunto de garrafas observadas, 91 em 100 possuem líquido potável e as outras 9 em 100 podem conter veneno, por exemplo. Continuando a ideia da observação, suponha que ao abrir os conteúdos das garrafas A e B descobriu-se que eram ácido clorídrico e água, respectivamente. Após essa observação, o valor de pertinência B permanece o mesmo $(0,91)$, enquanto que a 
probabilidade da afirmação A cai a zero.”

A abordagem LFP considera que os níveis de cinza são números fuzzy e, para cada pixel $g(i, j)$ da imagem, calcula-se a sua pertinência em relação a determinada região, considerando os vizinhos que possuem níveis de cinza próximos de $g(i, j)$. Ao considerar os valores de cinza como números fuzzy, incorpora-se a variabilidade inerente dos valores de cinza de imagens, proporcionando assim uma abordagem mais poderosa ao tratamento de imagens digitais, em comparação ao tratamento clássico, baseado em formulação analítica [BOAVENTURA, 2010].

Desta forma, o LFP propõe que o grau de pertinência do pixel central $g(i, j)$ definido pela vizinhança $W x W$ seja determinado por:

$$
\hat{\mu}_{g(i, j)}=\frac{\sum_{k=0}^{W-1} \sum_{l=0}^{W-1}\left[f_{g(i, j)} \cdot P(k, l)\right]}{\sum_{k=0}^{W-1} \sum_{l=0}^{W-1} P(k, l)},
$$

Sendo $f_{g}$ a função objetivo aplicada na vizinhança e $P$ a matriz de pesos dos pixels vizinhos. Este grau de pertinência define o código LFP que reflete a estrutura do micropadrão dentro da vizinhança considerada A Figura 4.8 exemplifica a operação.

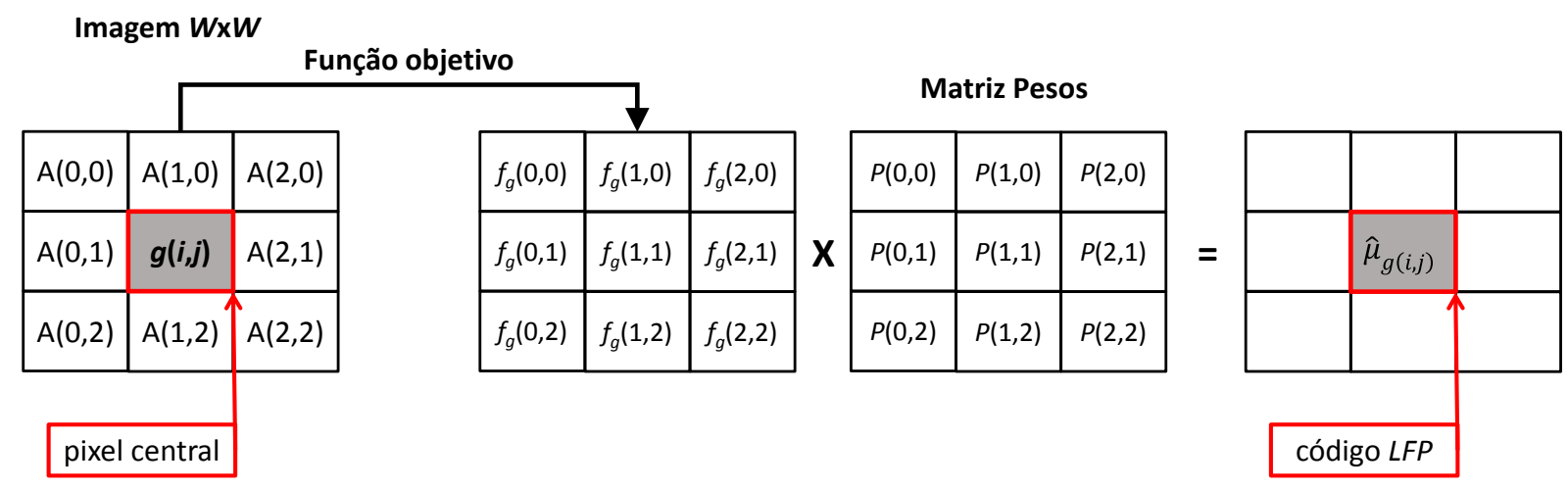

Figura 4.8. Procedimento do operador LFP

A definição de uma função objetivo é heurística e, portanto, não única [VIEIRA et al. 2012]; logo, depende apenas da aplicação em questão. Isso faz do LFP um descritor genérico, pois aceita qualquer função objetivo no seu procedimento. Além disso, o LFP pode ser considerado como uma generalização de outros descritores, como algumas derivações apresentadas a seguir. 
O Texture Unit, apresentado por He e Wang [1990], pode ser obtido aplicando-se a seguinte função objetivo e matriz peso:

$$
\begin{gathered}
f_{g(i, j)}=1+\operatorname{sgn}[A(k, l)-g(i, j)], \\
\operatorname{sgn}[A(k, l)-g(i, j)]=\left\{\begin{array}{ccc}
-1, & \text { se } & {[A(k, l)-g(i, j)]<0} \\
0 & \text { se } & {[A(k, l)-g(i, j)]=0,} \\
1 & \text { se } & {[A(k, l)-g(i, j)]>0}
\end{array}\right. \\
P=\left[\begin{array}{ccc}
1 & 3 & 9 \\
2187 & 0 & 27 \\
729 & 243 & 81
\end{array}\right]
\end{gathered}
$$

O LBP [OJALA; PIETIKÄINEN; HARWOOD, 1996] também pode ser obtido a partir da seguinte combinação:

$$
\begin{gathered}
f_{g(i, j)}=H[A(k, l)-g(i, j)], \\
H[A(k, l)-g(i, j)]=\left\{\begin{array}{lll}
0, & \text { se } & {[A(k, l)-g(i, j)]<0} \\
1, & \text { se } & {[A(k, l)-g(i, j)] \geq 0}
\end{array},\right. \\
P=\left[\begin{array}{ccc}
1 & 2 & 4 \\
128 & 0 & 8 \\
64 & 32 & 16
\end{array}\right]
\end{gathered}
$$

O detector de bordas FUNED, proposto por Boaventura [2010], pode ser renomeado para $L F P_{t}$ por utilizar uma função objetivo triangular e simétrica:

$$
f_{g(i, j)}=\operatorname{máx}\left(0 ; 1-\frac{|A(k, l)-g(i, j)|}{\delta}\right) \quad, \quad P=\left[\begin{array}{ccc}
1 & 1 & 1 \\
1 & 0 & 1 \\
1 & 1 & 1
\end{array}\right]
$$

Vieira [2013] apresentou mais duas funções objetivos para se usar com texturas. A primeira baseia-se em uma função sigmoide, denominada $L F P_{s}$, dada por:

$$
f_{g(i, j)}=\frac{1}{1+e^{\frac{-[A(k, l)-g(i, j)]}{\beta}}} \quad, \quad P=\left[\begin{array}{lll}
1 & 1 & 1 \\
1 & 1 & 1 \\
1 & 1 & 1
\end{array}\right]
$$

A segunda opção propõe o uso da função gaussiana, $L F P_{g}$, definida por:

$$
f_{g(i, j)}=e^{\frac{[A(k, l)-g(i, j)]^{2}}{\sigma}} \quad, \quad P=\left[\begin{array}{lll}
1 & 1 & 1 \\
1 & 1 & 1 \\
1 & 1 & 1
\end{array}\right]
$$

Embora a representação fuzzy adotada no descritor LFP seja um tanto compacta com 
relação à teoria dos números fuzzy, os resultados de reconhecimento de padrões de texturas têm se mostrado bastante eficientes [VIEIRA, 2013].

Um ponto a ser considerado com o uso da lógica fuzzy é o seu custo computacional, pois, ao contrário do $L B P$ que utiliza números binários, o LFP trabalha no conjunto dos números reais entre 0 e 1 , o que, em linguagem computacional, é mais dispendioso de se operar matematicamente. Porém, a biblioteca OpenCV dispõe de um operador de funções que pode otimizar este tempo, apresentado no Apêndice B.

\subsection{MÉTODO PROPOSTO}

O método proposto neste capítulo consiste em avaliar os modelos de segmentação de veículos em imagens de vídeo. Primeiramente, foi realizada uma busca na literatura pelos modelos de segmentação disponíveis, para então selecionar os modelos que seriam investigados. Vale ressaltar que na literatura esses modelos têm como propósito serem eficientes em diversos tipos de situações, sendo avaliados e calibrados em função de bases de imagens padrões usadas pela comunidade científica. No entanto, este trabalho foca apenas em imagens do tráfego veicular rodoviário. Assim, optou-se por escolher os modelos que tiveram os melhores resultados nessas mesmas condições.

Os códigos foram escritos em linguagem $\mathrm{C}++$ e compilados no software Microsoft Visual Studio 2012. Para auxiliar o processamento das imagens, foi utilizada a biblioteca de funções OpenCV versão 2.4.5. O computador usado foi um Core i7 3,4 GHz com 8 Gb de memória RAM.

\subsubsection{Coleta de dados}

Assim como no capítulo anterior, foram utilizados os vídeos obtidos em campo na SP-310, Rodovia Washington Luis, km 235, na entrada da cidade de São Carlos, SP. A corrente de tráfego na rodovia foi capturada por duas câmeras digitais, sendo posicionadas: uma frontal ao tráfego e outra em perspectiva, como ilustram as imagens da Figura 4.9. A resolução dos vídeos foi de 320x240 pixels e imagens coloridas foram usadas na modelagem do fundo (como descrito no Capítulo 3); para a segmentação foram utilizadas imagens em escala de cinza devido à restrição de alguns dos descritores de textura. 


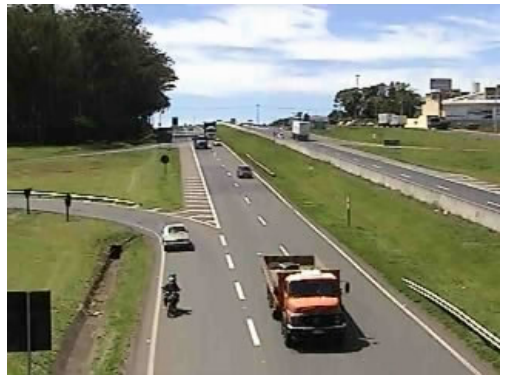

(a) Frontal - manhã

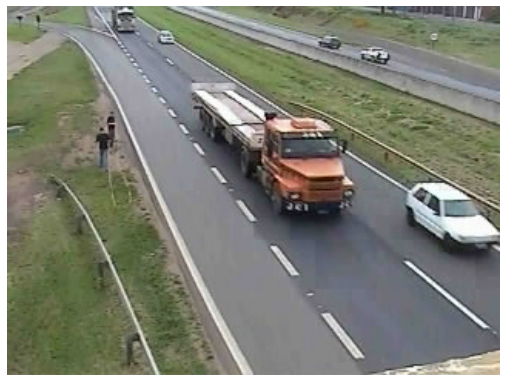

(d) Perspectiva - manhã

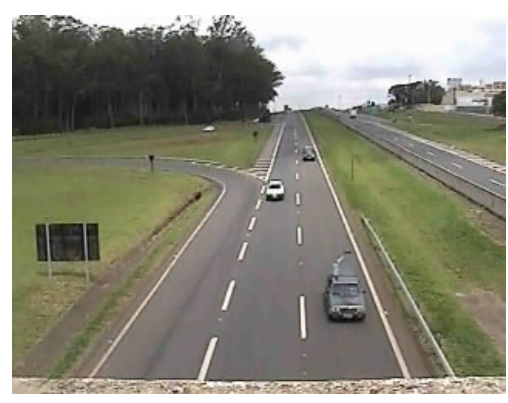

(b) Frontal - meio-dia

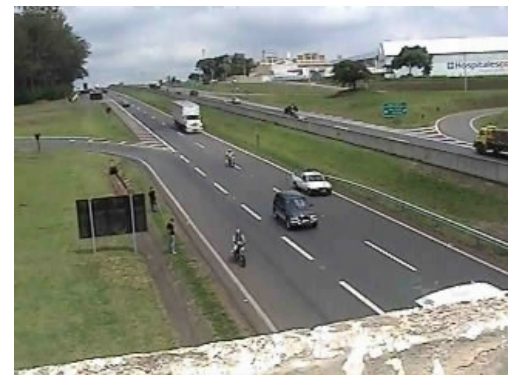

(e) Perspectiva - meio-dia

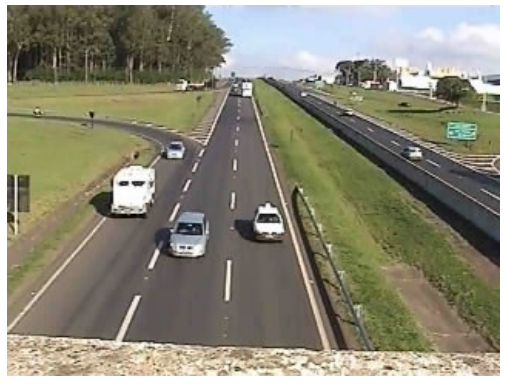

(c) Frontal - tarde

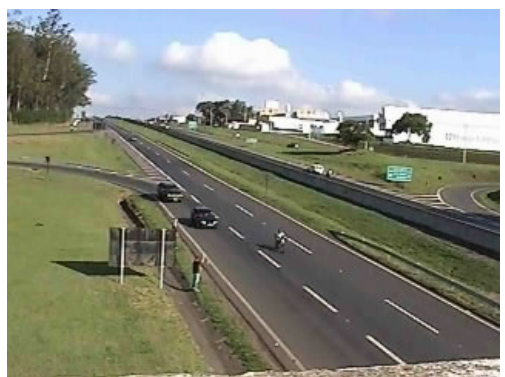

(f) Perspectiva - tarde

Figura 4.9. Vídeos coletados em campo e seus respectivos frames usados na comparação

As coletas foram realizadas em três períodos do dia: manhã (7h), meio-dia (12h) e tarde (17h), por um período de 1 hora, com o propósito de avaliar os algoritmos em diferentes condições de iluminação e sombra, fatores comumente observados em longos períodos de coletas de dados de tráfego.

\subsubsection{Ground truth}

O ground truth é uma imagem de referência que representa a segmentação ideal, em que os pixels em destaque representam os veículos corretamente segmentados. Para se determinar o ground truth, um frame foi aleatoriamente selecionado em cada um dos vídeos e os veículos contidos naquela imagem (Figura 4.9) foram segmentados manualmente. Desta forma, foi construído um conjunto de imagens ground truth para ser comparado com a resposta do processamento dos modelos de segmentação.

\subsubsection{Modelos de segmentação investigados}

Seis modelos foram escolhidos para a análise de segmentação. O primeiro usa o conceito básico e mais usual de subtração de fundo, enquanto os demais usam variações de padrões de texturas em imagens. Seguem os detalhes de cada método: 


\subsubsection{Subtração de Fundo}

Como já visto, a subtração de fundo (background subtraction) é o método mais usado em condições de ambiente externo, sem controle de iluminação. Vale lembrar também, que a subtração de fundo é altamente dependente do modelo de geração do background para uma melhor segmentação, como descrito no Capítulo 3. Os procedimentos aplicados neste método estão ilustrados na Figura 4.10.

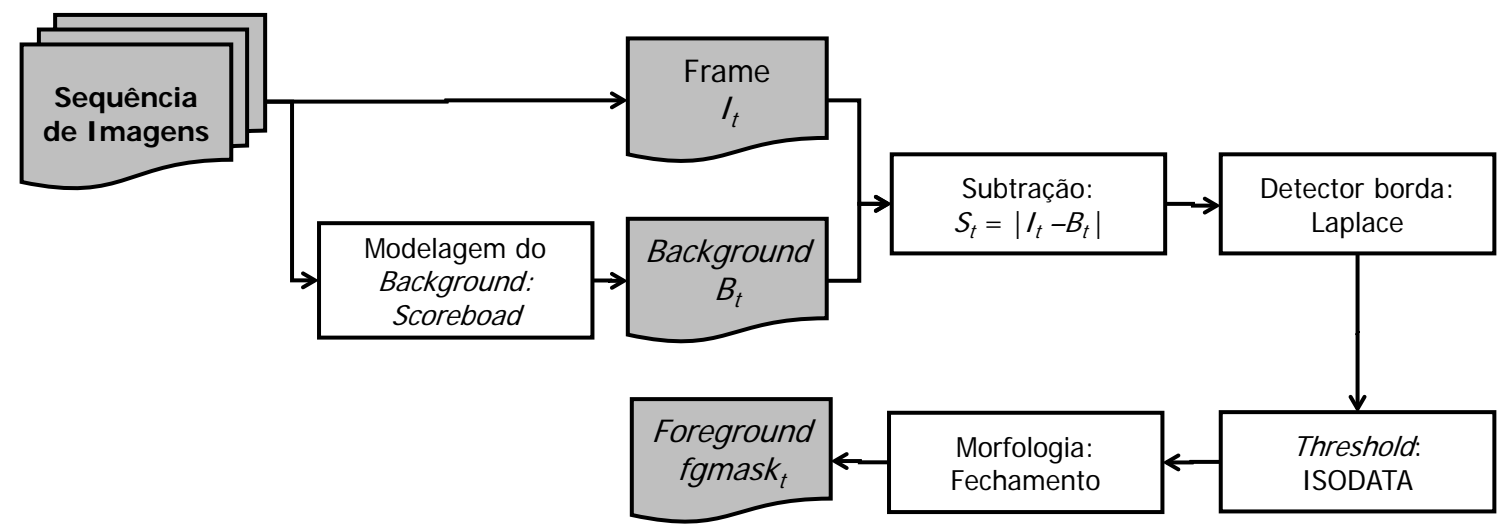

Figura 4.10. Processamento da subtração de fundo

- Subtração do frame $I_{t}$ pela imagem de background $B_{t}$ (obtido pelo Scoreboard);

- Aplicação de detector de borda Laplaciano [GONZALEZ; WOODS, 2007] com o propósito de se determinar os contornos dos objetos. Esta função já está codificada na biblioteca OpenCV pelo comando cv: :Laplacian(src,dst,ddepth,ksize), em que src e dst são as imagens de origem e destino, ddepth é um código que indica a quantização da imagem resultante e ksize é o tamanho da máscara;

- Em seguida, execução do algoritmo ISODATA, uma função threshold automática que determina o melhor valor limiar para separar apenas os objetos de interesse a cada instante $t$. Esta função é baseada em uma técnica iterativa de balanceamento de histogramas e foi codificada segundo descrito em Lam, Pang e Yung [2003];

- Por fim, aplicação da operação de fechamento, um operador da Morfologia Matemática [GONZALEZ; WOODS, 2007] capaz de preencher os vazios. Esta função é chamada no OpenCV por cv: :morphologyEx(src,dst,op,kernel), sendo src e dst as imagens de entrada e saída, op refere-se ao código da operação, para o fechamento usa-se MORPH_CLOSE e kernel é o formato do template que será usada na 
morfologia.

\subsubsection{Correlação}

Este método é derivado dos trabalhos de Lam, Pam e Yung [2003, 2004], os quais consideram que a distribuição espacial de uma textura pode ser descrita por coeficientes de correlação que avaliam a relação espacial linear entre as primitivas. Neste modelo, um único pixel é considerado uma textura primitiva, sendo a sua propriedade o nível de cinza. O descritor de textura de uma parte da imagem é calculado pela função autocorrelação:

$$
R_{(u, v)}=\frac{(2 M+1) \cdot(2 N+1)}{(2 M+1-u) \cdot(2 N+1-v)} \cdot \frac{\sum_{m=0}^{2 M-u} \sum_{n=0}^{2 N-v} p_{(m, n)} \cdot p_{(m+u, n+v)}}{\sum_{m=0}^{2 M} \sum_{n=0}^{2 N} p^{2}} \quad\left\{\begin{array}{l}
0 \leq u \leq 2 M \\
0 \leq v \leq 2 N
\end{array},\right.
$$

Sendo $u$ e $v$ as posições nas direções $m$ e $n$ e $2 M+1$ e $2 N+1$ são as dimensões da janela da imagem. Os autores Lam, Pam e Yung [2003, 2004] consideram que, como essas janelas são periódicas no domínio espacial, a função autocorrelação pode ser determinada no domínio de frequência pela potência do espectro da imagem, sendo $\mathcal{F}^{-1}$ a transformada inversa de Fourier:

$$
R=\mathcal{F}^{-1}\left\{|F|^{2}\right\}
$$

Para as imagens do frame e do background, cada pixel e seus respectivos vizinhos em uma janela de tamanho $N=15$ são extraídos em uma pequena imagem $p_{i}$ e $p_{b}$. Nestas imagens são aplicadas a função de autocorrelação, resultando nas imagens $R_{i}$ e $R_{b}$. O mapa de diferença de textura é então calculado pelo quadrado da diferença média de cada imagem $p_{i} \mathrm{e}$ $p_{b}$, na mesma localização $(x, y)$ no frame e no background:

$$
d_{T}=\frac{1}{(2 M+1) \cdot(2 N+1)} \cdot \sum_{u=0}^{2 M} \sum_{v=0}^{2 N}\left[R_{i(u, v)}-R_{b(u, v)}\right]^{2},
$$

A Figura 4.11 representa a aplicação deste método. Após a determinação da imagem diferença de texturas $d_{T}$, foi aplicada a função threshold ISODATA para segregar os veículos da imagem resultante. 


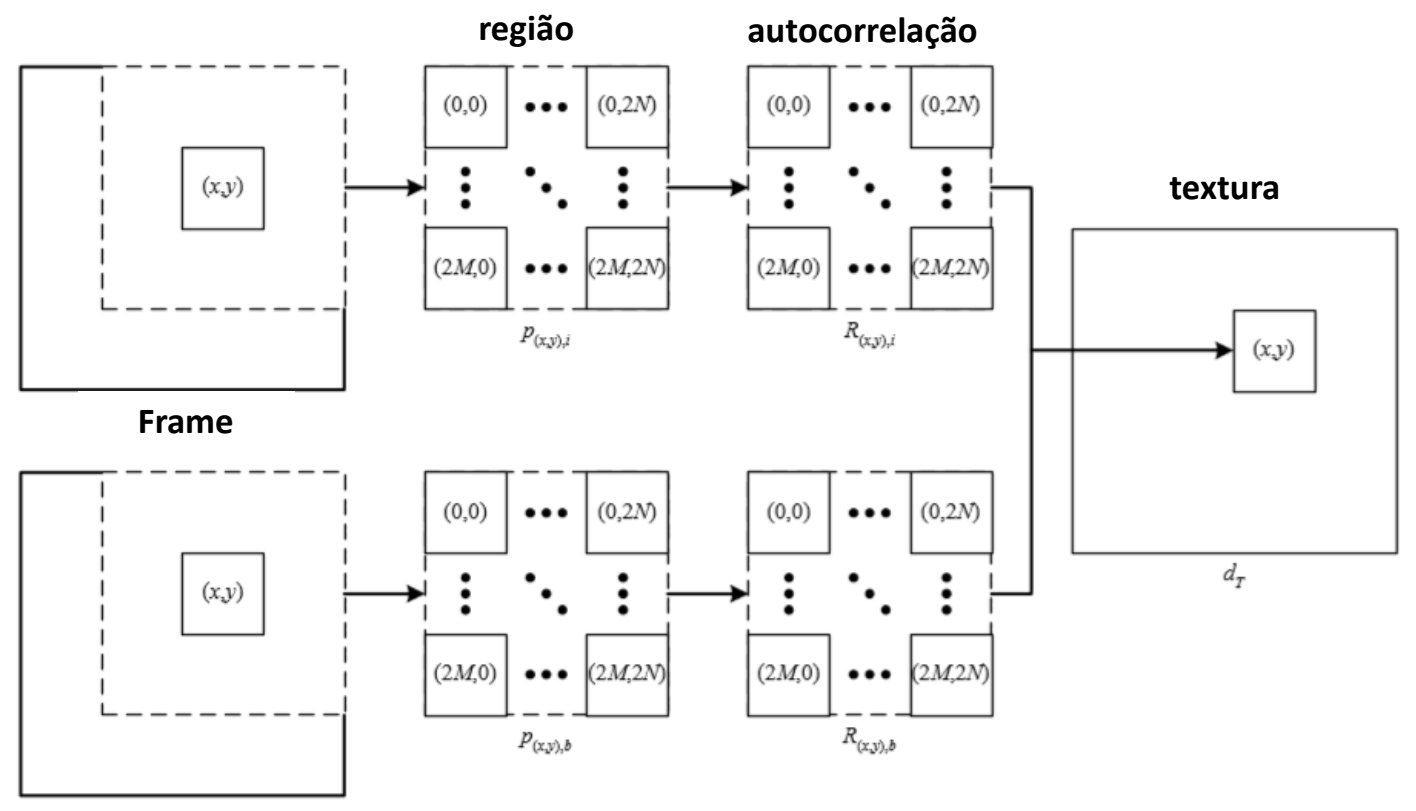

Background

Figura 4.11. Aplicação do método de correlação

\subsubsection{LBP}

Este método também é baseado em textura e detecta objetos em movimento através da microtextura LBP (Local Binary Pattern). O LBP é calculado pela seguinte equação:

$$
L B P=\sum_{p=0}^{P-1} s\left(g_{p}-g_{c}\right) \cdot 2^{p}, \quad s(x)= \begin{cases}1 & x \geq 0 \\ 0 & x<0\end{cases}
$$

Este método de detecção usando $L B P$ foi codificado segundo o trabalho de Heikkilä e Pietikäinen [2006]. Os autores usaram um histórico de histogramas LBP de uma região em volta de cada pixel para definir se o pixel é objeto ou fundo. Para isso, os autores descrevem o método computando o histograma $L B P$ em uma região circular de raio $R_{\text {region, }}$, definido com valor 9 [HEIKKILÄ; PIETIKÄINEN, 2006]. Cada pixel tem um vetor com $k$ grupos de histogramas adaptativos $\left\{m_{0}, m_{1}, \ldots, m_{k-1}\right\}$. Cada modelo de histograma tem um peso $w_{k}$ entre 0 e 1 , sendo que a soma de todos os $k$ pesos deve ser 1 .

A cada novo frame, o histograma de um pixel é comparado com este vetor de histogramas. A medida de proximidade usada foi a interseção de histogramas, definida por:

$$
\cap(\vec{a}, \vec{b})=\sum_{n=0}^{N-1} \min \left(a_{n}, b_{n}\right)
$$


Em que $\vec{a}$ e $\vec{b}$ são os histogramas e $N$ é o número de unidades do histograma, conhecidos como bins. Em linhas gerais, a atualização do método ocorre em dois casos:

- Caso a medida de proximidade seja inferior ao valor limiar $T_{P}(0,3)$ para todos os histogramas, então o histograma com menor peso é removido pelo novo histograma. Para este novo histograma é atribuído o valor peso inicial de 0,01. Este pixel é marcado como objeto;

- Caso a proximidade seja maior, o pixel representa o background, o peso $w_{k}$ com a maior proximidade é atualizados pela Equação 4.21 e, consequentemente, os demais pesos $w_{k}$ são atualizados pela Equação 4.22:

$$
\begin{array}{cc}
\vec{m}_{k}=\alpha_{b} \cdot \vec{h}+\left(1-\alpha_{b}\right) \cdot \vec{m}_{k}, & \alpha_{b} \in[0,1] \\
w_{k}=\alpha_{w} \cdot M_{k}+\left(1-\alpha_{w}\right) \cdot w_{k}, & \alpha_{w} \in[0,1]
\end{array}
$$

\subsubsection{LFP}

O LFP (Local Fuzzy Pattern) é outro descritor de textura que generaliza outros descritores apenas alterando a sua função objetivo. A fórmula geral $L F P$ calcula o valor de pertinência da textura em uma janela da imagem, geralmente $3 \times 3$ :

$$
\hat{\mu}_{g(i, j)}=\frac{\sum_{k=0}^{W-1} \sum_{l=0}^{W-1}\left[f_{g(i, j)} \cdot P(k, l)\right]}{\sum_{k=0}^{W-1} \sum_{l=0}^{W-1} P(k, l)},
$$

As variações do descritor de texturas LFP estão diretamente relacionadas com as funções objetivo utilizadas. Desta forma, optou-se usar as funções apresentadas por Vieira [2013]. O método de segmentação do LFP segue o mesmo procedimento usado no $L B P$, diferindo apenas no descritor usado.

A primeira função objetivo investigada foi a função triangular, denominada $L F P t$, definida pela seguinte função:

$$
f_{g(i, j)}=\operatorname{máx}\left(0 ; 1-\frac{|g(i, j)-A(k, l)|}{\delta}\right),
$$

Outra variação do LFP utiliza uma sigmoide como função objetivo: 


$$
f_{g(i, j)}=\frac{1}{1+e^{\frac{-[A(k, l)-g(i, j)]}{\beta}}},
$$

Por fim, outra variação do $L F P$, foi usando a função objetivo de uma gaussiana:

$$
f_{g(i, j)}=e^{\frac{-[A(k, l)-g(i, j)]^{2}}{\sigma}},
$$

O método $L F P$ foi definido para ser aplicado em uma janela $3 \times 3$, assim como no $L B P$, e os parâmetros $\delta$, $\beta$ e $\sigma$ das funções objetivos foram definidos com o valor 1,0. Vale ressaltar que esses parâmetros podem ser calibrados para melhorar a detecção.

Como o LFP está em desenvolvimento e as suas aplicações publicadas focaram no reconhecimento de padrões de texturas em imagens [BOAVENTURA, 2010; VIEIRA et al. 2012], esta tese de doutorado contribui com as pesquisas do LAVI, investigando a aplicação do LFP no âmbito de detecção e segmentação em vídeos.

\subsubsection{Análise do desempenho dos modelos}

O desempenho dos modelos investigados foi aferido pela sua representatividade em identificar os objetos na imagem. Para isso, após a geração da imagem de background de cada modelo, foi realizada uma subtração do frame atual com o background modelado. Esta imagem de diferença, denominada de fgmask (máscara de foreground) representa os objetos encontrados pelo sistema de detecção. Este método de análise é o mais usual para se comparar segmentações na literatura especializada.

A partir das imagens de fgmask, o desempenho dos modelos foi avaliado por dois quesitos: tempo de processamento e taxa de acerto. O tempo de processamento foi determinado durante a execução de cada modelo; a cada frame, uma função contabilizava o tempo gasto para se processar cada novo frame. A taxa de acerto foi calculada segundo as medidas de desempenho apresentadas na Tabela 4.1, obtidas ao comparar a imagem ground truth e a fgmask. 
Tabela 4.1. Tabela de contingência e cálculo das métricas comuns de desempenho

\begin{tabular}{l|l|l|l}
\hline \multirow{2}{*}{$\begin{array}{l}\text { Referência } \\
\text { (ground truth) }\end{array}$} & \multicolumn{2}{|l|}{ Resultado (fgmask) } & \multirow{2}{*}{ Total } \\
\cline { 2 - 3 } & Positivo (foreground) & Negativo (background) & \\
\hline Positivo (foreground) & Verdadeiro Positivo (VP) & Falso Negativo (FN) & Positivos (P) \\
\hline Negativo (background) & Falso Positivo (FP) & Verdadeiro Negativo (VN) & Negativos $(N)$ \\
\hline Taxa de Verdadeiro Positivo $=\frac{V P}{P}$ & Precisão $=\frac{V P}{V P+F P}$ & \\
Taxa de Falso Positivo $=\frac{F P}{N}$ & Exatidão $=\frac{V P+V N}{P+N}$ & \\
\hline
\end{tabular}

A Tabela 4.1 apresenta a tabela de contingência e suas métricas de desempenho [Metz, 1978; Fawcett, 2005], comumente usada na literatura para verificar a detecção de objetos em imagens. Para se obter esses parâmetros é necessário comparar as duas imagens e contar a quantidade de pixels de acordo com as seguintes definições:

- VP (verdadeiro positivo): objetos do ground truth que foram corretamente classificados no fgmask como objetos;

- VN (verdadeiro negativo): background do ground truth corretamente classificado no fgmask como background;

- $\quad$ FP (falso positivo): pixels de objetos no fgmask classificados erroneamente, pois representam background no ground truth;

- $\quad F N$ (falso negativo): pixels de background no fgmask classificados de forma errada, pois são objetos no ground truth;

\subsection{RESULTADOS OBTIDOS}

A Tabela 4.2 traz as imagens dos frames selecionados em cada vídeo, dos ground truth obtidos manualmente e dos resultados das imagens (fgmask) após cada método de segmentação. Os pixels em branco representam os objetos identificados em cada método.

As imagens da Tabela 4.2 evidenciam a presença de vários pixels como falso positivo, ou seja, pixels do background classificados como objeto. Da mesma forma, outra parcela dos pixels são falso negativo, objetos que foram classificados como background resultando objetos incompletos com vazios no seu interior.

Visualmente, a Tabela 4.2 apresenta a Subtração com as melhores identificações dos 
veículos, porém alguns veículos com vazios. O modelo da Correlação apresentou razoável identificação em apenas dois vídeos. Os modelos que usam textura ( $L B P$ e $L F P$ ) identificaram a forma dos veículos, porém vários pixels do fundo foram identificados como objetos.

Tabela 4.2. Resultados das imagens após a segmentação

\begin{tabular}{|c|c|c|c|c|c|c|}
\hline & \multicolumn{6}{|c|}{ Vídeos coletados } \\
\hline & $\begin{array}{l}\text { Frontal } \\
\text { manhã }\end{array}$ & $\begin{array}{l}\text { Frontal } \\
\text { meio-dia }\end{array}$ & $\begin{array}{l}\text { Frontal } \\
\text { tarde }\end{array}$ & $\begin{array}{l}\text { Perspectiva } \\
\text { manhã }\end{array}$ & $\begin{array}{l}\text { Perspectiva } \\
\text { meio-dia }\end{array}$ & $\begin{array}{l}\text { Perspectiva } \\
\text { tarde }\end{array}$ \\
\hline \multicolumn{7}{|c|}{ Frame } \\
\hline \multicolumn{7}{|c|}{ Ground Truth } \\
\hline \multicolumn{7}{|c|}{ Subtração } \\
\hline \multicolumn{7}{|c|}{ Correlação } \\
\hline \multicolumn{7}{|l|}{ LBP } \\
\hline \multicolumn{7}{|l|}{$L F P_{t}$} \\
\hline \multicolumn{7}{|l|}{$L F P_{s}$} \\
\hline$L F P_{g}$ & & & & & & 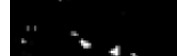 \\
\hline
\end{tabular}

\subsubsection{Tempo de processamento}

A Tabela 4.3 resume o tempo médio em segundos para se processar um frame em cada método investigado. Como parâmetro de referência, os vídeos geralmente são capturados a uma taxa de $30 \mathrm{fps}$ (frames por segundo), ou 0,0333 s/frame. 
Tabela 4.3. Resultados dos tempos médios da segmentação em s/frame

\begin{tabular}{lllllll}
\hline \multirow{2}{*}{ Vídeo } & \multicolumn{7}{l}{ Métodos avaliados } \\
\cline { 2 - 7 } & Subtração & Correlação & LBP & $L F P_{t}$ & $L F P_{s}$ & $L F P_{g}$ \\
\hline Frontal - manhã & 0,0334 & 17,1210 & 1,1522 & 1,4686 & 1,1563 & 1,1671 \\
Frontal - meio-dia & 0,0339 & 17,4280 & 1,1620 & 1,2043 & 1,4390 & 1,1680 \\
Frontal - tarde & 0,0347 & 16,9300 & 1,1598 & 1,2031 & 0,1124 & 0,1135 \\
Perspectiva - manhã & 0,0353 & 17,0240 & 1,1535 & 0,1430 & 0,1027 & 1,1636 \\
Perspectiva - meio-dia & 0,0343 & 16,9520 & 1,1577 & 1,2007 & 1,1573 & 1,1662 \\
Perspectiva - tarde & 0,0348 & 17,0800 & 1,1553 & 1,2064 & 1,4341 & 0,1110 \\
\hline Tempo médio & $\mathbf{0 , 0 3 4 4}$ & $\mathbf{1 7 , 0 8 9 2}$ & $\mathbf{1 , 1 5 6 8}$ & $\mathbf{1 , 0 7 1 0}$ & $\mathbf{0 , 9 0 0 3}$ & $\mathbf{0 , 8 1 4 9}$ \\
(s/frame) & & & & & & \\
\hline
\end{tabular}

De fato, o método da Subtração de Fundo corroborou os relatos da literatura, sendo o método mais rápido de processamento com 34,4 ms/frame (milissegundos), inclusive sendo o único com tempo próximo ao parâmetro de referência 33,3 ms/frame (30fps). Os demais métodos apresentaram tempos próximos a $1 \mathrm{~s} /$ frame, sendo o segundo melhor método o $L F P_{g}$ com 814,9 ms/frame seguido pelo $L F P_{s}$ com 900,3 ms/frames. Vale destacar que a Subtração de Fundo realiza simples operações pixel-a-pixel e o $L B P$ e o $L F P$ foram codificados de forma otimizada, relatada em detalhes no Apêndice B. Por outro lado, o método mais lento foi a Correlação (17 s/frame), por envolver muitas operações matemáticas, embora tenha sido codificado usando as funções otimizadas do OpenCV.

\subsubsection{Taxa de exatidão}

A taxa de exatidão (accuracy) dos modelos expressa a razão dos pixels corretamente identificados $(\mathrm{VP}+\mathrm{VN})$ pelo total de pixels do ground truth $(\mathrm{P}+\mathrm{N})$. Este parâmetro fornece um valor de taxa de acerto total, ou seja, o quanto o modelo consegue classificar objetos e background comparando-se com o ground truth. A Tabela 4.4 apresenta os valores calculados em cada método.

Tabela 4.4. Resultados da taxa de exatidão

\begin{tabular}{lllllll}
\hline \multirow{2}{*}{ Vídeo } & \multicolumn{7}{l}{ Métodos avaliados } \\
\cline { 2 - 7 } & Subtração & Correlação & LBP & $L F P_{t}$ & $L F P_{s}$ & $L F P_{g}$ \\
\hline Frontal - manhã & $95,3 \%$ & $96,0 \%$ & $92,7 \%$ & $74,0 \%$ & $72,8 \%$ & $87,3 \%$ \\
Frontal - meio-dia & $98,0 \%$ & $96,6 \%$ & $91,2 \%$ & $74,9 \%$ & $68,8 \%$ & $85,0 \%$ \\
Frontal - tarde & $94,8 \%$ & $94,1 \%$ & $91,4 \%$ & $73,8 \%$ & $70,2 \%$ & $89,0 \%$ \\
Perspectiva - manhã & $92,7 \%$ & $88,1 \%$ & $83,1 \%$ & $74,4 \%$ & $64,0 \%$ & $80,8 \%$ \\
Perspectiva - meio-dia & $92,5 \%$ & $94,2 \%$ & $91,4 \%$ & $68,8 \%$ & $66,1 \%$ & $87,0 \%$ \\
Perspectiva - tarde & $97,4 \%$ & $88,0 \%$ & $90,1 \%$ & $69,1 \%$ & $67,6 \%$ & $82,7 \%$ \\
\hline Exatidão média & $\mathbf{9 5 , 1 \%}$ & $\mathbf{9 2 , 8 \%}$ & $\mathbf{9 0 , 0} \%$ & $\mathbf{7 2 , 5 \%}$ & $\mathbf{6 8 , 3} \%$ & $\mathbf{8 5 , 3 \%}$ \\
\hline
\end{tabular}

A Subtração foi o modelo com a maior média de acertos totais (95,1\%), seguido pela Correlação (92,8\%) e pelo LBP (90,0\%). A pior média de acertos totais foi do $L F P_{s}(68,3 \%)$, lembrando que os parâmetros usados nas funções objetivo podem ser calibrados, através do 
treinamento do método. A Subtração apresentou taxas superiores a 92\% em todos os vídeos. Outro fato de destaque é que o vídeo “Perspectiva - manhã” teve os piores índices de exatidão na maioria dos métodos, isso pode ser explicado pelas variações de iluminação do sol durante todo o vídeo.

\subsubsection{Taxa de VP}

A taxa de verdadeiros positivos representa a porcentagem dos objetos corretamente identificados pelo modelo em relação ao total de objetos do ground truth. Este parâmetro reflete apenas a taxa de acertos dos objetos, retratado na Tabela 4.5.

Tabela 4.5. Resultados da taxa de verdadeiro positivo (VP)

\begin{tabular}{lllllll}
\hline \multirow{2}{*}{ Vídeo } & \multicolumn{7}{l}{ Métodos avaliados } \\
\cline { 2 - 7 } & Subtração & Correlação & LBP & $L F P_{t}$ & $L F P_{s}$ & $L F P_{g}$ \\
\hline Frontal - manhã & $82,1 \%$ & $47,3 \%$ & $61,3 \%$ & $86,7 \%$ & $69,2 \%$ & $69,2 \%$ \\
Frontal - meio-dia & $56,4 \%$ & $38,5 \%$ & $52,7 \%$ & $77,7 \%$ & $65,7 \%$ & $61,1 \%$ \\
Frontal - tarde & $72,4 \%$ & $8,1 \%$ & $41,8 \%$ & $75,1 \%$ & $54,9 \%$ & $47,6 \%$ \\
Perspectiva - manhã & $67,0 \%$ & $6,7 \%$ & $49,5 \%$ & $82,0 \%$ & $59,7 \%$ & $53,9 \%$ \\
Perspectiva - meio-dia & $64,6 \%$ & $0,0 \%$ & $35,1 \%$ & $67,8 \%$ & $58,4 \%$ & $34,0 \%$ \\
Perspectiva - tarde & $61,4 \%$ & $\mathbf{2 , 7 \%}$ & $\mathbf{2 6 , 4 \%}$ & $65,1 \%$ & $57,2 \%$ & $26,2 \%$ \\
\hline Taxa VP média & $\mathbf{6 7 , 3 \%}$ & $\mathbf{1 7 , 2 \%}$ & $\mathbf{4 4 , 5 \%}$ & $\mathbf{7 5 , 7 \%}$ & $\mathbf{6 0 , 9 \%}$ & $\mathbf{4 8 , 7 \%}$ \\
\hline
\end{tabular}

Como foi verificado na Tabela 4.2, nenhum dos métodos mostrou os objetos muito bem definidos, por isso os resultados da Tabela 4.5 mostram valores inferiores a $76 \%$. O melhor método de detecção dos objetos foi o $L F P_{t}$ (75,7\%), seguido pela Subtração (67,3\%) e $\operatorname{LFP}_{s}(60,9 \%)$. A correlação foi o pior método com 17,2\% de taxa VP, apresentando quatro dos seis vídeos com taxas inferiores a 9\%.

\subsection{CONSIDERAÇÕES FINAIS}

Esta etapa investigou a segmentação obtida ao utilizar três métodos de segmentação: subtração de fundo, correlação e segmentação baseada em textura. O primeiro método consiste na técnica mais consagrada na literatura. O segundo método é derivado dos trabalhos de Lam, Pang e Yung [2003; 2004], os quais despertaram especial interesse nesta pesquisa devido à boa segmentação descrita naqueles trabalhos. O terceiro método é derivado de Heikkilä e Pietikäinnen [2006], que propõe um método de modelagem e detecção de movimento baseado em textura. Este último método foi investigado com quatro descritores diferentes: $L B P, L F P_{t}, L F P_{s}, L F P_{g}$. Esses métodos foram testados nos vídeos obtidos em períodos diferentes do dia: manhã, meio-dia e tarde. 
Dentre os modelos investigados, conclui-se que o Background Subtraction foi o mais adequado para segmentação dos veículos nas imagens do tráfego. A subtração de fundo apresentou a melhor média do tempo de processamento (34,4 ms/frame), corroborando com os resultados apresentados na literatura, e obteve a melhor taxa de acertos totais (exatidão) com 95,1\% de média, variando de 92,5\% a 98,0\% nos seis vídeos testados. Quanto à taxa de VP (verdadeiro positivo) o modelo obteve 67,3\% de taxa de acerto considerando apenas os veículos, o segundo melhor índice dentre os modelos analisados. Assim, propõe-se que para o desenvolvimento do sistema, a subtração de fundo seja adotada para realizar a segmentação. 


\section{Sistema Automático de Coleta de Dados de Tráfego}

Este capítulo descreve o desenvolvimento do sistema automático de coleta de dados de tráfego, meta desta pesquisa de doutorado. A partir da definição do método de detecção de veículos em vídeos, é apresentada uma ferramenta de auxílio ao monitoramento de tráfego veicular, a obtenção do diagrama espaço-tempo, de onde é possível extrair os parâmetros da corrente de tráfego. Também é apresentada uma ferramenta para se extrair o comprimento dos veículos de forma iterativa.

\subsection{CONSIDERAÇÕES INICIAIS}

O estudo de tráfego é etapa fundamental em transportes, pois os dados das observações em campo fornecem a base para as tomadas de decisões em relação à infraestrutura e à operação dos sistemas de transportes. Além disso, a fidelidade dos dados está diretamente relacionada às prioridades de financiamento, elaboração de projetos de melhorias de transportes e gerenciamento do tráfego.

Em geral, os dados em campo são obtidos de acordo com o seu nível de representação: microscópico ou macroscópico. No nível microscópico, cada veículo é considerado único na corrente de tráfego, o que permite descrever o modo como os diferentes tipos de veículos se distribuem ao longo do tempo e espaço. Headway, espaçamento, tempo de viagem e movimentos de conversão são alguns dos parâmetros microscópicos. Por outro lado, o nível macroscópico tem interesse no movimento de grupos de veículos que constituem a corrente, permitindo a avaliação da fluidez do movimento geral dos veículos. Os parâmetros macroscópicos a citar são: a taxa de fluxo, a velocidade média e a densidade da corrente de tráfego.

As coletas de dados em campo concentram-se basicamente em obter parâmetros macroscópicos para descrever o comportamento do fluxo de tráfego por modelos matemáticos. Os modelos mais simples são os modelos macroscópicos que pressupõem a corrente de tráfego formada por veículos e condutores com características semelhantes. O modelo proposto por Greenshields et al. [1935] descreve a relação linear entre a densidade e a 
velocidade do fluxo de tráfego e, embora seja um modelo simplificado, é o conceito tradicionalmente aceito em Engenharia de Tráfego. Entretanto, Chandler, Herman e Montroll [1958] apontaram para a necessidade de dados individuais do comportamento dos motoristas para a melhor compreensão do tráfego, ao realizarem experimentos com veículos em uma pista de testes.

Com as modernas tecnologias disponíveis para coletas de dados, é possível melhorar o conhecimento do tráfego em um nível mais detalhado. Ao observar o comportamento dos motoristas na via, pode-se ajudar a melhorar o fluxo de tráfego e então reduzir atrasos no sistema de transportes. Dentre essas tecnologias, o rastreamento de veículos em imagens pode ser feito em determinado comprimento da rodovia, ao invés de um simples ponto, assim é possível, por exemplo, estimar a densidade real do trecho ao invés de simplesmente detectar a ocupação no sensor [KNOOP; HOOGENDOORN; VAN ZUYLEN, 2009].

Coifman et al. [1998] destacam que ao obter a trajetória espaço-tempo dos veículos, os parâmetros de tráfego são mais estáveis de se derivar do que as mesmas medidas obtidas em um sensor, que pode medir apenas no tempo. As trajetórias dos veículos produzem dados individuais, tais como espaçamento, headway, velocidade, aceleração e até mudanças de faixas, o que pode conduzir a um melhor modelamento da corrente de tráfego e um aumento da interpretação do comportamento dos motoristas [COIFMAN et al., 1998]. Além disso, ao agregar os dados microscópicos é possível obter os parâmetros macroscópicos; no processo inverso, é possível estimar parâmetros microscópicos médios a partir de dados macroscópicos.

Em trabalhos de visão computacional relacionados ao monitoramento do tráfego, poucos investigaram a real necessidade de dados microscópicos, como o diagrama espaçotempo [COIFMAN et al, 1998; KNOOP; HOOGENDOORN; VAN ZUYLEN, 2009; XU; SUN, 2013]. Visto isso, são apresentados os conceitos básicos de transformação perspectiva e parâmetros fundamentais do tráfego, essenciais ao entendimento deste capítulo.

\subsubsection{Transformação perspectiva}

A calibração da câmera é um passo essencial em sistemas de rastreamento de veículos em imagens. O objetivo da calibração da câmera envolve determinar um conjunto de parâmetros que descrevem o mapeamento dos pontos 3D do mundo real dentro de um plano 
2D na imagem [HEIKKILÄ; SÍLVEN, 1997]. Uma câmera calibrada permite relacionar medidas dos pixels com as medidas em unidades do mundo real (metros, por exemplo) o que é útil para tratar mudanças de escala (quando um veículo se aproxima ou afasta da câmera) e estimar a velocidade [BRADSKI; KAEHLER, 2008; KANHERE, 2008].

Em muitas aplicações de visão computacional, o desempenho do sistema é altamente dependente da precisão da calibração da câmera. Tal fato explica a variedade de métodos para calibração da câmera encontrados na literatura. O processo de calibração envolve o ajuste do modelo da geometria da câmera e do modelo da distorção da lente [BRADSKI; KAEHLER, 2008]. De maneira geral, na calibração são determinadas as características ópticas da câmera (parâmetros intrínsecos) e a referência do plano da imagem da câmera - posicionamento e orientação - em relação a um sistema de coordenadas (parâmetros extrínsecos) [TSAI, 1987].

Felizmente, no monitoramento do tráfego veicular, é possível simplificar a calibração pelo fato dos veículos se movimentarem no plano da superfície do pavimento, reduzindo o grau de liberdade da matriz tridimensional [WORRALL; SULLIVAN; BAKER, 1994]. Essa consideração simplifica a calibração, pois requer apenas a relação entre os pontos do mundo real e da imagem. [HEIKKILÄ; SÍLVEN, 1997].

A transformação perspectiva (ou transformação projetiva) projeta pontos tridimensionais sobre um plano e vice-versa [GONZALEZ; WOODS, 2007]. Essa transformação mapeia os pontos $P_{i}$ do mundo real, com coordenadas $\left(X_{i}, Y_{i}, Z_{i}\right)$, para os pontos $p_{i}$ projetados na imagem com coordenadas $\left(x_{i}, y_{i}\right)$, como mostra a Figura 5.1.

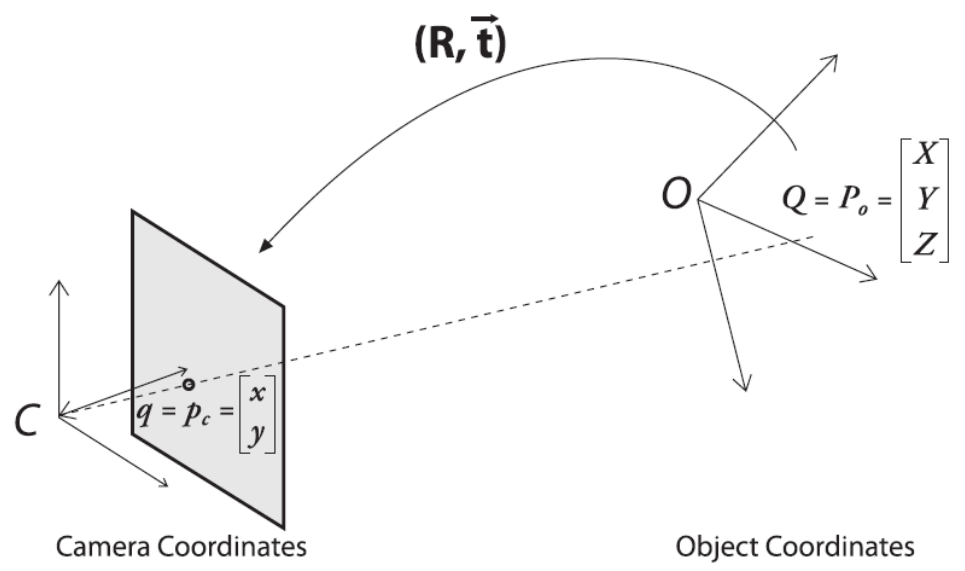

Figura 5.1. Conversão do objeto para o sistema de coordenadas da câmera [BRADSKI; KAEHLER, 2008]

A projeção dos pontos do mundo real no sistema de coordenadas da câmera é dada pela seguinte formulação: 


$$
p=H \cdot P \quad,\left[\begin{array}{l}
x \\
y \\
z
\end{array}\right]=\left[\begin{array}{lll}
h_{11} & h_{12} & h_{13} \\
h_{21} & h_{22} & h_{23} \\
h_{31} & h_{32} & h_{33}
\end{array}\right] \cdot\left[\begin{array}{l}
X \\
Y \\
Z
\end{array}\right]
$$

Como o plano da pista é considerado como $Z=0$, então tem-se que $h_{33}=1$, o que resulta em oito parâmetros desconhecidos na matriz $H$ da transformada. Cada ponto $P$ da calibração leva a duas equações; logo são necessário quatro ponto não-colineares para se encontrar a solução do sistema linear. Obtida a matriz $H$, o mapeamento entre as coordenadas da imagem $(p)$ e as coordenadas dos pontos no plano da pista $(P)$ é determinado por:

$$
\begin{gathered}
p=H \cdot P \\
P=H^{-1} \cdot p
\end{gathered}
$$

De fato, a transformada perspectiva é menos precisa que os métodos que consideram a calibração da distorção da lente, porém a sua facilidade de uso na prática torna-a mais conveniente [WORRALL; SULLIVAN; BAKER, 1994; HEIKKILÄ; SÍLVEN, 1997].

\subsubsection{Parâmetros fundamentais do tráfego}

Uma das ferramentas mais úteis para a análise de fluxo de veículos é o diagrama espaço-tempo. O diagrama espaço-tempo é nada mais que um gráfico que representa a relação entre a posição de cada veículo na corrente de tráfego e o tempo decorrido [DAGANZO, 1997].

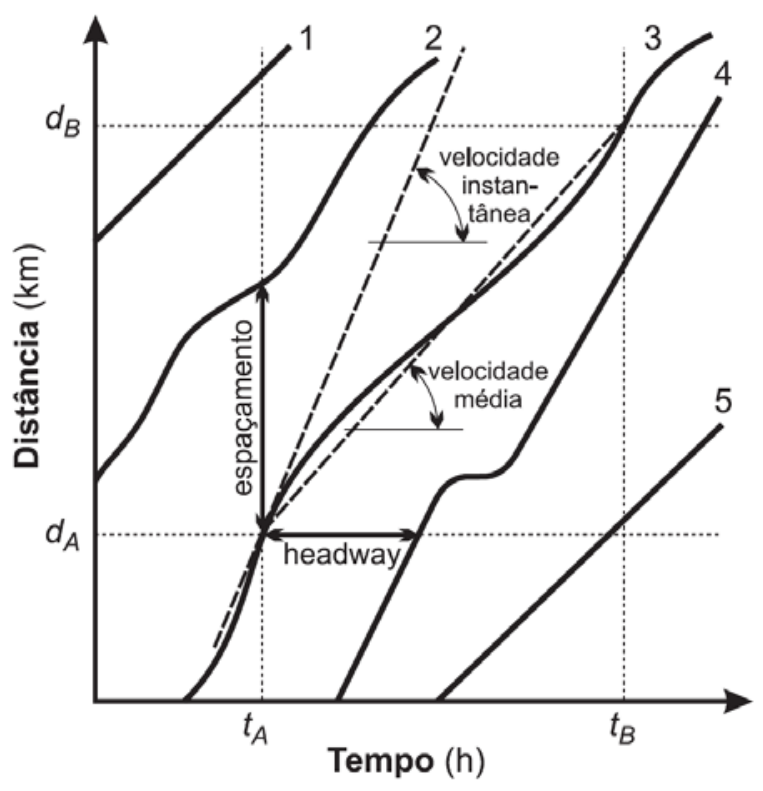

Figura 5.2. Diagrama espaço-tempo [SETTI, 2002] 
O diagrama espaço-tempo da Figura 5.2 exemplifica a trajetória de cinco veículos que trafegam em certa via com sentido unidirecional. No instante $t=0$, os veículos 1 e 2 já se encontram no trecho apresentado, enquanto os demais veículos (3, 4 e 5) entram no trecho em tempos $t_{i}>0$, sendo $i$ o índice do veículo. A partir do diagrama, podem-se determinar vários parâmetros que estão relacionados ao fluxo de veículos, como os parâmetros que representam a separação existente entre os veículos.

O headway é definido como sendo o intervalo de tempo entre a passagem de dois veículos sucessivos e é normalmente medido em um ponto em comum, como a roda dianteira ou o para-choque dianteiro dos veículos. Este mesmo ponto é o que descreve a linha desenhada no diagrama espaço-tempo. Deste modo, o headway é a separação horizontal entre as curvas que representam os veículos na Figura 5.2. Note-se que o headway depende das velocidades dos veículos, variando ao longo do trecho.

O espaçamento é a distância entre veículos sucessivos num certo instante, medida a partir do mesmo ponto de referência comum nos veículos. No diagrama, é a separação vertical entre as curvas dos veículos e também varia ao longo do tempo de acordo com a velocidade dos veículos.

O diagrama espaço-tempo também permite determinar a velocidade média ao longo de um trecho ou a velocidade instantânea dos veículos em um ponto qualquer da trajetória. A velocidade média é determinada pela razão entre o comprimento $\left(L=d_{B}-d_{A}\right)$ do trecho e o tempo gasto para percorrê-lo $\left(\Delta t=t_{B}-t_{A}\right)$, graficamente é representada pela declividade da reta, como mostrado no veículo 3. A velocidade instantânea representa a tangente a curva em cada ponto da trajetória e pode ser estimada pela diferença entre dois pontos muito próximos.

A partir dos parâmetros microscópicos é possível determinar os parâmetros macroscópicos. O fluxo ou volume de tráfego $(q)$ representa o número de veículos $(n)$ que passaram por determinada seção em determinado tempo $(\Delta t)$, geralmente usa-se o volume horário expresso em veic/h. Na Figura 5.2, entre os pontos $A$ e $B$ são observados três veículos em $\Delta t$ horas, logo o fluxo é de 3/ $\Delta t$ veic/h. É importante destacar que ao se analisar períodos inferiores a uma hora, o volume de tráfego horário equivalente é denominado taxa de fluxo de tráfego, pois dentro da hora pode haver variação do fluxo de tráfego.

O fluxo de tráfego está relacionado com o headway médio, pois é suposto que um determinado intervalo de tempo $(\Delta t)$ pode ser estimado pelos headways observados: 


$$
\begin{gathered}
\Delta t=\sum_{i=1}^{n} h_{i} \Rightarrow \bar{h}=\frac{1}{n} \cdot \sum_{i=1}^{n} h_{i} \\
q=\frac{n}{\Delta t}=\frac{1}{\bar{h}}
\end{gathered}
$$

A densidade de tráfego $(k)$ representa o número de veículos ( $n$ ) que se encontra em determinado comprimento do trecho $(L)$. O comprimento do trecho pode ser estimado pelo somatório dos espaçamentos $\left(s_{i}\right)$ :

$$
\begin{gathered}
L=\sum_{i=1}^{n} s_{i} \Rightarrow \bar{s}=\frac{1}{n} \cdot \sum_{i=1}^{n} s_{i} \\
k=\frac{n}{L}=\frac{1}{\bar{s}}
\end{gathered}
$$

A partir dessas duas medidas, pode-se estimar a velocidade da corrente de tráfego $(u)$ pela lei fundamental de tráfego que diz:

$$
q=k \cdot u
$$

Coifman et al. [1998] optaram pelo método de Edie [1963] que determina as medidas macroscópicas em uma determinada área do diagrama espaço-tempo. Neste método, Edie [1963] considerou $d(\varphi)$ a soma das distâncias viajadas por todos os veículos na região $\varphi$; $t(\varphi)$ a soma do tempo gasto por todos os veículos na mesma região $\varphi$; e $|\varphi|$ a área da região em análise, dada por $L \cdot \Delta t$. Assim, os parâmetros macroscópicos são expressos por:

$$
\begin{gathered}
q(\varphi)=\frac{d(\varphi)}{|\varphi|} \\
k(\varphi)=\frac{t(\varphi)}{|\varphi|} \\
u(\varphi)=\frac{q(\varphi)}{k(\varphi)}=\frac{d(\varphi)}{t(\varphi)}
\end{gathered}
$$

\subsection{MÉTODO PROPOSTO}

Como identificado na revisão bibliográfica, poucas pesquisas propuseram obter o diagrama espaço-tempo [COIFMAN et al, 1998; KNOOP; HOOGENDOORN; ZUYLEN, 2009; XU; SUN, 2013] e cada pesquisa usou um método diferente para obter a trajetória dos veículos. Desta forma, esta pesquisa propõe obter dados de tráfego através do diagrama espaço-tempo. A Figura 5.3 traz os processos realizados nesta pesquisa. 


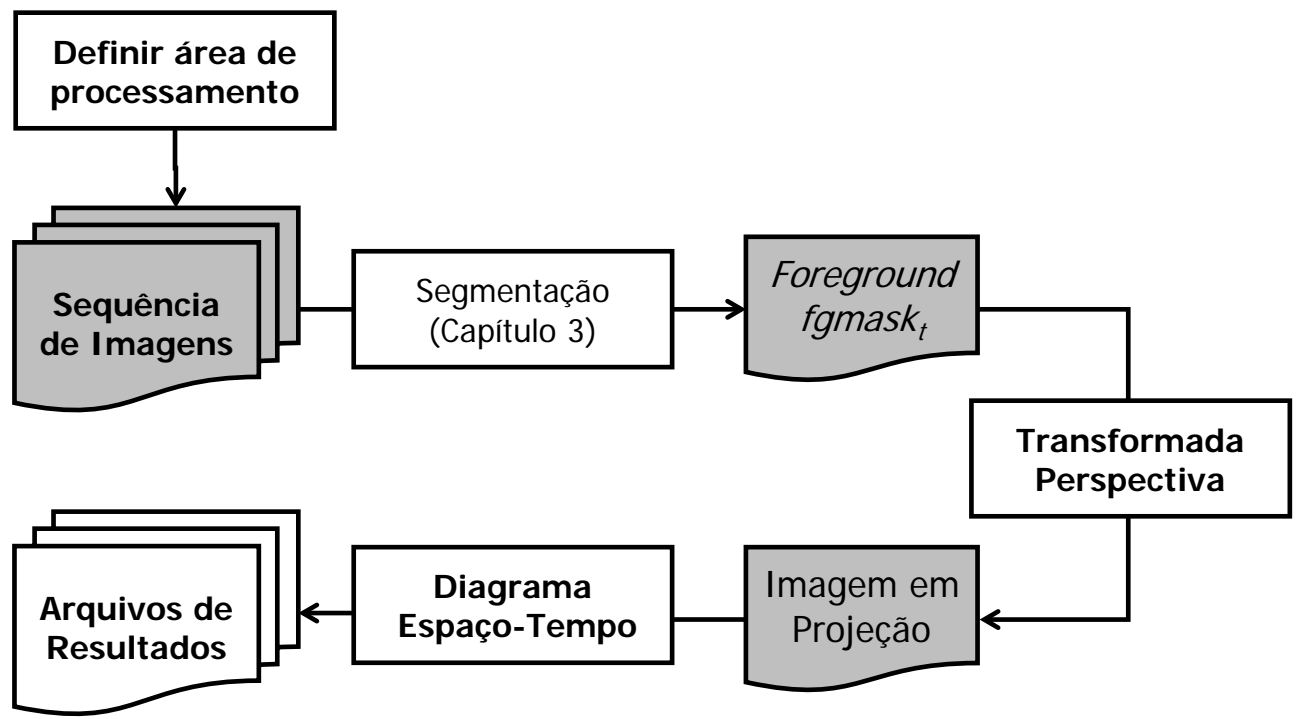

Figura 5.3. Diagrama de processos do sistema desenvolvido

\subsubsection{Definição da área de processamento}

Ao iniciar o programa, o primeiro passo é definir a área de processamento para a obtenção do diagrama espaço-tempo, denominada de work zone. O usuário define os quatro pontos de um retângulo para a obtenção dos parâmetros de tráfego (Figura 5.4a). Após esse passo, é necessário fornecer o número de faixas e o comprimento longitudinal do trecho analisado (Figura 5.4b). Somente a área de processamento (Figura 5.4c) é usada nas etapas seguintes de transformação perspectiva e cômputo do diagrama espaço-tempo.

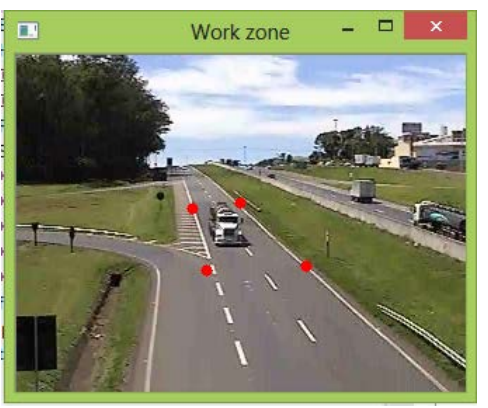

(a) Definição dos pontos

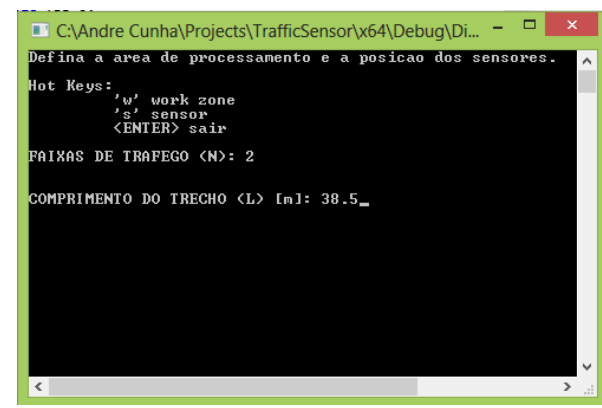

(b) Informações do trecho

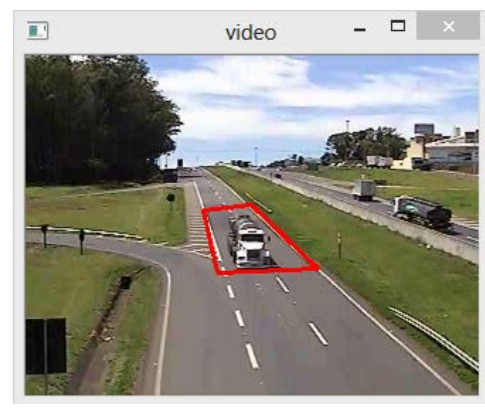

(c) Área de processamento

Figura 5.4. Definição da área de processamento

\subsubsection{Transformada perspectiva}

Com as informações inseridas pelo usuário, a transformada perspectiva é realizada na área de processamento com o propósito de se obter o mapeamento da imagem retangular da work zone definida pelo usuário. Para a transformada perspectiva usou-se as funções da biblioteca OpenCV: 
- cv: :getPerspectiveTransform( Point2f*src, Point2f*dst ): esta função retorna a matriz $3 \times 3 H$ que faz a mapeamento entre os pontos conhecidos do mundo real, representado pelo vetor *src, e os pontos da imagem, definidos no vetor de pontos *dst; e

- cv::warpPerspective( Mat src, Mat dst, Mat warp_matrix ): nesta função são fornecidas a imagem de entrada src, a imagem de destino dst, a matriz transformada warp_matrix obtida com a função anterior.

A aplicação destas funções resulta em uma imagem distorcida representando a transformação perspectiva e um novo sistema de coordenadas, como mostra a Figura 5.5.

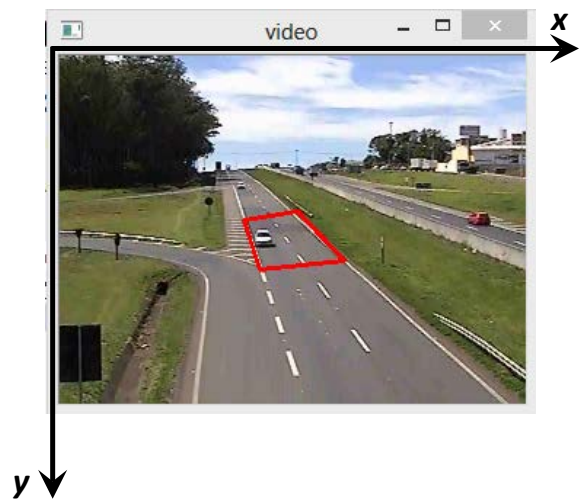

(a) Imagem do vídeo

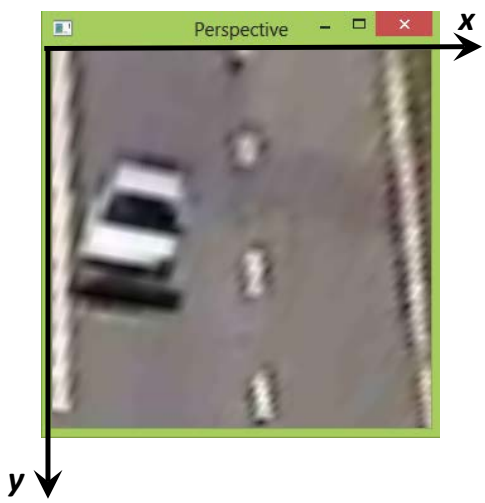

(b) Perspectiva da área

Figura 5.5. Aplicação da transformada perspectiva

\subsubsection{Diagrama espaço-tempo}

Coifman et al. [1998] argumentaram que obter o diagrama espaço-tempo fornece resultados mais robustos do que os métodos de rastreamento (tracking) existentes, pois os métodos de tracking detectam veículos independentes, o que leva a uma dificuldade inerente de ligar os veículos em duas imagens consecutivas para se obter a trajetória. Assim, esta pesquisa também optou por determinar o diagrama espaço-tempo ao invés do rastreamento na sequência de imagens. O método proposto para determinar o diagrama consiste das seguintes etapas:

- A partir da imagem dos veículos segmentadas fgmask, obteve-se os vetores dos pontos que definem cada região dos veículos, utilizando a função do OpenCV cv::findCountours(image, countours), sendo image a imagem segmentada 
(fgmask) e countours o resultado do vetor dos pontos do contorno dos objetos;

- Para cada vetor de pontos dos veículos, calcular o centroide da região através da função cv: :moments(Mat array), sendo array o vetor de pontos do veículo;

- Converter as coordenadas do centroide da imagem do tráfego para a imagem em perspectiva, sendo que a coordenada do eixo $x$ define a faixa de tráfego e a coordenada em $y$ fornece a posição longitudinal no trecho (vide Figura 5.5);

- Plotar no diagrama a coordenada y do centroide do veículo em perspectiva e o frame atual;

- Ligar os pontos no diagrama que estejam dentro de uma janela de 0,5 s no eixo $x$ e $5 \%$ do comprimento do trecho no eixo $y$;

- Armazenar em um vetor de pontos, definidos pelas coordenadas espaço e tempo, as trajetórias de cada veículo separado por faixa de tráfego.

A Figura 5.6 traz um exemplo do processo de construção do diagrama espaço-tempo durante a execução do vídeo em análise. A Figura 5.6a traz um frame do vídeo, enquanto a Figura 5.6b apresenta a imagem dos veículos segmentados (fgmask) após a aplicação do método descrito no Capítulo 4. Em seguida, a Figura 5.6c revela a área de processamento e os pontos dos centroides dos veículos da imagem fgmask. Na Figura 5.6d é apresentada a imagem em perspectiva do work zone. Por fim, a Figura 5.6e retrata o diagrama espaço-tempo atualizado de acordo com a execução do vídeo. Nota-se que as trajetórias dos veículos são diferenciadas por cores de acordo com o número de faixas especificado pelo usuário no início do programa. A diferenciação da faixa é feita pela coordenada $x$ do centroide do veículo e a largura da imagem em perspectiva. 


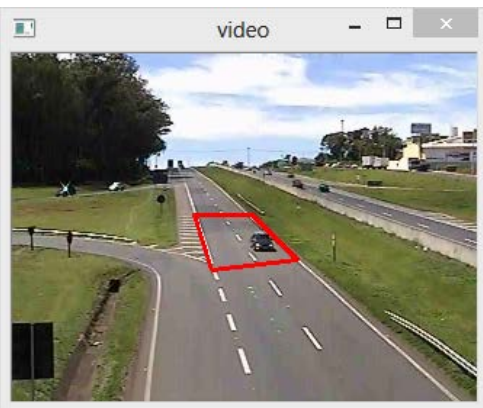

(a) vídeo

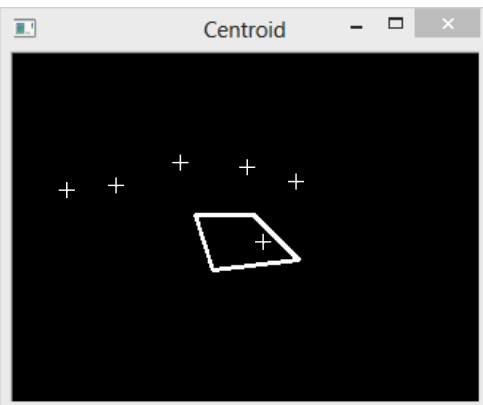

(c) centroides

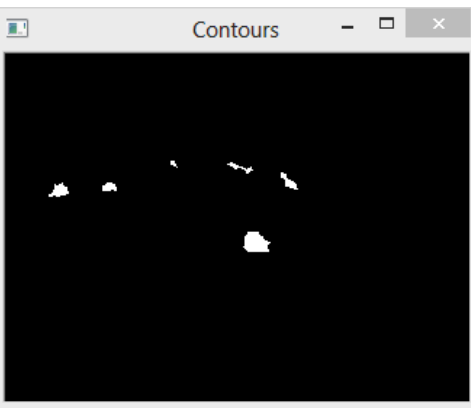

(b) fgmask

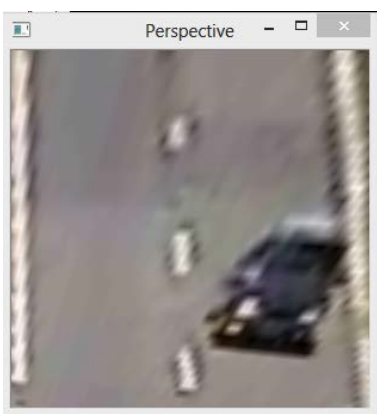

(d) Perspectiva

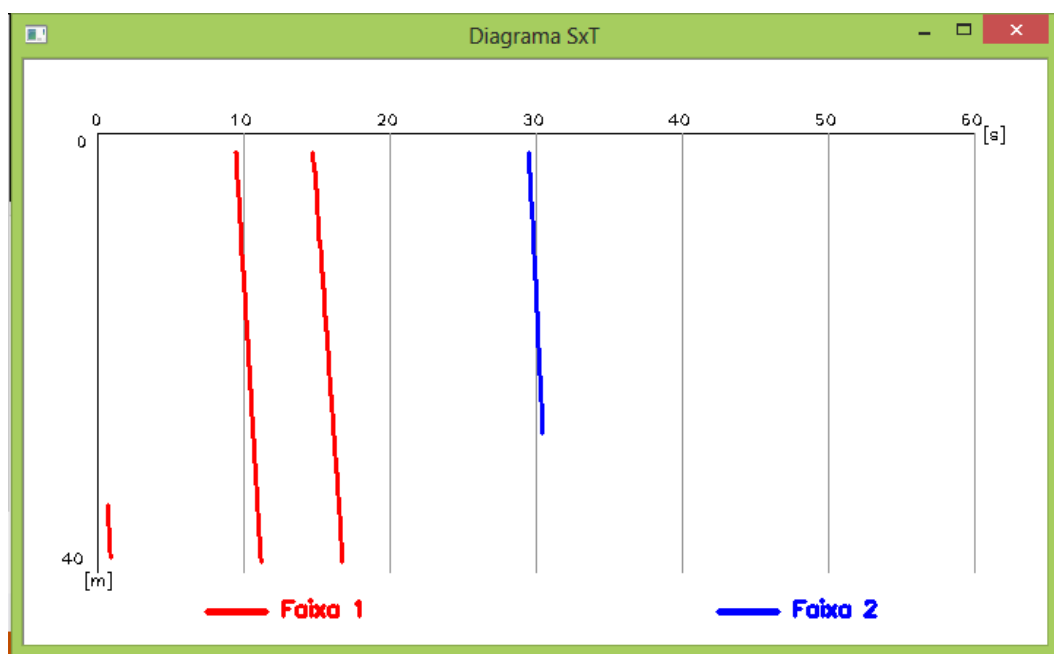

(e) Diagrama espaço-tempo

Figura 5.6. Etapas do sistema desenvolvido

\subsubsection{Arquivos relatórios}

Além do diagrama espaço-tempo apresentado em tempo de execução, três arquivos relatórios são escritos ao final da execução do sistema:

- TRAFFIC_DATA.txt: este arquivo armazena os dados a cada minuto de vídeo contendo o fluxo, a densidade, a velocidade da corrente, além da estimativa do headway médio, o espaçamento médio e o tempo médio de viagem; 
- VEHICLE_DATA.txt: este arquivo é o relatório completo contendo a faixa de tráfego, o número do veículo, o tempo e a posição em metros; e

- VEHICLE_SUMMARY.txt: este arquivo relata o resumo de cada veículo identificado pelo sistema, com informações do frame inicial, o frame final, a identificação da faixa de tráfego, o tempo de percurso em segundos no trecho, a distância percorrida em metros e a velocidade média.

\subsection{AVALIAÇÃO DO SISTEMA DESENVOLVIDO}

O desempenho do sistema desenvolvido nesta pesquisa foi avaliado comparando-se os resultados obtidos automaticamente com dados obtidos ou manualmente ou por outro dispositivo. A seguir, apresenta-se a comparação dos dados de velocidade, fluxo de tráfego e comprimento de veículos.

\subsubsection{Velocidade}

Durante uma das coletas em campo, foi utilizado um dispositivo móvel tipo "radarpistola” de detecção da velocidade dos veículos. A partir desse levantamento, a Figura 5.7 compara a distribuição das velocidades obtidas pelo sistema proposto versus as velocidades obtidas pelo dispositivo móvel. A intenção desta comparação é verificar a correlação dos dados, visto que ambos os dispositivos de coleta são suscetíveis a apresentar erros. 


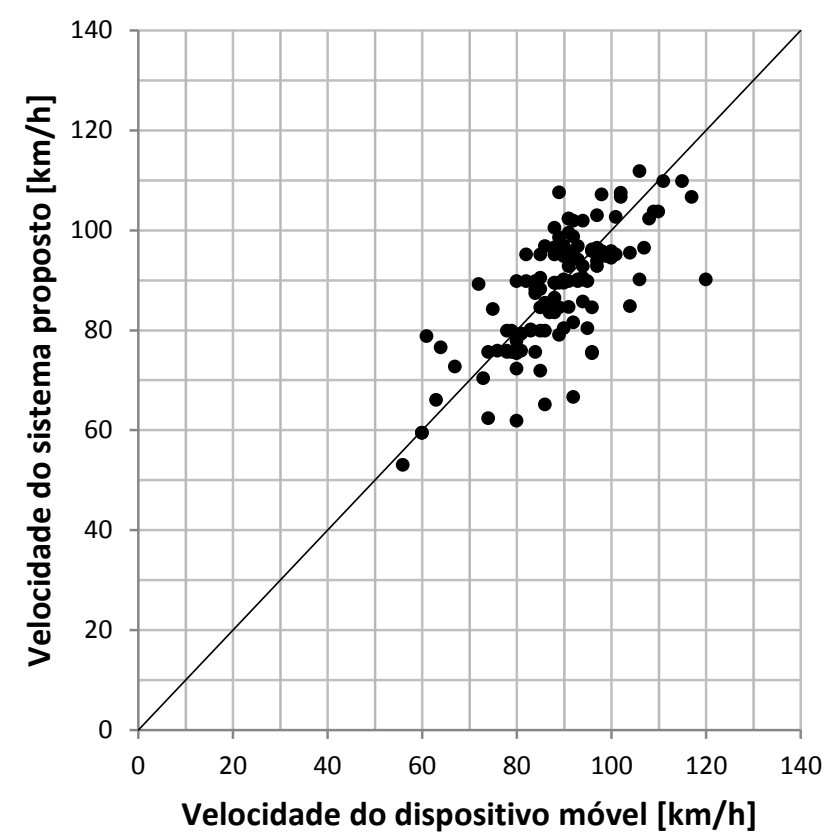

Figura 5.7. Comparação das velocidades obtidas no sistema proposto e no dispositivo móvel

Além da distribuição das velocidades obtidas, a Figura 5.7 apresenta a reta em $45^{\circ}$ com os pontos da correlação ideal. Nota-se que os pontos encontram-se distribuído ao longo de toda esta reta, com alguns pontos afastados da correlação ideal, o que representa as maiores diferenças nos valores das velocidades. A Figura 5.8 traz os histogramas das velocidades obtidas em cada dispositivo.

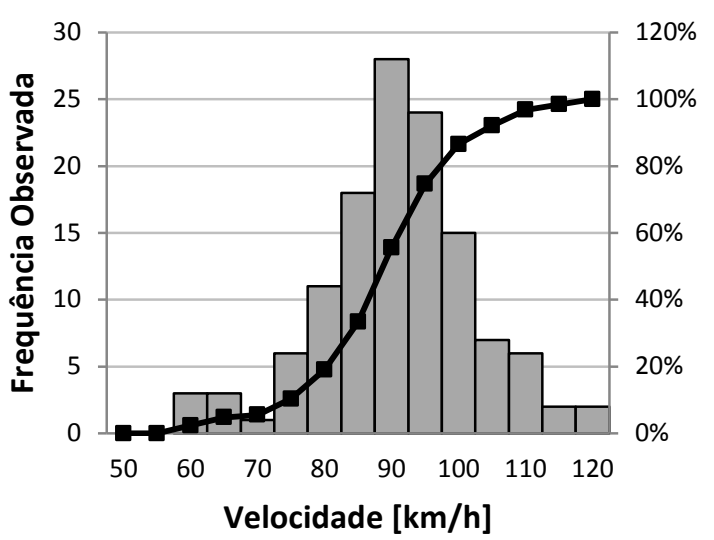

(a) Dispositivo móvel

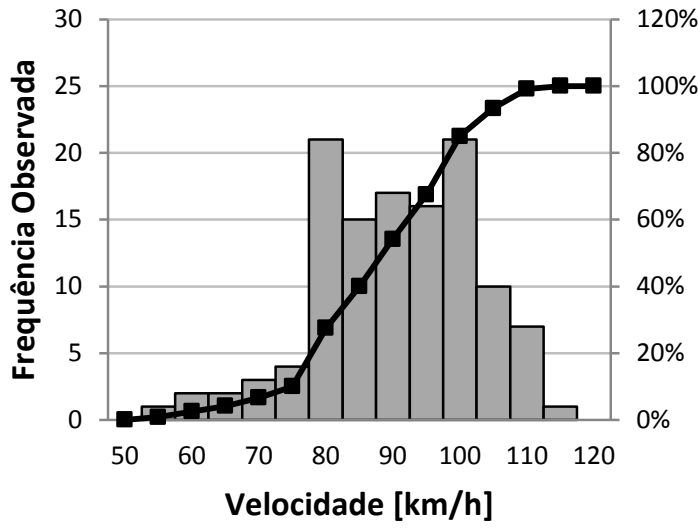

(b) Sistema proposto

Figura 5.8. Histograma das velocidades obtidas

Com o propósito de verificar a aderência das distribuições de velocidades do sensor e do sistema proposto, foram investigadas duas hipóteses: 
- $H_{0}$ : afirma que não há discrepância entre as velocidades obtidas no sensor e obtidas no sistema proposto;

- $H_{1}$ : afirma que existe discrepância entre as velocidades obtidas no sensor e obtidas no sistema proposto.

No teste Qui-quadrado $\left(\chi^{2}\right)$ com $95 \%$ de nível de confiança não se rejeita $H_{0}$, pois obteve-se $\chi_{\text {cal }}^{2}=99,80$ menor do que o valor crítico $\chi_{\text {crítico }}^{2}=146,58$. Utilizando outro teste de aderência, o teste de Kolmogorov-Smirnoff também não se rejeita $H_{0}$ com 95\% de nível de confiança pois a maior diferença relativa entre as distribuições foi $D=0,09682$ dentro do limite $D_{\text {crítico }}$ de 0,17347 . Assim, conclui-se que as velocidades obtidas no sistema proposto para o vídeo analisado apresentou boa representação ao se comparar com o dispositivo móvel.

Uma última análise foi feita calculando-se os erros relativos através da diferença entre a velocidade obtida na imagem e a velocidade obtida pelo radar. A Figura 5.9 apresenta a distribuição dos erros relativos. Nota-se que cerca de $60 \%$ dos dados apresentaram erros inferiores a $6 \%$, enquanto $85 \%$ dos dados obtiveram erros inferiores a $14 \%$.

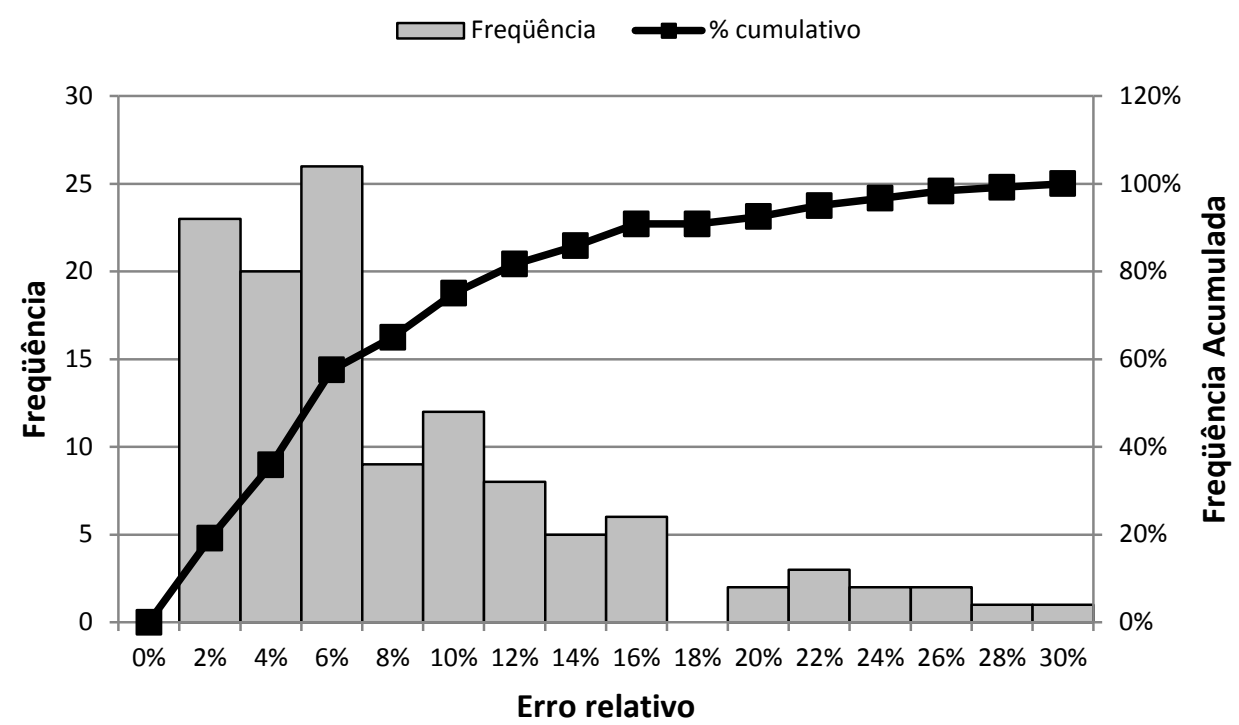

Figura 5.9. Distribuição de erros entre as velocidades obtidas na imagem e no sensor

A Tabela 5.1 ilustra uma amostra da comparação dos dados de velocidades. A tabela completa dos 126 veículos encontra-se no Apêndice A. O sistema de imagens teve uma taxa de detecção de 95,2\%, isto é, 120 veículos foram detectados corretamente dos 126 detectados manualmente com o radar. A média dos erros relativos é de 7,3\% e, consequentemente, a taxa média de acerto é de 92,7\% para os dados analisados. 
Tabela 5.1. Amostra dos resultados das velocidades

\begin{tabular}{|c|c|c|c|c|c|c|c|}
\hline \multirow{2}{*}{$\begin{array}{l}\text { ID } \\
\text { veículo }\end{array}$} & \multirow[b]{2}{*}{ Faixa } & \multirow{2}{*}{$\begin{array}{l}\text { Tempo } \\
\text { [mm:ss] }\end{array}$} & \multirow[b]{2}{*}{ Frame } & \multicolumn{2}{|c|}{ Velocidade $[\mathrm{km} / \mathrm{h}]$} & \multirow[b]{2}{*}{ Erro (\%) } & \multirow[b]{2}{*}{ Acerto (\%) } \\
\hline & & & & Sensor & Imagem & & \\
\hline 1 & 1 & $00: 15$ & 450 & 76,00 & 75,87 & $0,2 \%$ & $99,8 \%$ \\
\hline 2 & 2 & 00:30 & 910 & 117,00 & 106,62 & $8,9 \%$ & $91,1 \%$ \\
\hline 3 & 1 & $00: 43$ & 1304 & 90,00 & 80,36 & $10,7 \%$ & $89,3 \%$ \\
\hline 4 & 1 & 00:49 & 1480 & 92,00 & 101,88 & $10,7 \%$ & $89,3 \%$ \\
\hline 5 & 2 & $01: 13$ & 2196 & 109,00 & 103,68 & $4,9 \%$ & $95,1 \%$ \\
\hline 6 & 1 & $01: 24$ & 2519 & 91,00 & 102,24 & $12,4 \%$ & $87,6 \%$ \\
\hline 7 & 2 & $01: 30$ & 2713 & 85,00 & 88,20 & $3,8 \%$ & $96,2 \%$ \\
\hline 8 & 1 & $01: 32$ & 2760 & 80,00 & 61,85 & $22,7 \%$ & $77,3 \%$ \\
\hline 9 & 1 & $01: 36$ & 2880 & 86,00 & - & - & - \\
\hline 10 & 1 & 01:39 & 2970 & 81,00 & 75,87 & $6,3 \%$ & $93,7 \%$ \\
\hline 11 & 2 & $01: 50$ & 3300 & 97,00 & 96,43 & $0,6 \%$ & $99,4 \%$ \\
\hline 12 & 2 & 01:55 & 3460 & 102,00 & 106,62 & $4,5 \%$ & $95,5 \%$ \\
\hline 13 & 1 & 01:59 & 3580 & 78,00 & 79,80 & $2,3 \%$ & $97,7 \%$ \\
\hline 14 & 2 & 02:07 & 3815 & 91,00 & 92,74 & $1,9 \%$ & $98,1 \%$ \\
\hline 15 & 2 & 02:08 & 3845 & 94,00 & 92,74 & $1,3 \%$ & $98,7 \%$ \\
\hline 16 & 2 & $02: 13$ & 3994 & 97,00 & 92,74 & $4,4 \%$ & $95,6 \%$ \\
\hline 17 & 1 & $02: 27$ & 4410 & 89,00 & 107,52 & $20,8 \%$ & $79,2 \%$ \\
\hline 18 & 2 & $02: 31$ & 4535 & 93,00 & 94,08 & $1,2 \%$ & $98,8 \%$ \\
\hline 19 & 1 & $02: 31$ & 4535 & 93,00 & 90,09 & $3,1 \%$ & $96,9 \%$ \\
\hline 20 & 1 & $02: 38$ & 4742 & 108,00 & 102,24 & $5,3 \%$ & $94,7 \%$ \\
\hline
\end{tabular}

\subsubsection{Fluxo de tráfego}

Os fluxos de tráfego obtidos pelo sistema foram comparados com contagens manuais. O sistema desenvolvido gera o arquivo TRAFFIC_DATA.txt com dados de taxa de fluxo de tráfego, densidade e velocidade da corrente de tráfego a cada minuto do vídeo. A contagem manual foi realizada assistindo-se ao vídeo e contabilizando-se o total de veículos que passaram a cada minuto.

O primeiro teste foi feito no vídeo de teste da velocidade, denominado vídeo-1, com 18 minutos. A Figura 5.10 retrata os valores obtidos na contagem manual e na contagem automática do sistema proposto. Nota-se que, de modo, geral o sistema proposto conseguiu representar as variações do fluxo a cada minuto, as duas curvas apresentam o mesmo padrão de variação. Entretanto, a coleta automática em todos os períodos de contagem superestimou o número de veículos, numa média de 4 veículos a mais do que a contagem manual. Isto pode ser explicado pelo fato de alguns veículos mudarem de faixa de tráfego, o que altera a posição do centroide do veículo e consequentemente altera o vetor que guarda a trajetória do veículo. Este processo poderia ser recodificado para se evitar esta superestimação. 


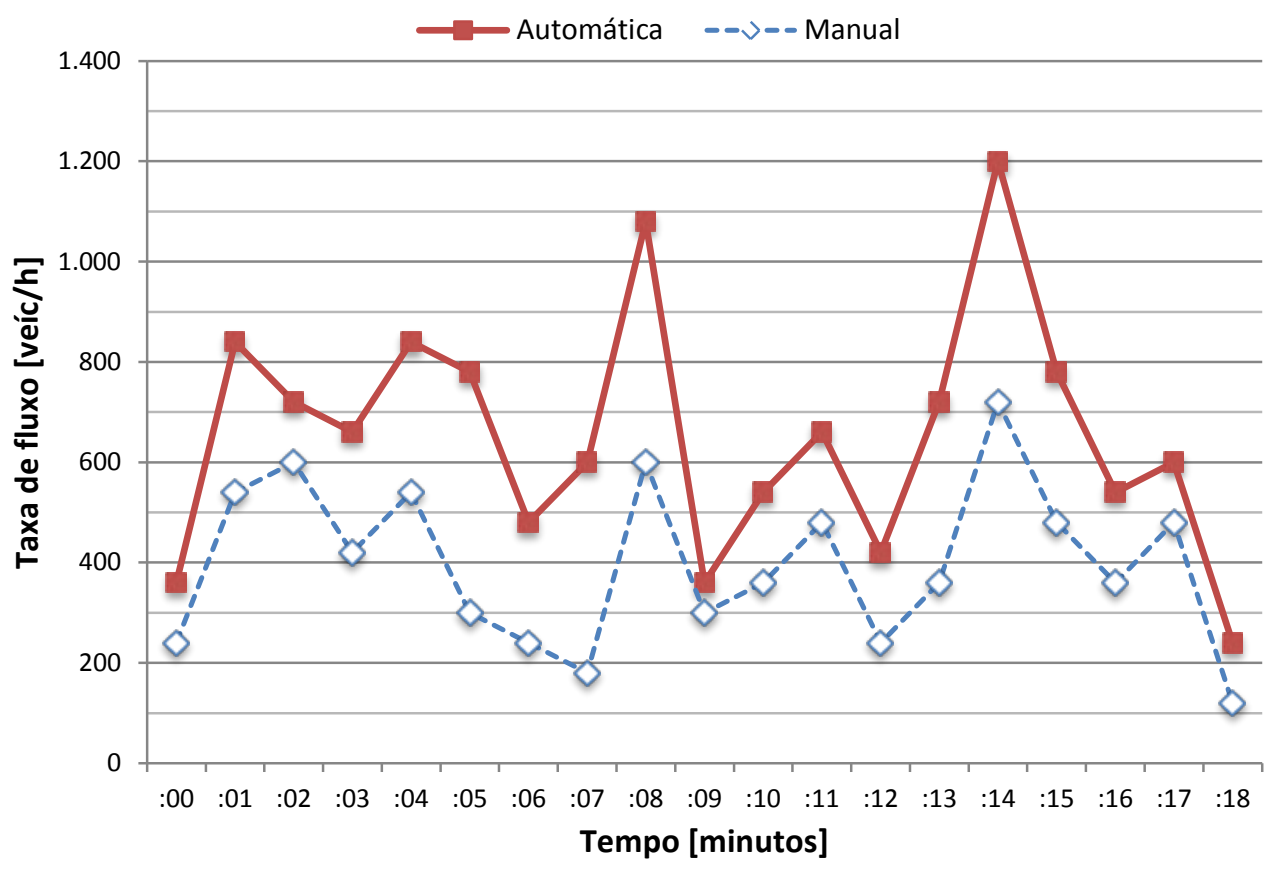

Figura 5.10. Comparação dos volumes de tráfego no vídeo-1

Além deste vídeo, foram testados outros quatro vídeos, com um tempo menor de execução, devido ao tempo de processamento manual. Esses outros testes foram analisados com uma parte entre 5 e 7 minutos dos vídeos.

A Figura 5.11 ilustra os resultados da taxa de fluxo nos vídeos 2, 3 e 4. Dentre esses, o vídeo-2 (Figura 5.11a) foi o que apresentou a maior diferença das variações do fluxo. Por outro lado, de modo geral, a Figura 5.11 mostra que os padrões das variações da taxa de fluxo são similares para os vídeos 3 e 4. É interessante notar que, para esses vídeos, o sistema automático proposto, na maioria das vezes, subestimou a contagem, ao contrário do vídeo 1 (Figura 5.10). 


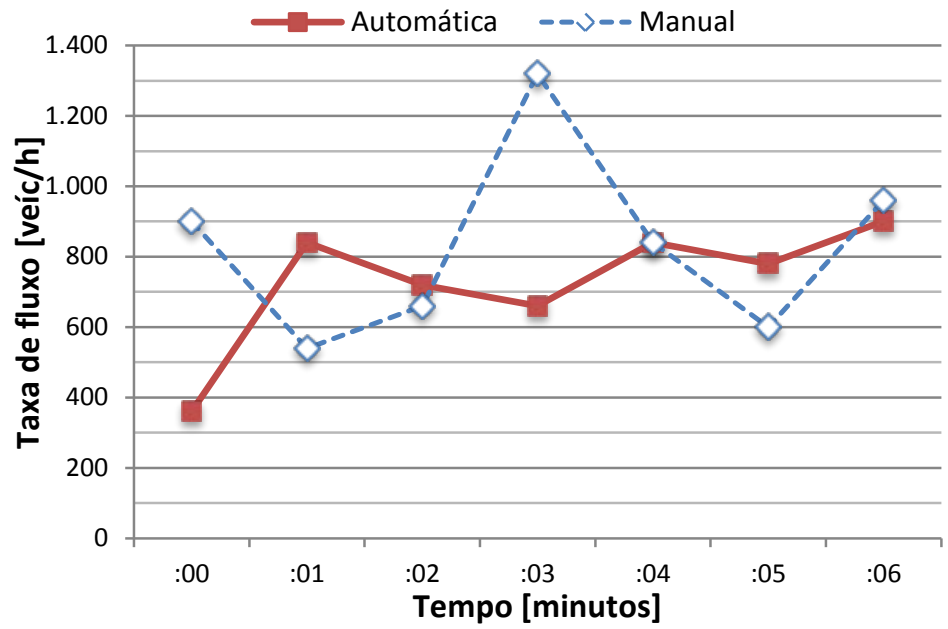

(a) Vídeo-2

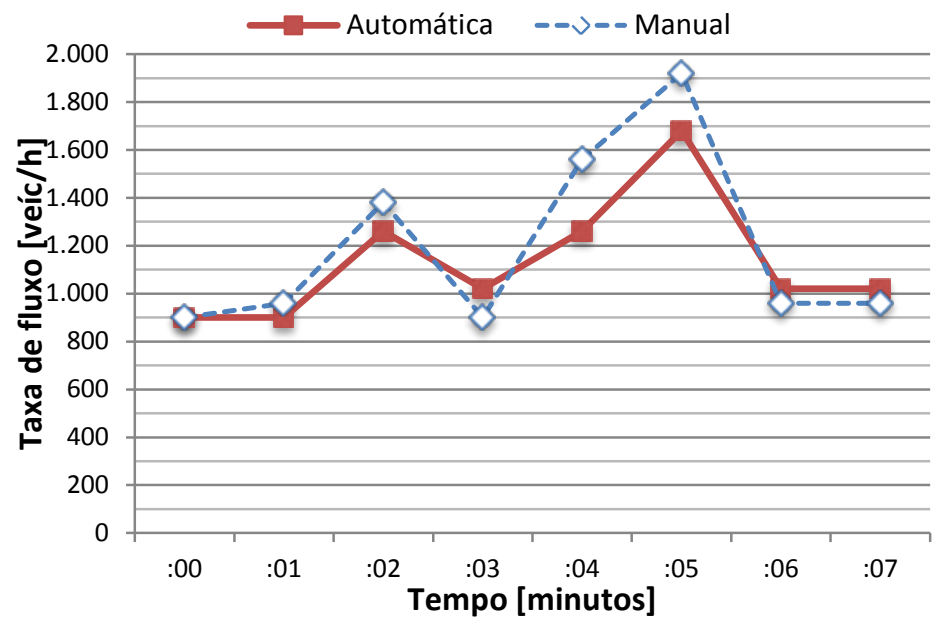

(b) Vídeo-3

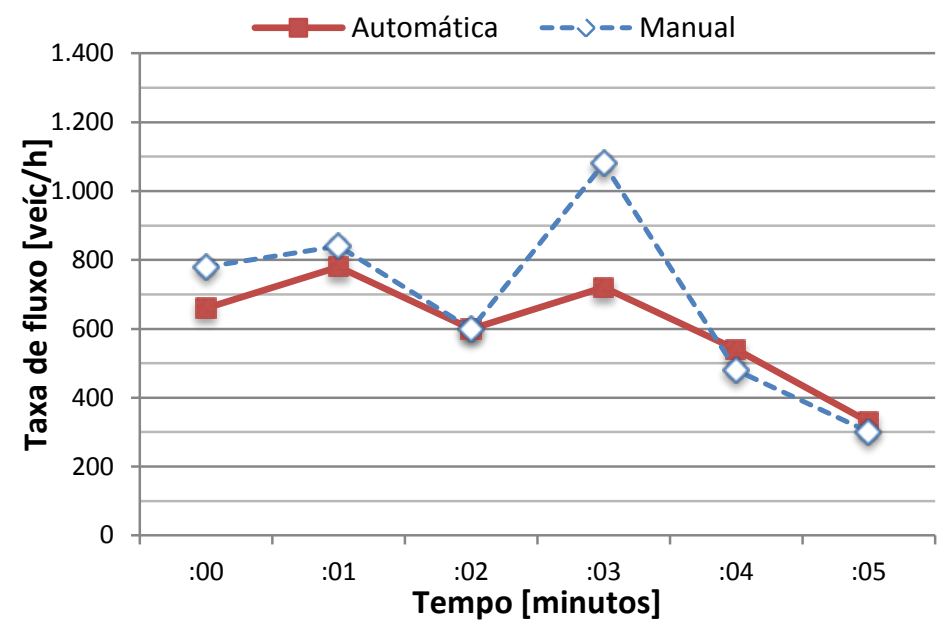

(c) Vídeo-4

Figura 5.11. Comparação dos volumes de tráfego nos vídeos 2 a 4 
A Figura 5.12 ilustra os resultados do vídeo-5. Este vídeo merece destaque pelo fato de ter apresentado o maior erro na contagem de veículos. No segundo minuto do vídeo, a contagem manual apresenta 25 veículos (taxa de fluxo de 1.500 veic/h), enquanto que o sistema contabilizou 64 veículos (3.840 veic/h). Nos demais pontos da curva, as curvas se mantiveram com os mesmos padrões de variação.

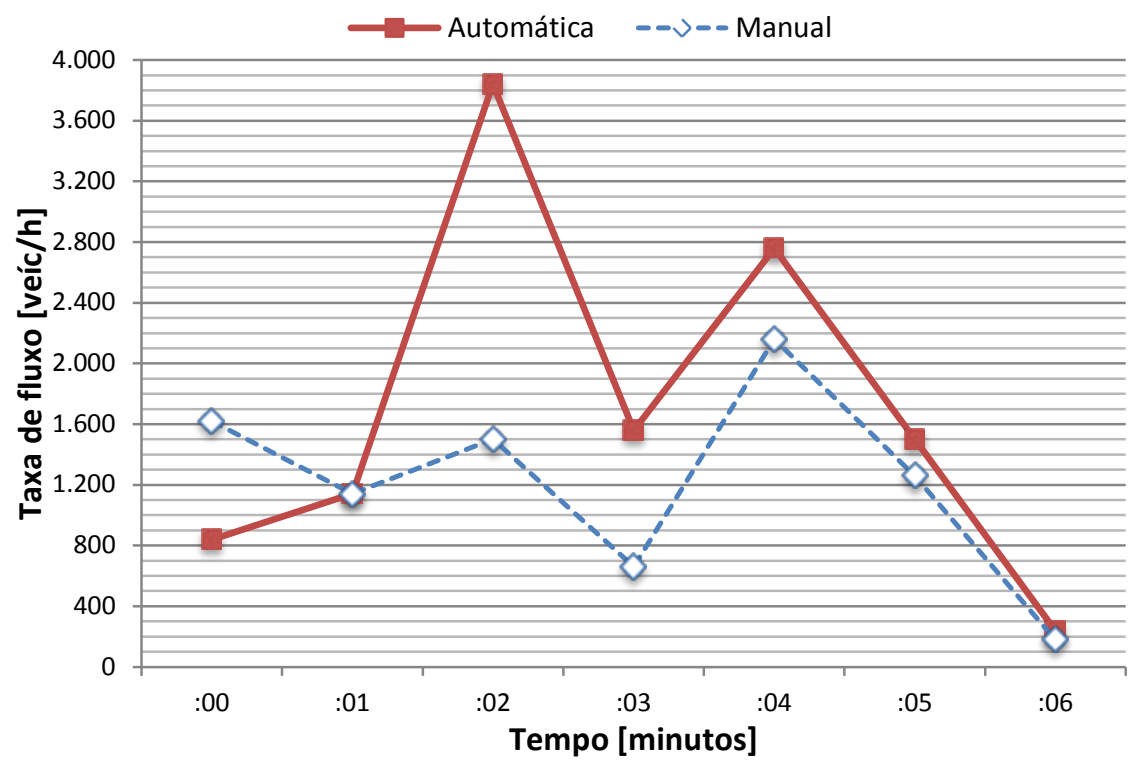

Figura 5.12. Comparação dos volumes de tráfego no vídeo-5

Ao investigar em detalhes o vídeo 5, foram constatados a ocorrência de dois problemas comumente relatados na literatura:

- Entre o intervalo de 2 e 3 minutos, mais precisamente nos instantes $2 \mathrm{~m} 36 \mathrm{~s}$ e 2m58s, o operador da filmagem acabou esbarrando na câmera e movimentando a captura da cena, o que ocasionou a perda do background até então determinado. Desta forma, a partir desses instantes houve certa perda da identificação dos objetos, pois o sistema de detecção precisou reconstruir o background;

- Além da movimentação, observou-se que o vídeo-5 foi o que mais sofreu com mudanças bruscas de iluminação, devido à passagem de nuvens no horário da coleta. A literatura relata esse efeito ao se trabalhar com imagens em ambientes externo e apresenta diferentes métodos para tratá-lo. A Figura 5.13 ilustra o exemplo de uma das ocorrências observadas. 


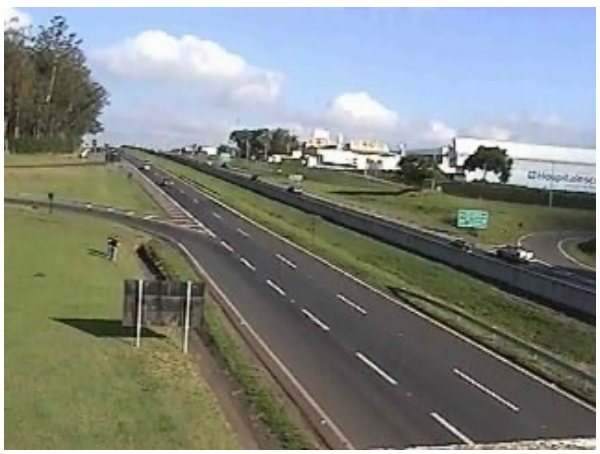

(a) Instante $3 \mathrm{~m} 45 \mathrm{~s}$ - frame \#6749

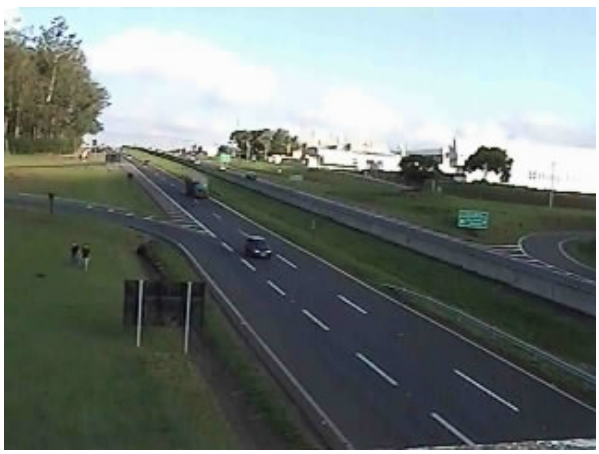

(b) Instante 4m00s - frame \#7207

Figura 5.13. Mudança brusca de iluminação vídeo 5

\subsubsection{Comprimento}

Com a realização da transformada perspectiva, é possível estimar qualquer medida na imagem. Assim, foi desenvolvida uma "trena virtual” para extrair o comprimento dos veículos, ainda manualmente, a partir do vídeo. Para ativar a ferramenta, a tecla “T” deve ser pressionada; então basta selecionar dois pontos para que a medida seja calculada. Essa ferramenta é extremamente útil no auxílio de coletas de dados em postos de pesagem, obtendo as medidas de comprimentos dos caminhões. Desta forma, pode-se aumentar o banco de dados da caracterização dos caminhões típicos em rodovias brasileiras [CUNHA; MODOTTI; SETTI, 2008]. Optou-se por fazer essa ferramenta ainda manualmente, pois de forma automática é necessário estimar na imagem a angulação de referência para se determinar os pontos extremos dos veículos.

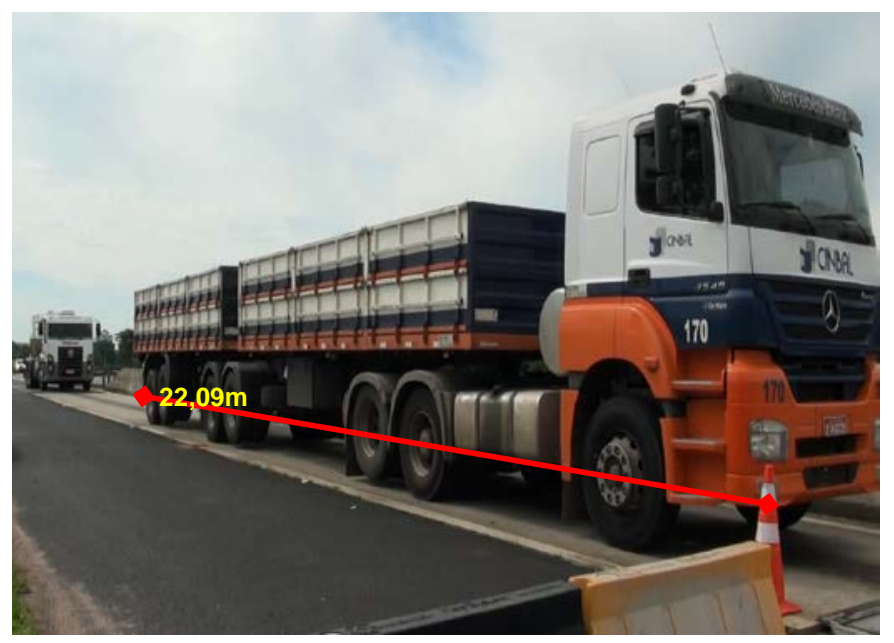

Figura 5.14. Extraindo o comprimento do veículo 


\subsection{CONSIDERAÇÕES FINAIS}

Este capítulo apresentou o desenvolvimento do sistema automático de coleta de dados de tráfego através de imagens de vídeo. O sistema proposto determinou o diagrama espaço-tempo dos veículos em tempo de execução do vídeo. Além disso, ao final do processo três arquivos relatórios são gerados: TRAFFIC_DATA.txt (contendo os parâmetros macroscópicos da corrente de tráfego a cada minuto), VEHICLE_DATA.txt (descreve os pontos das trajetórias de cada veículo, com posição, tempo e faixa de tráfego) e VEHICLE_SUMMARY.txt (resumo dos veículos identificados com sua velocidade média e distância percorrida).

Para a criação do diagrama espaço-tempo, usou-se a imagem em perspectiva e os centroides dos veículos a partir da imagem segmentada fgmask. Os resultados das medidas de tráfego obtidas com o sistema desenvolvido foram avaliados comparando com as medidas obtidas em coletas manuais e utilizando um dispositivo móvel.

A taxa média de acerto das velocidades dos veículos foi de 92,7\%, comparando as velocidades do sistema de imagem com a velocidade do radar tipo pistola. Além disso, os testes estatísticos de Qui-quadrado e Kolmogorov-Smirnov não rejeitam a hipótese que as distribuições de velocidades são similares. Já a taxa de fluxo de tráfego foi avaliada em cinco vídeos e as respostas apresentaram certa similaridade apenas no padrão de variação do fluxo no tempo, sendo os valores significativamente bem diferentes. Foi constatado que a identificação dos veículos necessita ser mais robusta, pois ora o sistema superestimou a taxa de fluxo e ora subestimou. A robustez do sistema de contagem veicular pode ser melhorada com o ajuste dos parâmetros dos métodos de segmentação. Por fim, foi apresentada uma ferramenta para iterativamente extrair a medida do comprimento dos veículos. 


\section{Conclusões e Sugestões}

A tese defendida nesta pesquisa considera que é possível obter parâmetros da corrente de tráfego baseado em visão computacional. Baseado nesta proposição, a meta deste trabalho foi desenvolver um sistema de coleta automática de dados do tráfego veicular a partir do pós-processamento de imagens de vídeos em rodovias. Para atingir esta meta, foram definidos os seguintes objetivos:

- A partir do estado da técnica, definir o melhor método para detecção e segmentação de veículos em imagens de rodovias;

- Estabelecer, a partir do estado da técnica, o melhor processo para rastreamento de veículos em imagens de vídeo de rodovias; e

- Desenvolver uma ferramenta de software que permita a coleta automática de parâmetros da corrente de tráfego, a partir de imagens de vídeos em rodovias, usando as técnicas de segmentação e rastreamento desenvolvidas nas etapas anteriores.

A meta e os objetivos propostos para esta pesquisa foram atingidos, uma vez que os três objetivos propostos foram alcançados. A seguir são apresentadas as conclusões obtidas para cada objetivo proposto.

\subsection{CONCLUSÕES}

Quanto ao primeiro objetivo, estabelecer uma fundamentação teórica sobre o tema visão computacional, uma extensa revisão bibliográfica foi realizada nos temas relacionados ao processamento de imagens, coleta de dados de tráfego e, principalmente, programação e uso da biblioteca OpenCV. Os conceitos de visão computacional foram iniciados nas disciplinas oferecidas nos programas de pós-graduação do Departamento de Engenharia Elétrica (SEL) e do Instituto de Ciências Matemáticas e de Computação (ICMC), além da extensa bibliografia consultada, tanto livros como também artigos científicos. De todo este conhecimento adquirido, conclui-se que, de fato, a Visão Computacional é um campo extenso 
e multidisciplinar, abrangendo diversas áreas do conhecimento, o que estimula interessados de outras áreas a contribuir no desenvolvimento de novas técnicas e algoritmos.

O embasamento teórico requer uma ênfase em linguagem de programação, pois é imprescindível para o entendimento das técnicas e a propagação do conhecimento. As linguagens de programação, em especial a linguagem C++ e o Matlab, têm sido um dos meios mais eficazes de comunicação entre os pesquisadores da área de visão computacional, visto que, ao disponibilizar novas técnicas em funções com código aberto, facilitam, e muito, a sua compreensão. A biblioteca OpenCV, por exemplo, tem ganhado destaque mundial por ser escrita nas linguagens mais usadas na comunidade científica, além de ter código aberto e uso livre. Assim, conclui-se que é de fundamental importância dedicar-se ao aprendizado de linguagem de programação em aplicações de Visão Computacional.

Quanto ao segundo objetivo de determinar o estado da técnica dos métodos de detecção e segmentação, diversas conclusões podem ser tecidas, pois este assunto foi dividido em duas etapas: modelagem de background e segmentação dos objetos.

A primeira etapa foi fundamental, pois a partir de uma adequada imagem de background aumentou-se a chance de uma melhor segmentação dos frames da corrente de tráfego. Assim, foram investigados seis modelos de geração de background conceituados na literatura: Média, Mediana, Misturas de Gaussianas, Moda, Probabilidade e Scoreboard. Os testes foram avaliados em vídeos obtidos em períodos diferentes do dia: manhã, meio-dia e tarde. Os resultados desta etapa mostraram que o Scoreboard foi o modelo mais adequado para a identificação dos objetos em imagem do tráfego. Dentre todos os métodos, o Scoreboard obteve a melhor taxa de exatidão com 95,7\% de média, variando de 92,8\% a 98,2\% nos seis vídeos testados; o segundo melhor tempo de processamento (18,9 s/frame); e a terceira melhor taxa de verdadeiro positivo, com 45,1\% de acerto dos objetos. Conclui-se que o Scoreboard apresentou resultados satisfatórios e foi definido para o uso na próxima etapa.

A segunda etapa investigou três métodos de segmentação: subtração de fundo, mapa de textura e segmentação baseada em textura - sendo investigados quatro descritores de texturas $\left(L B P, L F P_{t}, L F P_{s}, L F P_{g}\right)$. Esses métodos também foram testados nos vídeos em períodos diferentes do dia: manhã, meio-dia e tarde. Da análise do desempenho dos modelos, conclui-se que o Background Subtraction foi o mais adequado para a segmentação dos 
veículos nas imagens do tráfego para o sistema proposto. A avaliação do desempenho da subtração de fundo resultou nos seguintes parâmetros: o melhor tempo de processamento (34,4 ms/frame), corroborando os resultados descritos na literatura; a melhor taxa de acertos totais (exatidão) com 95,1\% de média, variando de 92,5\% a 98,0\% nos seis vídeos testados; e o segunda melhor taxa de VP (verdadeiro positivo) com 67,3\% de acerto dos veículos. Assim, conclui-se que para o desenvolvimento do sistema automático de coleta de dados, a subtração de fundo combinada com o modelo Scoreboard de geração do background são os métodos mais promissores para realizar a segmentação os veículos.

Por fim, o terceiro objetivo foi desenvolver uma ferramenta para realizar a coleta automática de dados de tráfego a partir de imagens de vídeos em rodovias. O sistema proposto determinou um diagrama espaço-tempo das trajetórias dos veículos em tempo de execução do vídeo. As trajetórias foram construídas a partir do centroide dos veículos identificados na na imagem segmentada em perspectiva. Além do diagrama, ao final do processamento, três arquivos relatórios são gerados: TRAFFIC_DATA.txt (contendo os parâmetros macroscópicos da corrente de tráfego a cada minuto), VEHICLE_DATA.txt (descreve os pontos das trajetórias de cada veículo, com posição, tempo e faixa de tráfego) e VEHICLE_SUMMARY.txt (resumo dos veículos identificados com sua velocidade média e distância percorrida).

Para avaliar o desempenho do sistema proposto, as medidas de tráfego obtidas nesta pesquisa foram comparadas com medidas obtidas em coletas manuais e em um radar de velocidade. Os resultados apontaram para uma boa representação da velocidade dos veículos, com taxa de acerto de 92,7\% comparada com as velocidades do radar. Além disso, os testes estatísticos de Qui-quadrado e Kolmogorov-Smirnov mostraram uma boa aderência da distribuição das velocidades do método em relação aos valores medidos em campo. Entretanto, para a taxa de fluxo de tráfego, os resultados não foram satisfatórios. De modo geral, comparando com as coletas manuais, os resultados do sistema proposto apresentaram certa similaridade no padrão de variação do fluxo no tempo, entretanto os valores da taxa de fluxo foram bem diferentes. Conclui-se que a identificação dos veículos no diagrama precisa ser mais robusta, para reduzir os erros de superestimar ou subestimar a taxa de fluxo. Por fim, também foi apresentada uma ferramenta iterativa para extrair a medida do comprimento dos veículos. 


\subsection{SUGESTÕES DE TRABALHOS FUTUROS}

Como este trabalho apresentou um software de coleta automática de dados de tráfego, sugere-se o desenvolvimento de uma interface mais amigável ao usuário, contendo formulários e botões para fácil manuseio do sistema. A interface pode conter os botões básicos de controle do vídeo, como: play, pause, avançar e retroceder. Também pode conter os botões do sistema proposto: definição da área de processamento e da trena virtual, assim como controles como abrir um arquivo, salvar uma determinada imagem, entre outros. Outra ferramenta útil seria a interação com o diagrama espaço-tempo com o propósito de se obter os parâmetros de tráfego em tempo de execução.

Quanto aos métodos de segmentação, sugere-se investigar em detalhes os descritores de texturas, visto que o LFP apresentou a maior taxa VP, acertos dos objetos. O LFP é um descritor recente na literatura, ainda em fase de exploração, e traz uma característica muito peculiar de generalizar os outros descritores a partir de diferentes funções objetivo. Esta característica de ser modelável a cada propósito traz grandes benefícios, uma vez que, com um único descritor, pode ser possível extrair diferentes características da imagem. Além da função objetivo, os parâmetros das funções LFP devem ser calibrados para o propósito do descritor.

Outra sugestão é melhorar o processo de construção da trajetória do veículo no diagrama, para evitar que veículos sejam contados em duplicidade ou perdidos. Por Recomenda-se também testar o sistema em mais vídeos em diferentes condições: de iluminação (dia e noite), climáticas (sol, nublado, chuvoso) e de tráfego veicular (livre e congestionado) com o objetivo de avaliar a robustez do sistema em qualquer situação. Por fim, nos vídeos avaliados nesta pesquisa o tráfego de veículo estava em direção à câmera, deste modo sugere-se avaliar o desempenho do método em vídeos com sentido contrário. 


\section{APÊNDICE A TABELA de Resultados}

Esta seção apresenta os resultados da comparação entre as velocidades obtidas pelo sistema automático proposto e as velocidades obtidas pelo radar móvel. No total, 126 veículos foram detectados, sendo identificados 120 no sistema proposto (95,2\%), ou seja, uma perda de $4,8 \%$ dos veículos observados.

Tabela A.1. Comparativo entre velocidades do radar e do sistema obtido por imagem

\begin{tabular}{|c|c|c|c|c|c|c|c|c|}
\hline \multirow[b]{2}{*}{ ID } & \multirow[b]{2}{*}{ Veiculo } & \multirow[b]{2}{*}{ Faixa } & \multirow[b]{2}{*}{ Tempo } & \multirow[b]{2}{*}{ Frame } & \multicolumn{2}{|c|}{ Velocidade $[\mathrm{km} / \mathrm{h}]$} & \multirow{2}{*}{$\begin{array}{l}\text { Erro } \\
\text { (\%) }\end{array}$} & \multirow{2}{*}{$\begin{array}{l}\text { Acerto } \\
(\%)\end{array}$} \\
\hline & & & & & Radar & Imagem & & \\
\hline 1 & Del Rey Branco & 1 & $00: 15$ & 450 & 76,00 & 75,87 & $0,2 \%$ & $99,8 \%$ \\
\hline 2 & Mondeo Preto & 2 & $00: 30$ & 910 & 117,00 & 106,62 & $8,9 \%$ & $91,1 \%$ \\
\hline 3 & Vectra Preto & 1 & $00: 43$ & 1304 & 90,00 & 80,36 & $10,7 \%$ & $89,3 \%$ \\
\hline 4 & Caminhão MB 1113 Verde Claro & 1 & 00:49 & 1480 & 92,00 & 101,88 & $10,7 \%$ & $89,3 \%$ \\
\hline 5 & Fit Preto & 2 & $01: 13$ & 2196 & 109,00 & 103,68 & $4,9 \%$ & $95,1 \%$ \\
\hline 6 & Caminhão MB 1113 Laranja & 1 & 01:24 & 2519 & 91,00 & 102,24 & $12,4 \%$ & $87,6 \%$ \\
\hline 7 & Golf Vinho & 2 & 01:30 & 2713 & 85,00 & 88,20 & $3,8 \%$ & $96,2 \%$ \\
\hline 8 & Caminhão MB 1113 Azul Claro & 1 & 01:32 & 2760 & 80,00 & 61,85 & $22,7 \%$ & $77,3 \%$ \\
\hline 9 & Palio Preto & 1 & 01:36 & 2880 & 86,00 & - & & \\
\hline 10 & Fiorino Azul Escuro & 1 & 01:39 & 2970 & 81,00 & 75,87 & $6,3 \%$ & $93,7 \%$ \\
\hline 11 & S-10 Preto & 2 & 01:50 & 3300 & 97,00 & 96,43 & $0,6 \%$ & $99,4 \%$ \\
\hline 12 & Caminhão MB Azul & 2 & $01: 55$ & 3460 & 102,00 & 106,62 & $4,5 \%$ & $95,5 \%$ \\
\hline 13 & Caminhão MB 1113 Azul Claro & 1 & 01:59 & 3580 & 78,00 & 79,80 & $2,3 \%$ & $97,7 \%$ \\
\hline 14 & Strada Preto & 2 & $02: 07$ & 3815 & 91,00 & 92,74 & $1,9 \%$ & $98,1 \%$ \\
\hline 15 & Gol Branco & 2 & $02: 08$ & 3845 & 94,00 & 92,74 & $1,3 \%$ & $98,7 \%$ \\
\hline 16 & Caminhão VW Branco & 2 & $02: 13$ & 3994 & 97,00 & 92,74 & $4,4 \%$ & $95,6 \%$ \\
\hline 17 & Caminhão MB Branco & 1 & $02: 27$ & 4410 & 89,00 & 107,52 & $20,8 \%$ & $79,2 \%$ \\
\hline 18 & Ipanema Preto & 2 & $02: 31$ & 4535 & 93,00 & 94,08 & $1,2 \%$ & $98,8 \%$ \\
\hline 19 & Caminhão Vermelho & 1 & $02: 31$ & 4535 & 93,00 & 90,09 & $3,1 \%$ & $96,9 \%$ \\
\hline 20 & Eco Esport Preto & 1 & $02: 38$ & 4742 & 108,00 & 102,24 & $5,3 \%$ & $94,7 \%$ \\
\hline 21 & C3 Preto & 1 & $02: 45$ & 4960 & 90,00 & 96,84 & $7,6 \%$ & $92,4 \%$ \\
\hline 22 & Caminhão MB Branco & 1 & $02: 49$ & 5071 & 88,00 & 95,09 & $8,1 \%$ & $91,9 \%$ \\
\hline 23 & Caminhão GMC Branco & 1 & $02: 59$ & 5366 & 92,00 & 98,70 & $7,3 \%$ & $92,7 \%$ \\
\hline 24 & Gol Branco & 1 & 03:18 & 5946 & 79,00 & 75,60 & $4,3 \%$ & $95,7 \%$ \\
\hline 25 & Fit Prata & 1 & $03: 28$ & 6245 & 89,00 & 78,96 & $11,3 \%$ & $88,7 \%$ \\
\hline 26 & Fiorino Branco & 1 & 03:29 & 6265 & 82,00 & - & & \\
\hline 27 & Belina Prata / Azul & 1 & 03:45 & 6752 & 120,00 & 90,09 & $24,9 \%$ & $75,1 \%$ \\
\hline 28 & S-10 Prata & 1 & 03:48 & 6838 & 90,00 & 90,09 & $0,1 \%$ & $99,9 \%$ \\
\hline 29 & Fusca Branco & 1 & 03:53 & 6992 & 85,00 & 90,41 & $6,4 \%$ & $93,6 \%$ \\
\hline 30 & Corsa Preto & 1 & 03:59 & 7168 & 80,00 & 72,24 & $9,7 \%$ & $90,3 \%$ \\
\hline 31 & Monza Vermelho & 1 & 04:07 & 7407 & 89,00 & 84,49 & $5,1 \%$ & $94,9 \%$ \\
\hline 32 & Gol Branco & 1 & 04:10 & 7500 & 83,00 & 80,08 & $3,5 \%$ & $96,5 \%$ \\
\hline 33 & Gol Vermelho & 1 & $04: 15$ & 7645 & 96,00 & 84,49 & $12,0 \%$ & $88,0 \%$ \\
\hline 34 & Megane Prata / Dourado & 1 & $04: 18$ & 7741 & 85,00 & 71,82 & $15,5 \%$ & $84,5 \%$ \\
\hline 35 & Ônibus Branco & 1 & 04:27 & 8004 & 88,00 & 96,48 & $9,6 \%$ & $90,4 \%$ \\
\hline 36 & Celta Prata & 1 & 04:33 & 8194 & 104,00 & 84,79 & $18,5 \%$ & $81,5 \%$ \\
\hline 37 & Strada Branco & 1 & 04:46 & 8582 & 86,00 & 65,06 & $24,3 \%$ & $75,7 \%$ \\
\hline 38 & Caminhão MB 1113 Azul & 1 & $04: 50$ & 8700 & 87,00 & - & & \\
\hline 39 & Parati Prata & 1 & 04:54 & 8820 & 85,00 & 79,80 & $6,1 \%$ & $93,9 \%$ \\
\hline 40 & Sprinter Branco & 1 & 05:07 & 9204 & 94,00 & 101,88 & $8,4 \%$ & $91,6 \%$ \\
\hline
\end{tabular}




\begin{tabular}{|c|c|c|c|c|c|c|c|c|}
\hline \multirow[b]{2}{*}{ ID } & \multirow[b]{2}{*}{ Veiculo } & \multirow[b]{2}{*}{ Faixa } & \multirow[b]{2}{*}{ Tempo } & \multirow[b]{2}{*}{ Frame } & \multicolumn{2}{|c|}{ Velocidade $[\mathrm{km} / \mathrm{h}]$} & \multirow{2}{*}{$\begin{array}{l}\text { Erro } \\
\text { (\%) }\end{array}$} & \multirow{2}{*}{$\begin{array}{l}\text { Acerto } \\
\text { (\%) }\end{array}$} \\
\hline & & & & & Radar & Imagem & & \\
\hline 41 & Caminhão Azul & 1 & $05: 30$ & 9900 & 61,00 & 78,75 & $29,1 \%$ & $70,9 \%$ \\
\hline 42 & Caminhonete Branco & 1 & $05: 38$ & 10132 & 91,00 & 89,78 & $1,3 \%$ & $98,7 \%$ \\
\hline 43 & Gol Preto & 1 & $05: 45$ & 10353 & 93,00 & 89,78 & $3,5 \%$ & $96,5 \%$ \\
\hline 44 & Palio Branco & 1 & $05: 48$ & 10455 & 104,00 & 95,42 & $8,2 \%$ & $91,8 \%$ \\
\hline 45 & Caminhão Ford Azul & 1 & 06:05 & 10952 & 78,00 & 75,87 & $2,7 \%$ & $97,3 \%$ \\
\hline 46 & Gol Branco & 1 & 06:08 & 11039 & 74,00 & 75,60 & $2,2 \%$ & $97,8 \%$ \\
\hline 47 & Corsa Sedan Preto & 1 & $06: 23$ & 11490 & 88,00 & 84,79 & $3,6 \%$ & $96,4 \%$ \\
\hline 48 & Caminhão MB Branco & 1 & $06: 30$ & 11704 & 79,00 & 79,80 & $1,0 \%$ & $99,0 \%$ \\
\hline 49 & Uno Branco & 1 & 07:06 & 12769 & 84,00 & 88,20 & $5,0 \%$ & $95,0 \%$ \\
\hline 50 & Moto & 1 & $07: 18$ & 13127 & 87,00 & 84,79 & $2,5 \%$ & $97,5 \%$ \\
\hline 51 & Courier Branco & 1 & $07: 27$ & 13398 & 86,00 & 79,80 & $7,2 \%$ & $92,8 \%$ \\
\hline 52 & Del Rey Vinho & 1 & 08:02 & 14446 & 90,00 & 89,46 & $0,6 \%$ & $99,4 \%$ \\
\hline 53 & Kombi Branco & 1 & 08:04 & 14513 & 89,00 & 89,46 & $0,5 \%$ & $99,5 \%$ \\
\hline 54 & Caminhão MB 1113 Branco & 1 & 08:09 & 14658 & 92,00 & 94,42 & $2,6 \%$ & $97,4 \%$ \\
\hline 55 & Golf Vermelho & 1 & $08: 15$ & 14836 & 94,00 & 90,41 & $3,8 \%$ & $96,2 \%$ \\
\hline 56 & Corolla Preto & 2 & 08:21 & 15015 & 115,00 & 109,72 & $4,6 \%$ & $95,4 \%$ \\
\hline 57 & Caminhão Branco & 1 & $08: 35$ & 15436 & 74,00 & 62,37 & $15,7 \%$ & $84,3 \%$ \\
\hline 58 & Stilo Preto & 1 & $08: 38$ & 15525 & 84,00 & 87,36 & $4,0 \%$ & $96,0 \%$ \\
\hline 59 & Caminhão MB 1113 Amarelo & 1 & $08: 48$ & 15825 & 85,00 & 84,49 & $0,6 \%$ & $99,4 \%$ \\
\hline 60 & Quantum Branco & 2 & $08: 55$ & 16034 & 110,00 & 103,68 & $5,7 \%$ & $94,3 \%$ \\
\hline 61 & Parati Prata & 2 & $08: 58$ & 16124 & 93,00 & 96,77 & $4,1 \%$ & $95,9 \%$ \\
\hline 62 & Caminhão Amarelo / Branco & 1 & 09:06 & 16364 & 91,00 & 95,42 & $4,9 \%$ & $95,1 \%$ \\
\hline 63 & Caminhão Branco & 1 & 09:08 & 16435 & 90,00 & 94,75 & $5,3 \%$ & $94,7 \%$ \\
\hline 64 & Polo Sedan Preto & 2 & $09: 28$ & 17023 & 107,00 & 96,43 & $9,9 \%$ & $90,1 \%$ \\
\hline 65 & Focus Prata & 2 & 09:44 & 17503 & 111,00 & 109,72 & $1,2 \%$ & $98,8 \%$ \\
\hline 66 & Palio Branco & 1 & 09:58 & 17923 & 97,00 & 95,76 & $1,3 \%$ & $98,7 \%$ \\
\hline 67 & Caminhão Scania Preto / Branco & 1 & $10: 15$ & 18432 & 75,00 & 84,20 & $12,3 \%$ & $87,7 \%$ \\
\hline 68 & Caminhão Volvo Branco & 1 & $10: 20$ & 18582 & 89,00 & 98,47 & $10,6 \%$ & $89,4 \%$ \\
\hline 69 & Ônibus Branco & 1 & $10: 26$ & 18762 & 60,00 & 59,43 & $1,0 \%$ & $99,1 \%$ \\
\hline 70 & Kombi Branco & 1 & $10: 32$ & 18942 & 88,00 & 89,46 & $1,7 \%$ & $98,3 \%$ \\
\hline 71 & KA Vermelho & 1 & $10: 44$ & 19301 & 56,00 & 53,01 & $5,3 \%$ & $94,7 \%$ \\
\hline 72 & Caminhão Volvo Branco & 1 & $10: 49$ & 19451 & 86,00 & 96,77 & $12,5 \%$ & $87,5 \%$ \\
\hline 73 & Gol Prata & 1 & $11: 04$ & 19908 & 97,00 & 93,74 & $3,4 \%$ & $96,6 \%$ \\
\hline 74 & Fiorino Branco & 1 & $11: 06$ & 19965 & 100,00 & 95,76 & $4,2 \%$ & $95,8 \%$ \\
\hline 75 & Caminhão Ford Vermelho & 1 & 11:11 & 20110 & 78,00 & 75,60 & $3,1 \%$ & $96,9 \%$ \\
\hline 76 & Parati Preto & 1 & $11: 15$ & 20230 & 87,00 & 83,52 & $4,0 \%$ & $96,0 \%$ \\
\hline 77 & Caminhão Branco & 1 & $11: 23$ & 20470 & 80,00 & 75,33 & $5,8 \%$ & $94,2 \%$ \\
\hline 78 & F-1000 Amarelo & 1 & $11: 32$ & 20740 & 95,00 & 80,36 & $15,4 \%$ & $84,6 \%$ \\
\hline 79 & Caminhão Vermelho & 1 & $11: 40$ & 20981 & 88,00 & 86,46 & $1,8 \%$ & $98,2 \%$ \\
\hline 80 & Saveiro Branco & 1 & $11: 53$ & 21369 & 88,00 & 83,48 & $5,1 \%$ & $94,9 \%$ \\
\hline 81 & D-20 Branco & 1 & $12: 35$ & 22628 & 86,00 & 84,79 & $1,4 \%$ & $98,6 \%$ \\
\hline 82 & Gol Branco & 1 & $12: 40$ & 22780 & 94,00 & 90,09 & $4,2 \%$ & $95,8 \%$ \\
\hline 83 & F-250 Preto & 1 & $12: 43$ & 22868 & 101,00 & 102,60 & $1,6 \%$ & $98,4 \%$ \\
\hline 84 & Del Rey Prata & 1 & $12: 47$ & 22988 & 97,00 & 102,96 & $6,1 \%$ & $93,9 \%$ \\
\hline 85 & Gol Preto & 2 & 13:04 & 23501 & 86,00 & 85,38 & $0,7 \%$ & $99,3 \%$ \\
\hline 86 & Parati Prata & 2 & $13: 26$ & 24156 & 100,00 & 94,42 & $5,6 \%$ & $94,4 \%$ \\
\hline 87 & Caminhão Vermelho & 1 & 13:41 & 24606 & 82,00 & 89,71 & $9,4 \%$ & $90,6 \%$ \\
\hline 88 & Gol Azul & 1 & $13: 49$ & 24846 & 106,00 & 90,09 & $15,0 \%$ & $85,0 \%$ \\
\hline 89 & Saveiro Branco & 1 & $13: 54$ & 24995 & 96,00 & 96,10 & $0,1 \%$ & $99,9 \%$ \\
\hline 90 & Sprinter Branco & 1 & $13: 57$ & 25086 & 101,00 & 95,09 & $5,9 \%$ & $94,1 \%$ \\
\hline 91 & C4 Preto & 2 & $14: 01$ & 25208 & 99,00 & 94,75 & $4,3 \%$ & $95,7 \%$ \\
\hline 92 & Del Rey Prata & 1 & $14: 04$ & 25295 & 96,00 & 95,76 & $0,2 \%$ & $99,8 \%$ \\
\hline 93 & S-10 Branco & 1 & $14: 05$ & 25325 & 92,00 & 95,76 & $4,1 \%$ & $95,9 \%$ \\
\hline 94 & Caminhão Branco & 1 & $14: 06$ & 25356 & 92,00 & 66,58 & $27,6 \%$ & $72,4 \%$ \\
\hline 95 & Celta Vermelho & 1 & $14: 10$ & 25480 & 83,00 & 79,80 & $3,9 \%$ & $96,1 \%$ \\
\hline
\end{tabular}




\begin{tabular}{|c|c|c|c|c|c|c|c|c|}
\hline \multirow[b]{2}{*}{ ID } & \multirow[b]{2}{*}{ Veiculo } & \multirow[b]{2}{*}{ Faixa } & \multirow[b]{2}{*}{ Tempo } & \multirow[b]{2}{*}{ Frame } & \multicolumn{2}{|c|}{ Velocidade $[\mathrm{km} / \mathrm{h}]$} & \multirow{2}{*}{$\begin{array}{l}\text { Erro } \\
\text { (\%) }\end{array}$} & \multirow{2}{*}{$\begin{array}{l}\text { Acerto } \\
\text { (\%) }\end{array}$} \\
\hline & & & & & Radar & Imagem & & \\
\hline 96 & Tipo Preto & 1 & $14: 12$ & 25544 & 81,00 & 79,24 & $2,2 \%$ & $97,8 \%$ \\
\hline 97 & Fiesta Prata / Laranja & 1 & $14: 14$ & 25595 & 81,00 & 79,24 & $2,2 \%$ & $97,8 \%$ \\
\hline 98 & Gol Branco & 1 & $14: 17$ & 25686 & 92,00 & 81,48 & $11,4 \%$ & $88,6 \%$ \\
\hline 99 & Caminhão Vinho & 1 & $14: 29$ & 26045 & 67,00 & 72,66 & $8,4 \%$ & $91,6 \%$ \\
\hline 100 & Caminhão Scania Azul & 2 & $14: 36$ & 26257 & 102,00 & 107,39 & $5,3 \%$ & $94,7 \%$ \\
\hline 101 & Caminhonete Branco & 1 & $14: 47$ & 26584 & 91,00 & 84,56 & $7,1 \%$ & $92,9 \%$ \\
\hline 102 & Caminhão MB Azul / Branco & 1 & $14: 48$ & 26617 & 104,00 & - & & \\
\hline 103 & Ônibus Branco & 1 & $15: 10$ & 27283 & 64,00 & 76,52 & $19,6 \%$ & $80,4 \%$ \\
\hline 104 & Caminhão Scania Preto & 1 & $15: 13$ & 27371 & 84,00 & 89,78 & $6,9 \%$ & $93,1 \%$ \\
\hline 105 & Palio Preto & 1 & $15: 27$ & 27794 & 95,00 & 89,78 & $5,5 \%$ & $94,5 \%$ \\
\hline 106 & Ônibus Branco & 1 & $15: 31$ & 27909 & 91,00 & 99,43 & $9,3 \%$ & $90,7 \%$ \\
\hline 107 & Caminhão Branco & 1 & $15: 37$ & 28083 & 85,00 & 95,09 & $11,9 \%$ & $88,1 \%$ \\
\hline 108 & Kombi Branco & 1 & $15: 44$ & 28300 & 98,00 & 107,10 & $9,3 \%$ & $90,7 \%$ \\
\hline 109 & Eco Esport Prata & 1 & $15: 46$ & 28360 & 94,00 & 85,68 & $8,9 \%$ & $91,1 \%$ \\
\hline 110 & Civic Dourado & 2 & $15: 54$ & 28593 & 80,00 & 77,84 & $2,7 \%$ & $97,3 \%$ \\
\hline 111 & Caminhão Azul / Amarelo & 1 & $16: 03$ & 28862 & 98,00 & 95,76 & $2,3 \%$ & $97,7 \%$ \\
\hline 112 & Caminhão MB 1113 Azul / Branco & 1 & $16: 07$ & 28982 & 96,00 & 75,60 & $21,3 \%$ & $78,8 \%$ \\
\hline 113 & Ônibus Branco & 1 & $16: 10$ & 29071 & 73,00 & 70,31 & $3,7 \%$ & $96,3 \%$ \\
\hline 114 & Caminhão MB 1113 Azul & 2 & $16: 13$ & 29171 & 72,00 & 89,15 & $23,8 \%$ & $76,2 \%$ \\
\hline 115 & Vectra Branco & 1 & $16: 23$ & 29462 & 63,00 & 66,00 & $4,8 \%$ & $95,2 \%$ \\
\hline 116 & Caminhão Ford Branco & 1 & $16: 35$ & 29822 & 80,00 & 89,78 & $12,2 \%$ & $87,8 \%$ \\
\hline 117 & Caminhão Branco & 1 & $17: 40$ & 29972 & 82,00 & 95,09 & $16,0 \%$ & $84,0 \%$ \\
\hline 118 & Fox Prata & 1 & $17: 15$ & 31035 & 84,00 & 75,60 & $10,0 \%$ & $90,0 \%$ \\
\hline 119 & Caminhão Branco & 1 & $17: 20$ & 31170 & 60,00 & 59,43 & $1,0 \%$ & $99,1 \%$ \\
\hline 120 & Caminhão Branco & 1 & $17: 34$ & 31589 & 88,00 & 89,46 & $1,7 \%$ & $98,3 \%$ \\
\hline 121 & Caminhão Azul & 1 & $17: 38$ & 31717 & 106,00 & 111,72 & $5,4 \%$ & $94,6 \%$ \\
\hline 122 & Caminhão MB 1113 Azul & 1 & $17: 51$ & 32098 & 88,00 & 100,44 & $14,1 \%$ & $85,9 \%$ \\
\hline 123 & Monza Vinho & 1 & $17: 54$ & 32189 & 96,00 & 75,33 & $21,5 \%$ & $78,5 \%$ \\
\hline 124 & Caminhão MB Branco & 1 & $17: 58$ & 32319 & 91,00 & 102,24 & $12,4 \%$ & $87,6 \%$ \\
\hline 125 & Courier Branco & 1 & 18:05 & 32528 & 88,00 & - & & \\
\hline 126 & Corsa Branco & 1 & 18:11 & 32698 & 72,00 & - & & \\
\hline & & & & Média: & 89,0 & 87,9 & $7,3 \%$ & $92,7 \%$ \\
\hline & & & & Mínimo: & 56,0 & 53,0 & $0,1 \%$ & $70,9 \%$ \\
\hline & & & & Máximo: & 120,0 & 111,7 & $29,1 \%$ & $99,9 \%$ \\
\hline
\end{tabular}




\section{APÊNDICE B BIBLIOTECA OPENCV}

O OpenCV (Open Source Computer Vision Library) é uma biblioteca de visão computacional e aprendizado de máquinas com código aberto. O OpenCV foi desenvolvido para fornecer uma infraestrutura comum em aplicações de visão computacional e acelerar o uso de aprendizado de máquinas no desenvolvimento de sistemas automáticos.

\section{B.1 INSTALAÇÃO}

Nesta seção, é apresentada a instalação utilizando Microsoft Visual Studio 2012 em ambiente Windows. Nesta pesquisa, foram utilizadas as versões mais recentes da biblioteca OpenCV e, neste tutorial, a versão 2.4.6.0 de julho de 2013 foi usada. O arquivo OpenCV2.4.6.0.exe da biblioteca pode ser obtido no endereço: http://sourceforge.net/projects/opencv library/files/opencv-win/2.4.6/. A instalação pode ser feita de dois modos: utilizando os arquivos pré-compilados ou compilando os arquivos da biblioteca.

\section{B.1.1 Usando arquivos pré-compilados}

Esta instalação é a mais simples e a mais rápida de ser executada. Seguem os passos:

- Descompactar o arquivo OpenCV-2.4.6.0.exe em uma pasta, por exemplo c: \Opencv. Diversas pastas constam neste pacote;

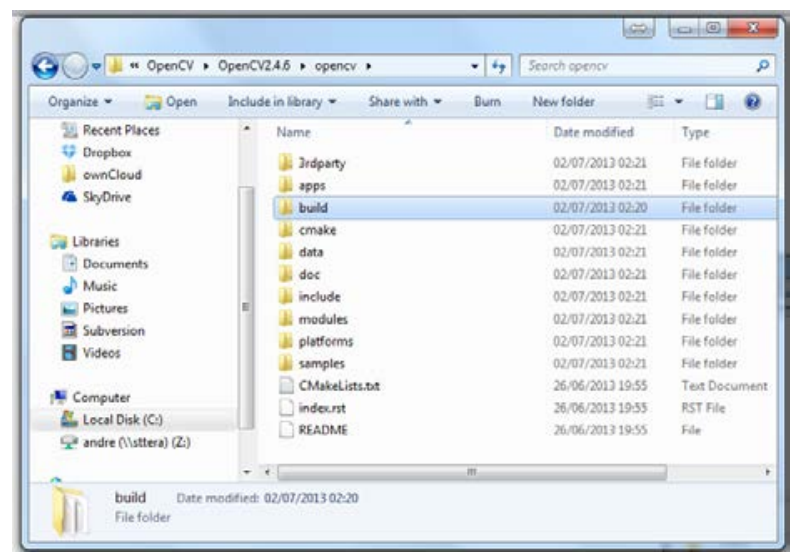

- A pasta build contém: a pasta docs com a documentação da biblioteca OpenCV; a pasta include com os códigos fontes; e as pastas java, pynthon, 
x64 e x32 contendo os arquivos já compiladas em seus respectivos compiladores. As pastas x64 e x32 contêm os arquivos para o Visual Studio;

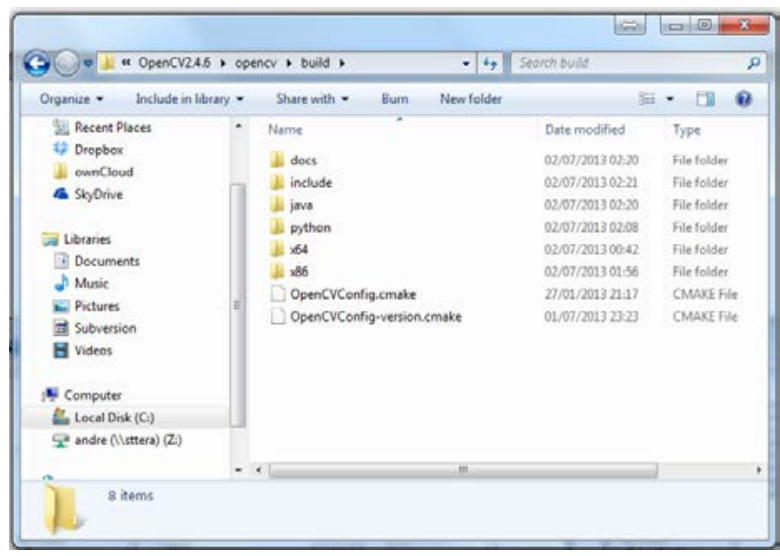

- Registrar o OpenCV nas variáveis de ambiente do computador. Esta configuração encontra-se em Painel de Controle, depois em Sistema e Editar as variáveis do sistema. No path deve ser inserido o caminho dos arquivos binários da biblioteca OpenCV. Como foi utilizada a versão 64 bits do Visual Studio 2012 (versão de número 11.0), o caminho da pasta dos arquivos

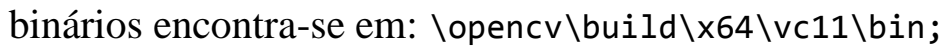

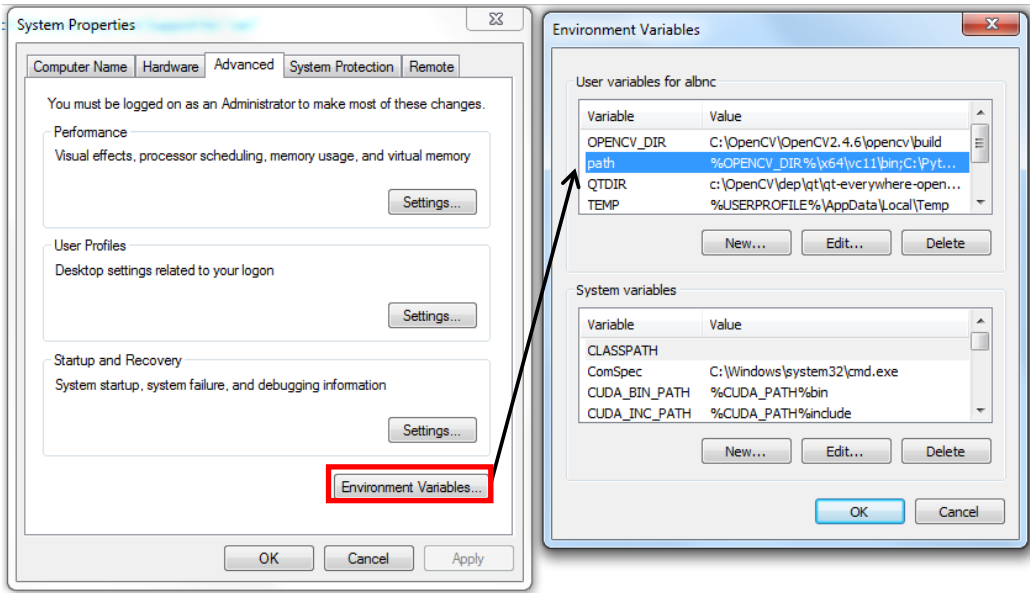

- Agora as configurações dos projetos no Visual Studio. Para configurar uma única vez, abra um novo projeto e clique em View e depois em Property Manager. Selecione o modo de operação Debug e o compilador, neste caso 64 bits, clique com o botão direito do mouse e escolha Add New Project Properties Sheet. 


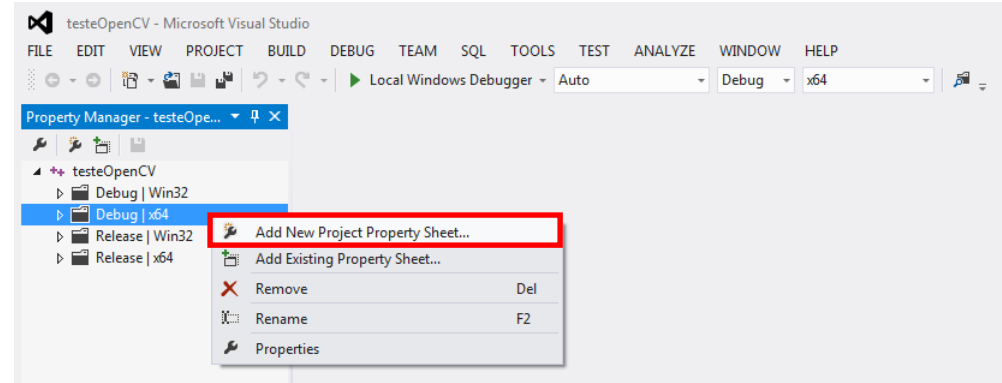

- Dê um nome a essa configuração, por exemplo: OpencvDebug. Nos próximos projetos, basta carregar este arquivo para incorporar essas propriedades. Em seguida, clique com o botão direito no nome criado e escolha Proprierties;

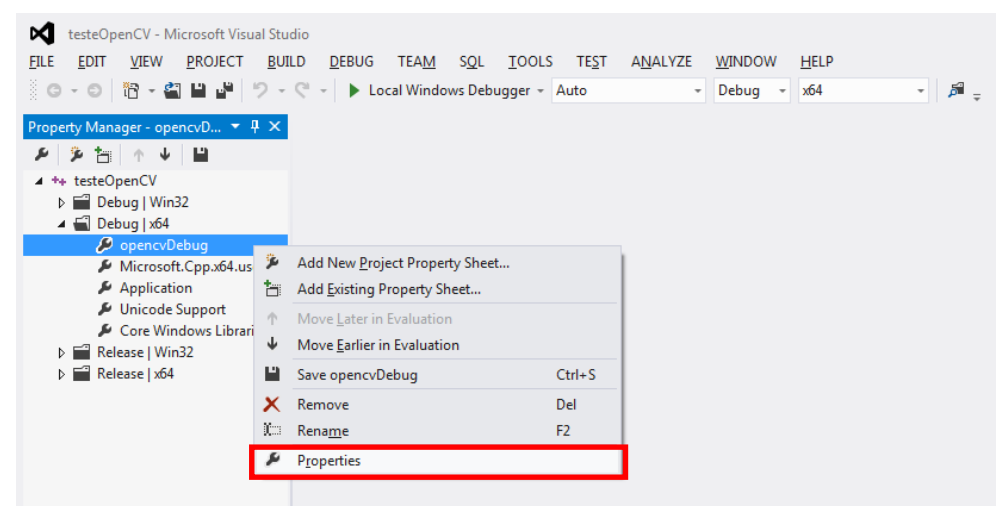

- Ao lado esquerdo, escolha a opção $V C++$ Directories. Em Include Directories coloque o caminho dos cabeçalhos dos códigos fontes, são dois

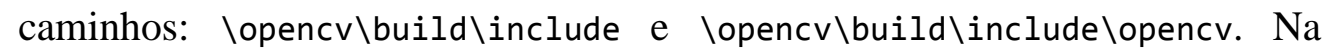
opção Library Directories insira o caminho das bibliotecas de funções:

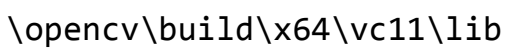

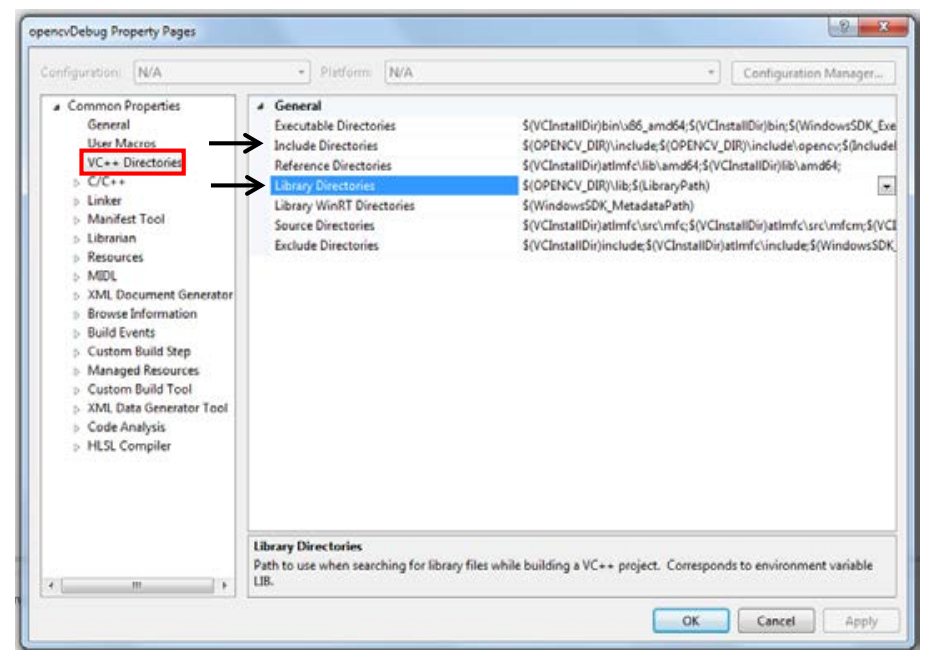

- Por fim, selecione a opção Linker e depois Input ao lado direito. Em seguida 
insira a lista de nomes das bibliotecas estática (extensão .lib) no campo Additional Dependencies: opencv_calib3d246d.lib, opencv_contrib246d.lib, opencv_core246d.lib, opencv_features2d246d.lib, opencv_flann246d.lib, opencv_gpu246d.lib, opencv_haartraining_engined.lib, opencv_highgui246d.lib, opencv_imgproc246d.lib, opencv_legacy246d.lib, opencv_ml246d.lib, opencv_nonfree246d.lib, opencv_objdetect246d.lib, opencv_ocl246d.lib, opencv_photo246d.lib, opencv_stitching246d.lib, opencv_superres246d.lib, opencv_ts246d.lib, opencv_video246d.lib, opencv_videostab246d.lib;

- Caso queira usar o modo Release, repita os passos (d) a (g), sendo que os nomes dos arquivos das bibliotecas estáticas não devem conter a letra $d$ antes da extensão .lib, ficando assim: opencv_calib3d246.lib, opencv_contrib246.lib, opencv_core246.lib, opencv_features2d246.lib, opencv_flann246.lib, opencv_gpu246.lib, opencv_haartraining_engine.lib, opencv_highgui246.lib, opencv_imgproc246.lib, opencv_legacy246.lib, opencv_ml246.lib, opencv_nonfree246.lib, opencv_objdetect246.lib, opencv_ocl246.lib, opencv_photo246.lib, opencv_stitching246.lib, opencv_superres246.lib, opencv_ts246.lib, opencv_video246.lib, opencv_videostab246.lib;

\section{B.1.2 Compilando os arquivos}

Esta instalação tem como propósito compilar os arquivos da biblioteca OpenCV no próprio computador, ajustando as configurações particulares do sistema em uso. Para realizar esta tarefa, é necessário instalar o programa $\mathrm{CMake}^{2}$, ferramenta que prepara os arquivos necessários à instalação de acordo com a configuração do sistema utilizado. Nesta instalação também é possível personalizar as bibliotecas adquirindo outros pacotes extras, tais como:

- Intel Threading Building Blocks (TBB) no uso de processadores em paralelo;

- Pynthon libraries para interface com a linguagem Pynthon;

\footnotetext{
${ }^{2}$ http://www.cmake.org/cmake/resources/software.html
} 
- Eigen biblioteca C++ de álgebra linear;

- CUDA Toolkit acelerador de desempenho de algoritmos;

- entre outros.

Esta instalação é mais demorada, entretanto, por ser compilado na própria máquina tem-se a vantagem da biblioteca ter sido gerada de forma otimizada, logo o desempenho será melhor durante a execução das funções. Seguem os passos da instalação:

a) Descompactar o arquivo OpenCV-2.4.6.0.exe em uma pasta, por exemplo C: \OpenCV.

b) Instalar o software CMake. Inicialize o CMake e indique no primeiro campo a pasta com os arquivos fontes do OpenCV e no segundo campo o caminho onde será criado as bibliotecas;

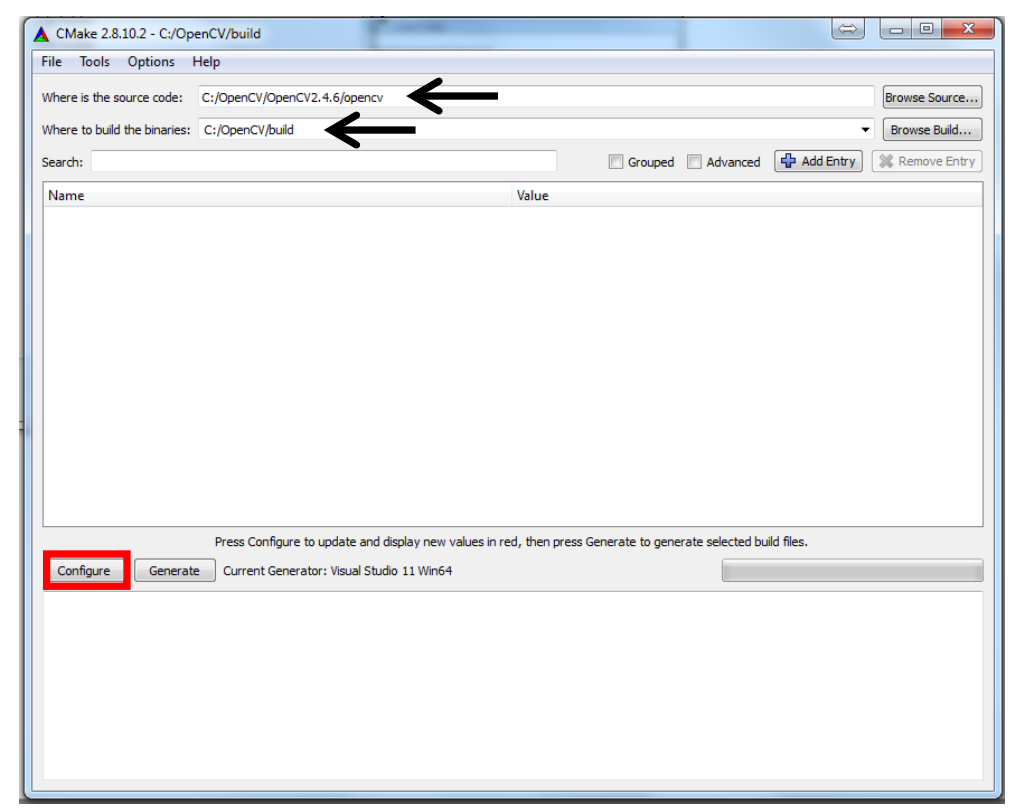

c) Pressione o botão Configure e selecione o compilador usado no computador, neste caso o Visual Studio 1164 bits. 


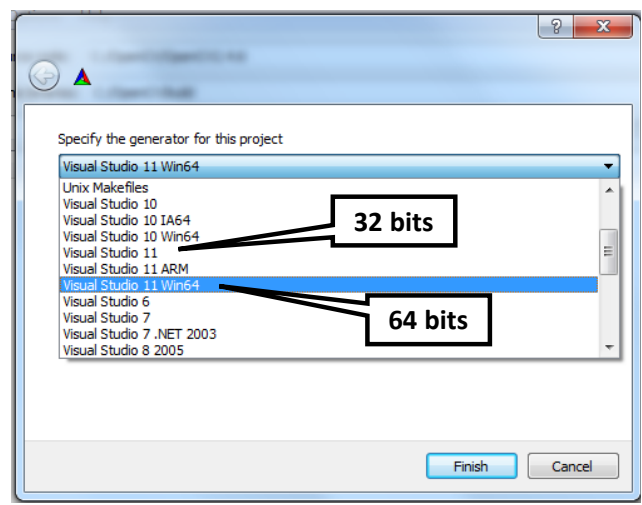

d) O CMake inicializará a verificação das variáveis do sistema do computador e localizará a maioria dos pacotes existentes. Os nomes das bibliotecas estão destacados em vermelho, pois, neste passo, é possível alterar as configurações apresentadas, marcando ou desmarcando as opções;

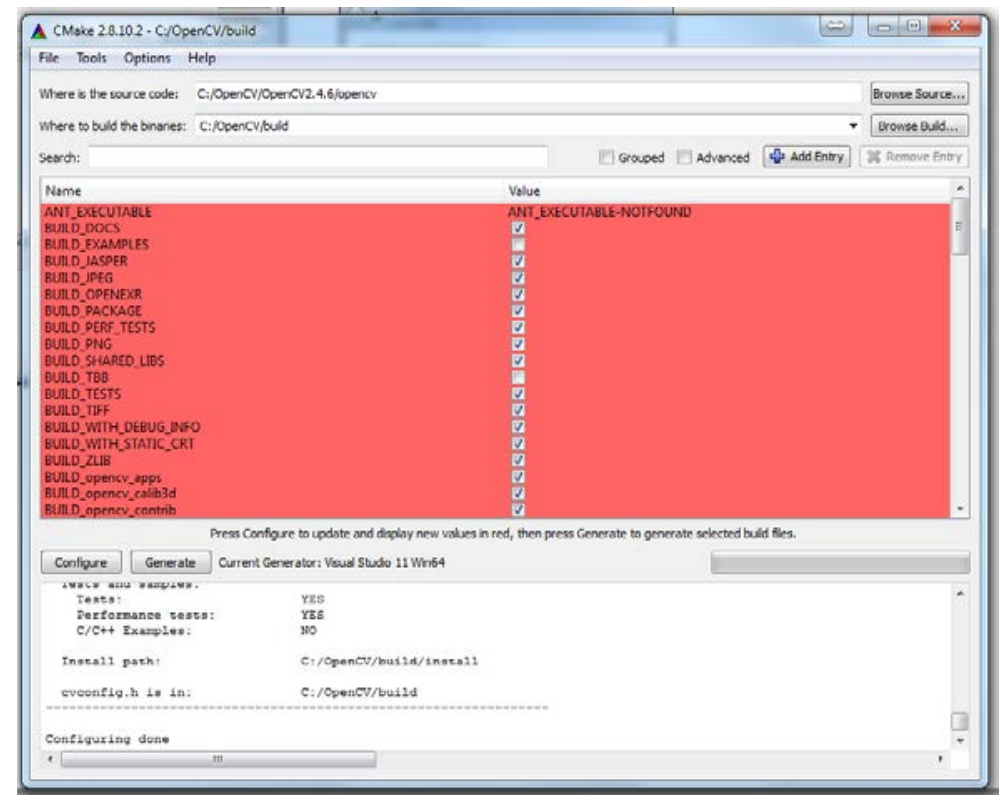

e) Mesmo que não tenha alterado item algum, pressione o botão Configure novamente até desaparecer o destaque em vermelho. Verifique também se não aparecem mensagens de erro na barra inferior. Em seguida, pressione o botão Generate e o CMake criará os arquivos com as funções da biblioteca OpenCV no caminho especificado; 


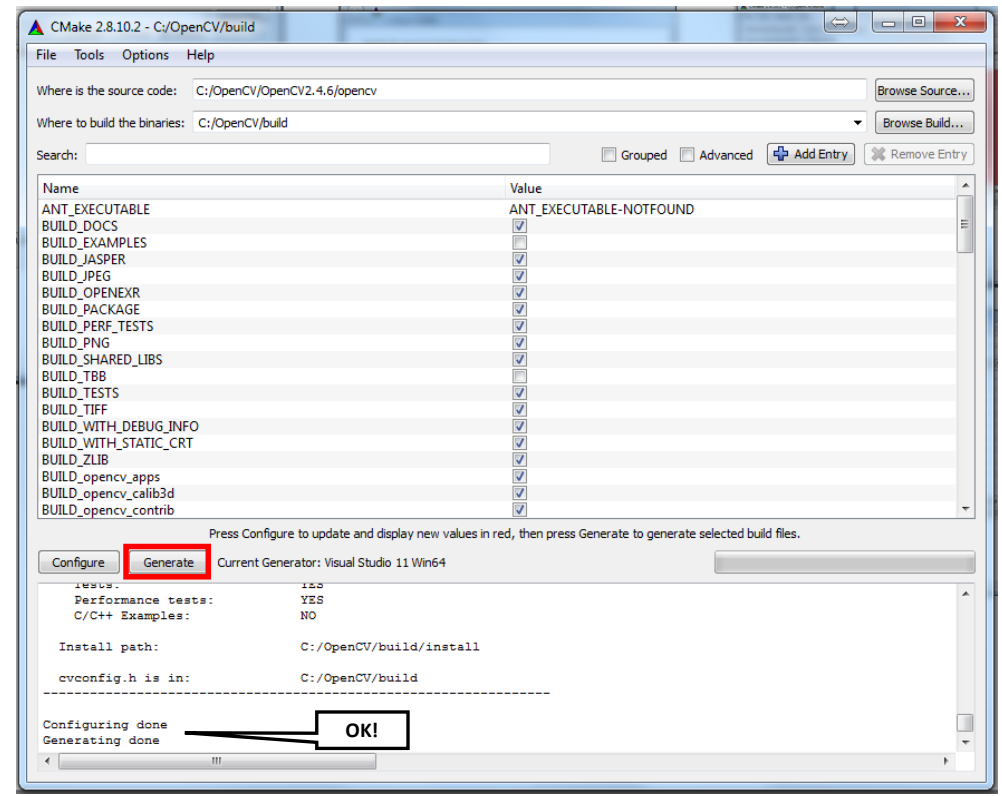

f) Feche o CMake e abra no Visual Studio o arquivo OpenCV.sln no diretório da solução gerada pelo CMake;

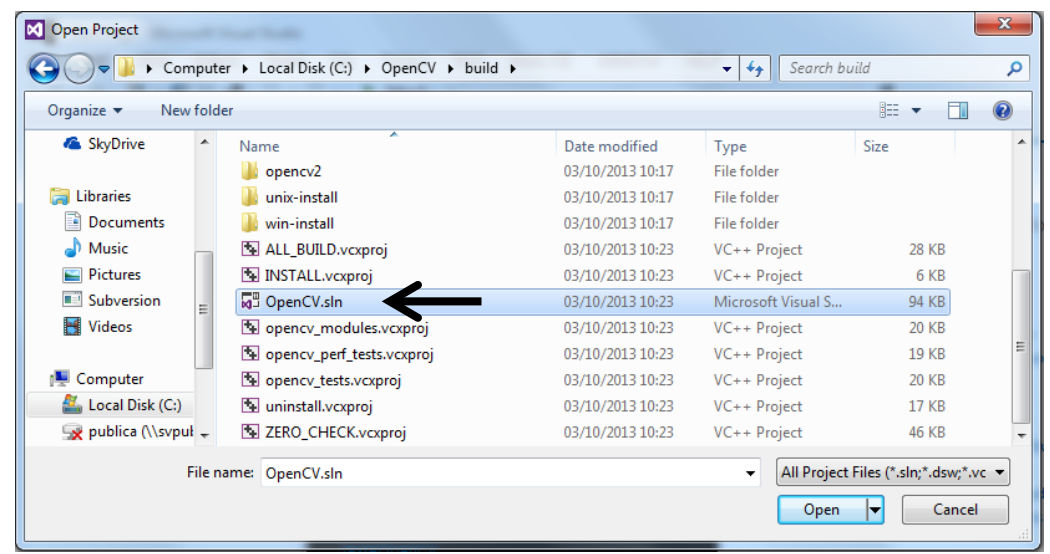

g) Execute o projeto $A L L \_B U I L D$ deste arquivo no modo Debug e Release. Esta etapa demora certo tempo para executar cada modo, pois todo o conjunto de funções e exemplos do OpenCV serão compilados;

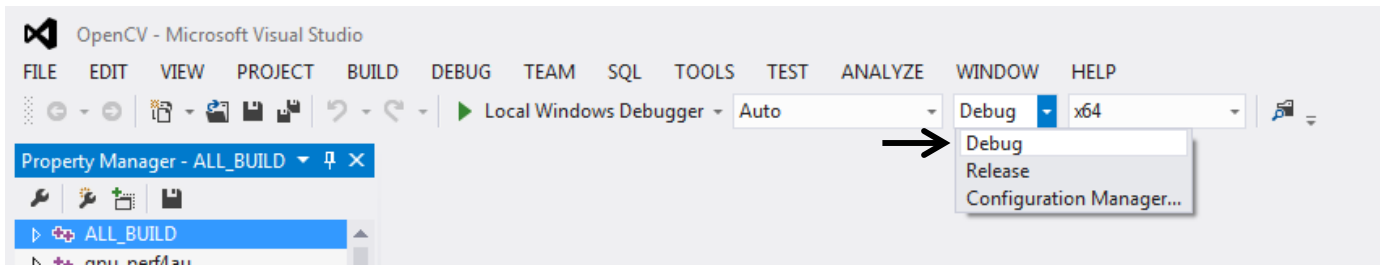

h) Por fim, os arquivos binários são gerados na pasta \bin;

i) Registar nas variáveis de ambiente do computador a pasta \bin gerada. Configurar as propriedades do projeto, atribuindo o caminho dos arquivos de 
cabeçalho \include e das bibliotecas \lib conforme os itens (f)-(h) da instalação anterior.

\section{B.2 CRIANDO FILTROS PRÓPRIOS}

A filtragem espacial é uma operação muito usada no processamento de imagens, o seu conceito envolve parametrizar cada pixel considerando as informações da sua vizinhança. Matematicamente, a filtragem espacial de uma imagem $f(x, y)$ de dimensões $M$ x $N$ por uma máscara $w(u, v)$ de dimensões $m \times n$ é dada pela expressão:

$$
g(x, y)=\sum_{u=0}^{m-1} \sum_{v=0}^{n-1} w(u, v) \cdot f\left(x+u-\frac{m}{2}, y+v-\frac{n}{2}\right)
$$

A Figura B.15 ilustra o processo da filtragem espacial utilizando uma vizinhança $3 \times 3$.

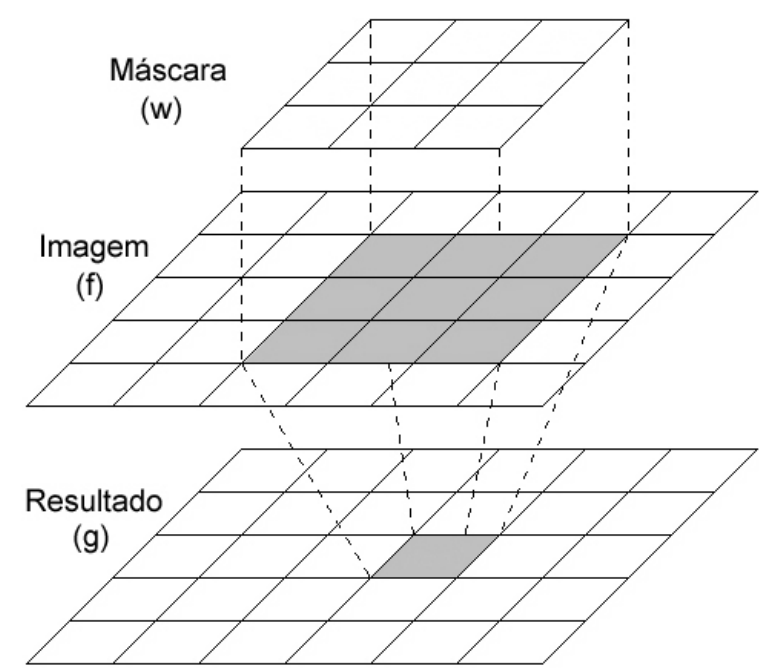

Figura B.15. Esquema ilustrativo da aplicação de filtro

O processo da filtragem é considerado linear pois envolve a multiplicação pixel a pixel da imagem pela máscara e o somatório destes produtos. A biblioteca OpenCV oferece este processamento na função $c v:$ :filter $2 D(s r c, d s t$, ddepth, kernel), sendo: src a imagem de entrada, dst a imagem resultante, ddepth a quantização da image (valores inteiros ou decimais, denominado float), e kernel a máscara $w$ (Figura B.15). Portanto, para usar a filtragem, basta definir a máscara $w$ e executar a função cv : : filter2D.

Por outro lado, quando se necessita realizar operações não-lineares, como no caso 
dos descritores de textura, é comum os usuários do OpenCV escreverem as suas próprias funções de filtro. Entretanto, o OpenCV fornece as classes Basefilter e FilterEngine que realizam este procedimento, mas é pouco explorado pelos usuários, visto que não se encontra material explicando o seu funcionamento além do manual de referência ${ }^{3}$.

Em linguagem de programação, o conceito de classe pode ser definido como uma representação concreta de um conceito [STROUSTRUP, 2000]. Uma classe tem duas principais características: herança e polimorfismo. A herança é a forma eficaz e segura de reaproveitamento de código, ou seja, é possível derivar uma classe de outra reaproveitando assim todo o código escrito e acrescentando novas características à classe derivada. Já o polimorfismo implica em múltiplas formas de uso de um mesmo recurso, isto é, uma determinada classe pode ser criada para realizar tarefas genéricas, ou apresentar uma estrutura geral, enquanto as tarefas mais específicas são realizadas funções ainda não definidas, mas pertencente à estrutura da classe para que o usuário utilize-a do seu modo [STROUSTRUP, 2000]. Em C++, o polimorfismo refere-se às funções virtuais.

Uma analogia ao conceito de classe pode ser representado pelo descritor de texturas $L F P$, visto no Capítulo 5. O LFP pode representar vários outros descritores apenas trocando a sua função objetivo, este é o fundamento do polimorfismo. Pode-se criar uma classe do LFP contendo todo o método de cálculo do descritor, desde a extração da janela, a multiplicação da máscara e etc. Já a função objetivo é definida como a função virtual e pode realizar qualquer operação definida pelo usuário. A seguir, a descrição da criação da classe $L F P$.

A classe FilterEngine é a classe base genérica que está totalmente estruturada com os procedimentos necessários para a filtragem espacial, tais como: tratamento das bordas da imagem e a extração da vizinhança de cada pixel. A classe Basefilter é uma classe derivada da FilterEngine e traz a função virtual a ser definida pelo usuário. A estrutura da classe Basefilter é dada por:

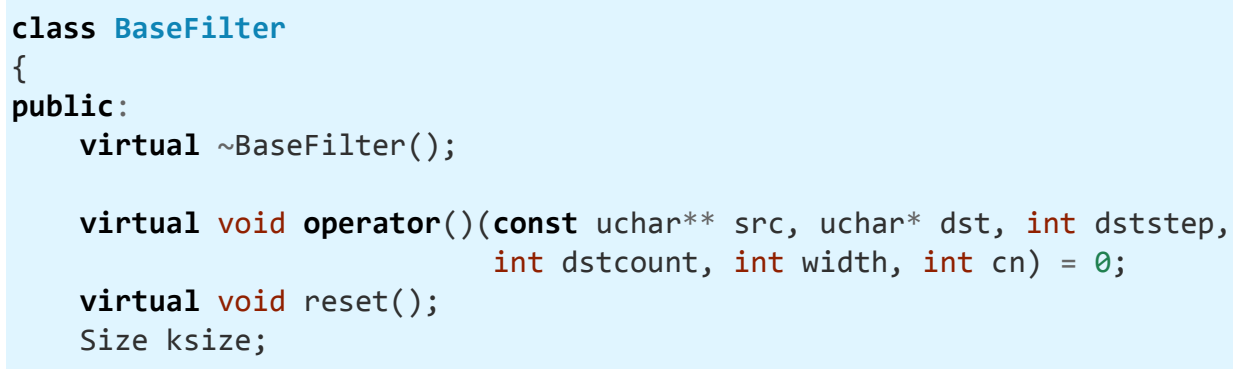

${ }^{3}$ http://docs.opencv.org/modules/imgproc/doc/filtering.html?highlight=basefilter\#BaseFilter 
Point anchor;

\} ;

Sendo operator() a função virtual a ser definida pelo usuário; a variável ksize armazena a largura e altura da máscara; e anchor é uma variável do tipo ponto que armazena o centro da máscara, o valor padrão é o centro da máscara. O ponto chave desta classe está na coordenada dos pixels da imagem de entrada (variável src), que são dadas por:

int row_src $=$ dstcount + ksize.height -1 ;

int col_src $=($ width + ksize.width -1$) * c n$;

A seguir é apresentada a classe criada para realizar as operações dos descritores de texturas, definido como a classe MicroPatternFilter. Verificou-se que o uso da classe genérica Basefilter como descritor de textura reduziu cerca de 30\% o tempo de processamento comparando com a mesma função sem o uso da classe genérica. 
O arquivo de declaração micropatternfilter.h (conhecido como header em $\mathrm{C}++$ ), é assim estruturado:

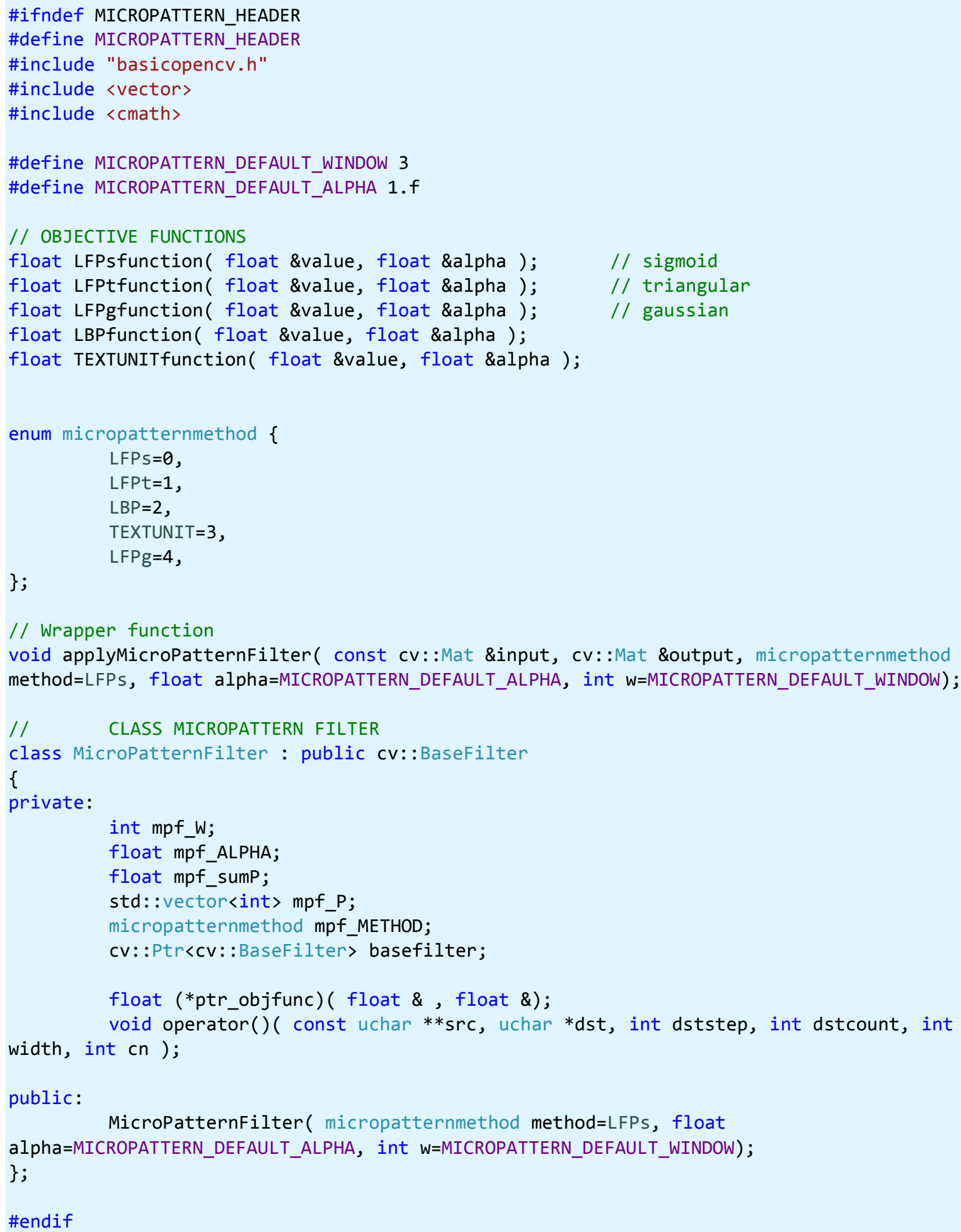




\section{O arquivo de definição micropatternfilter.cpp:}

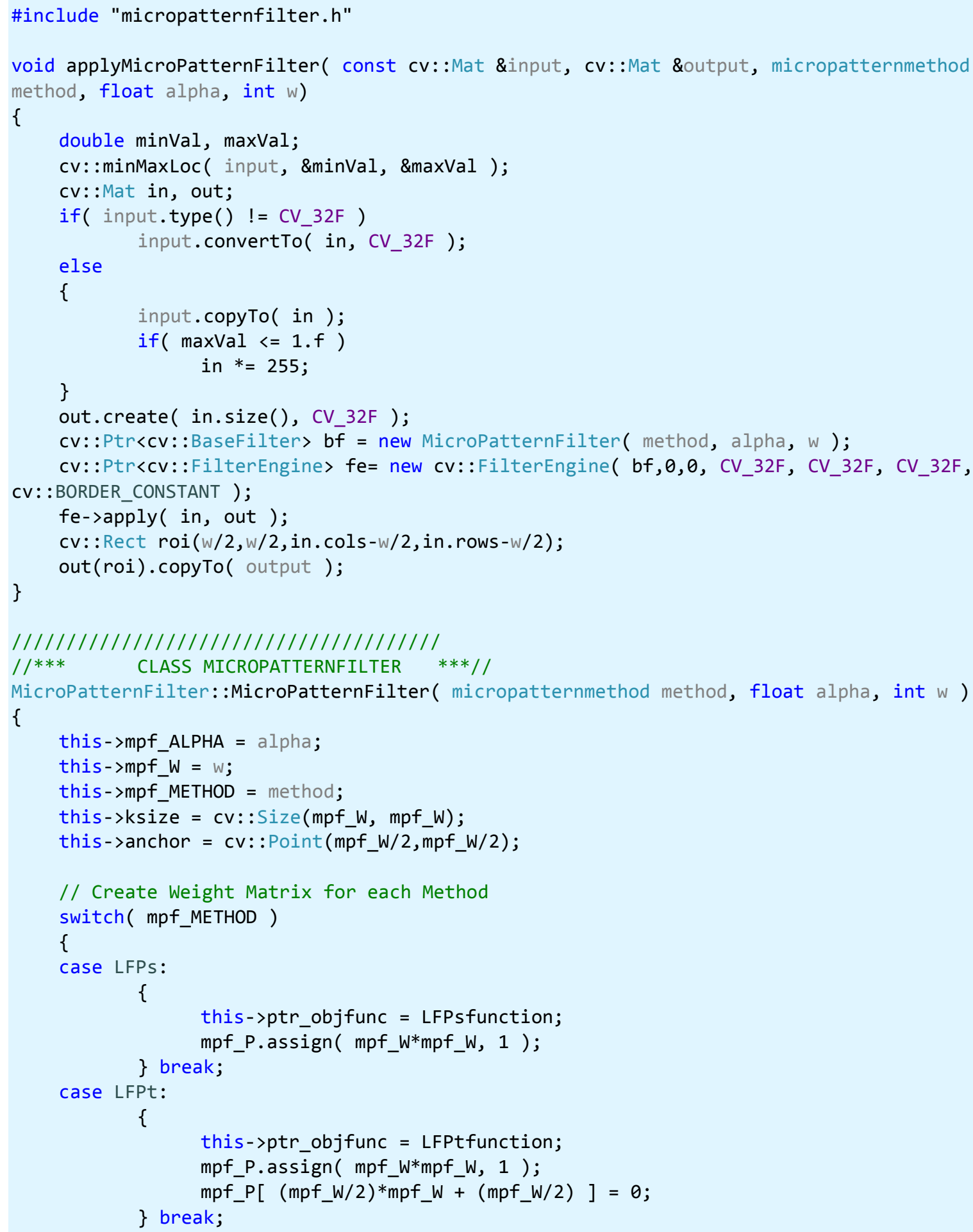




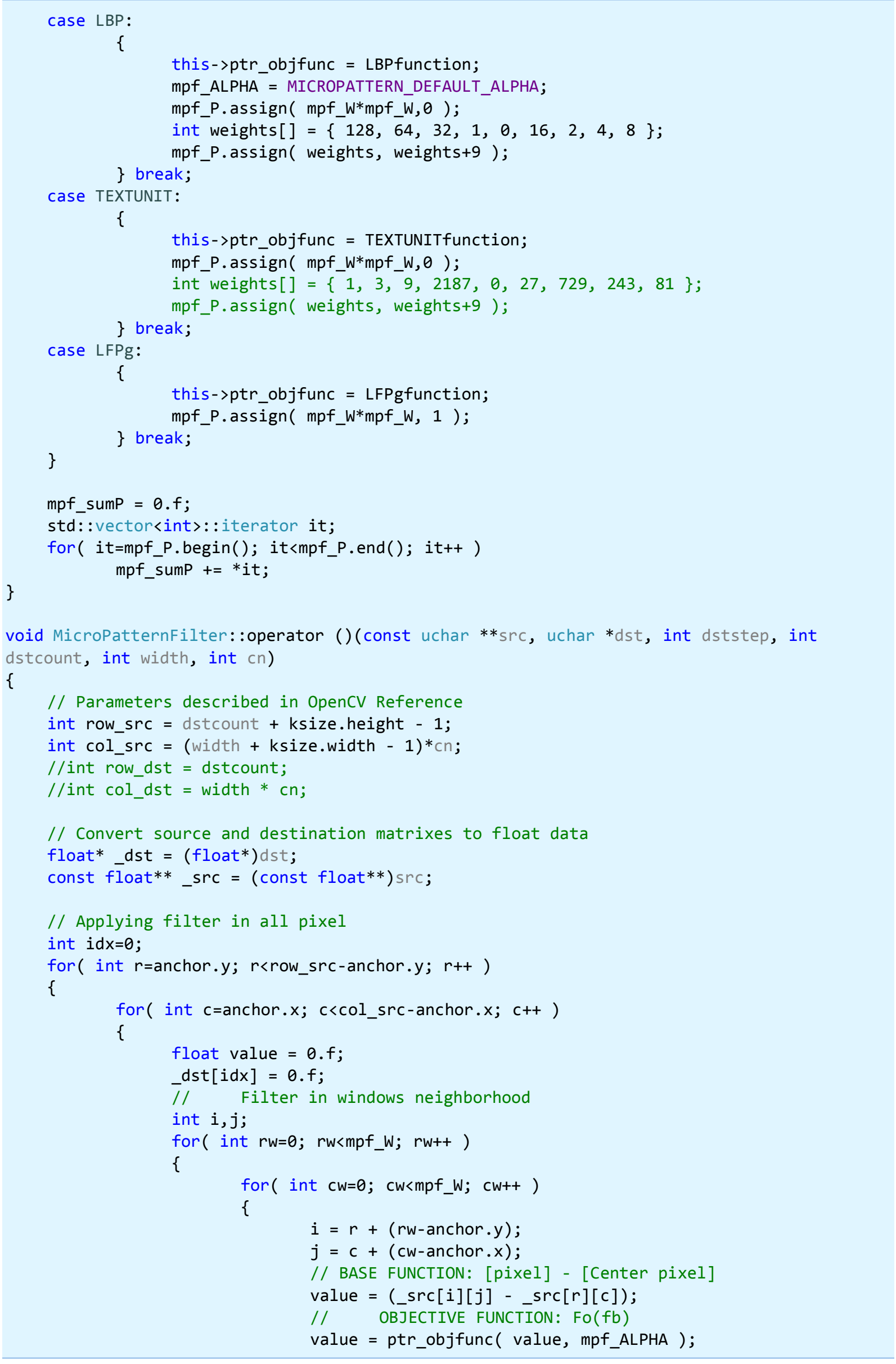




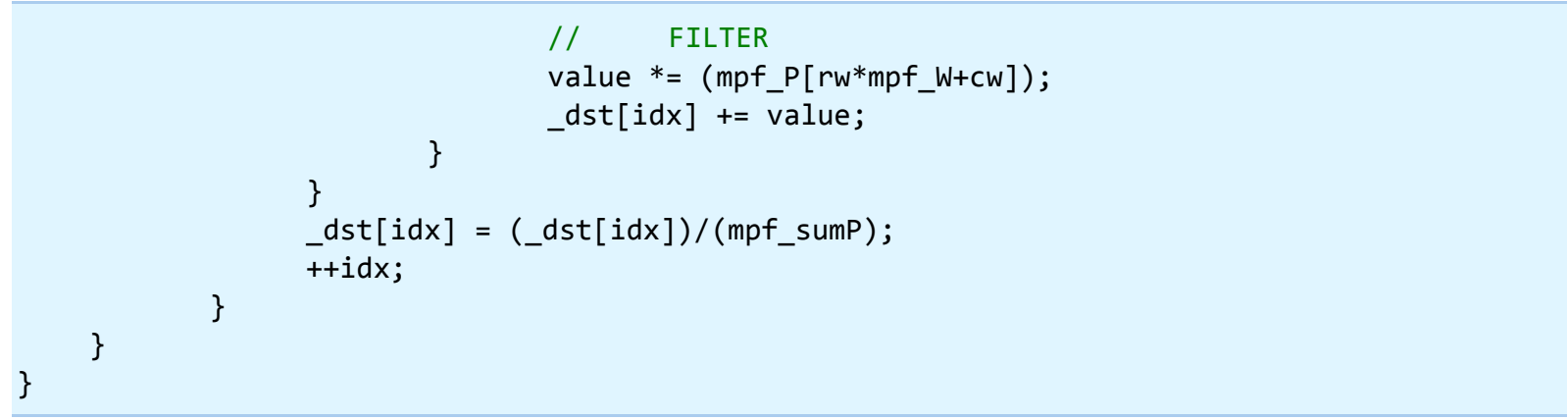

Por fim, o arquivo de definição das funções objetivos objectivefunctions.cpp:

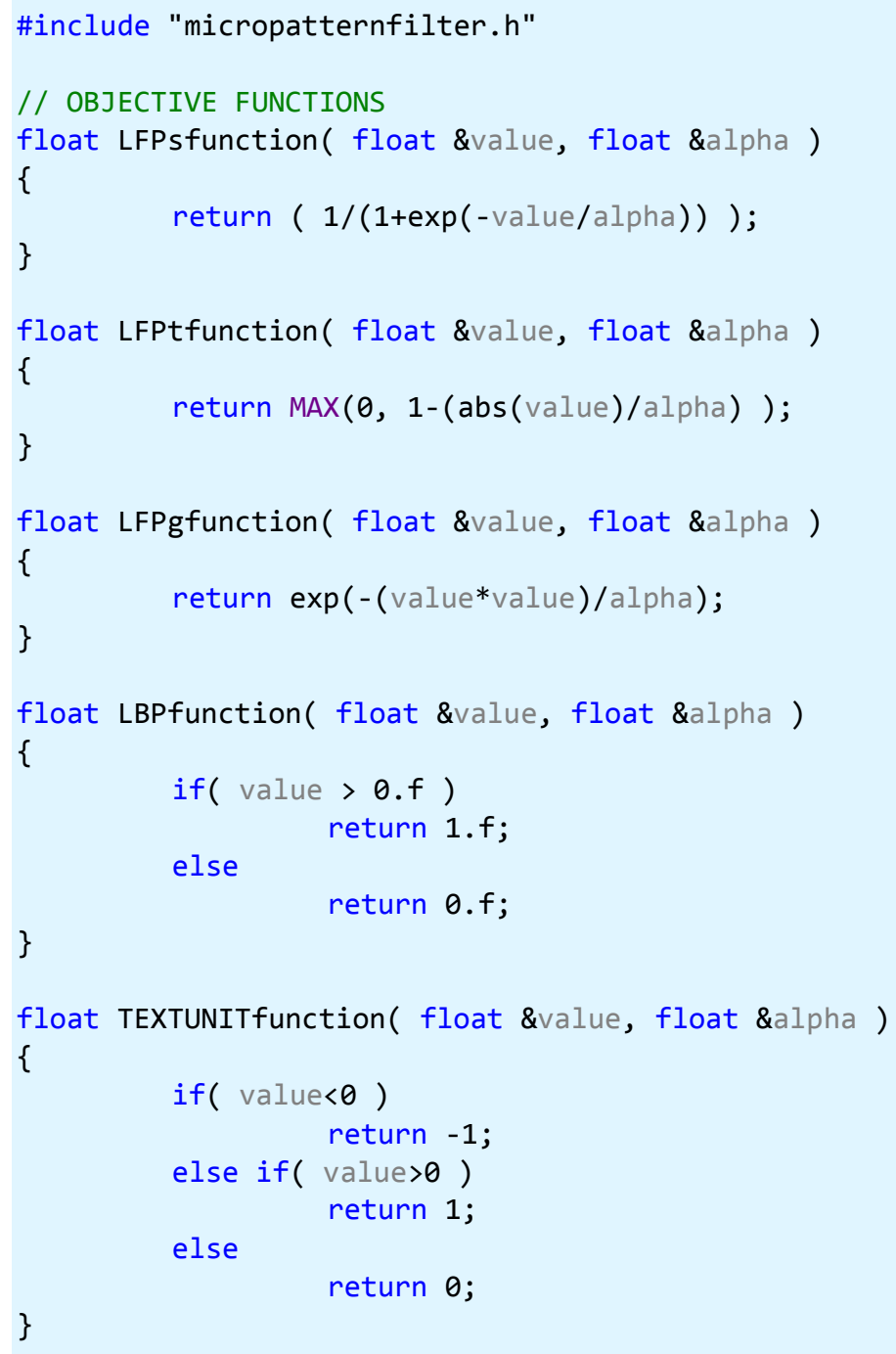


Arquivo exemplo da execução do descritor de textura, testemp.cpp

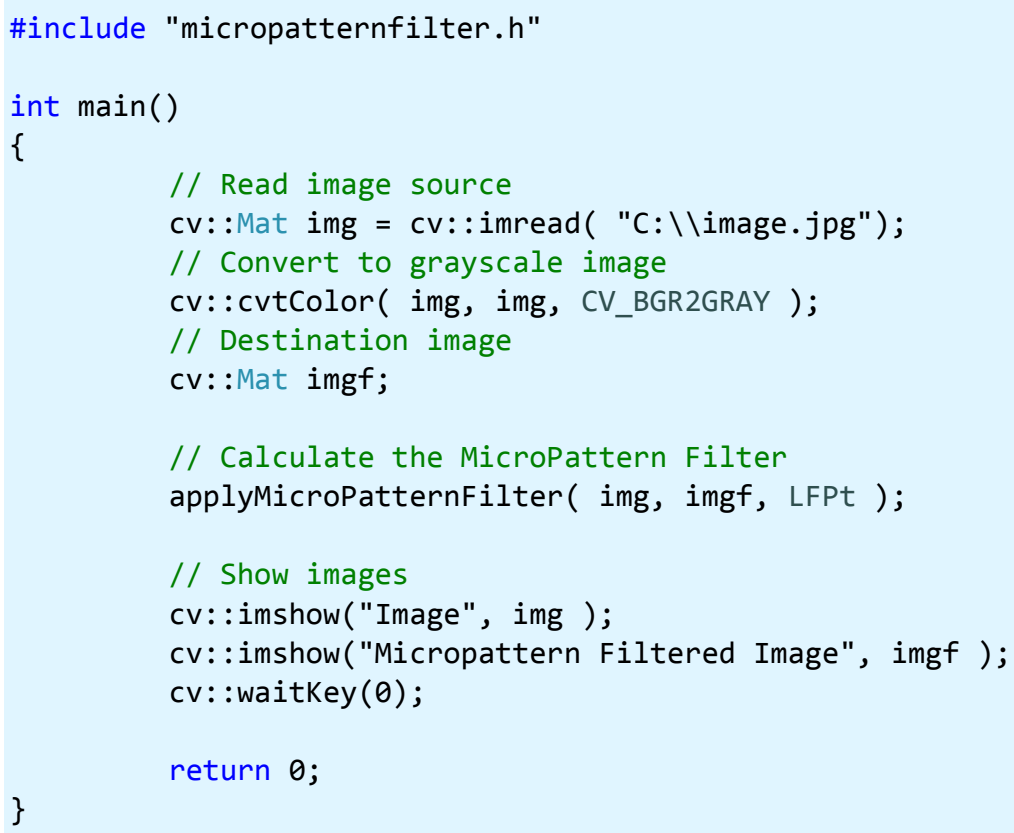




\section{REFERÊNCIAS BIBLIOGRÁFICA}

AHONEN, T., HADID, A., PIETIKÄINEN, M. (2006) Face Description with Local Binary Patterns: Application to Face Recognition. IEEE Transactions on Pattern Analysis and Machine Intelligence, v. 28, n. 12, p. 2037-2041. DOI:

10.1109/TPAMI.2006.244.

ALBUQUERQUE, M. P.; ALBUQUERQUE, M. P. (2000) Processamento de Imagens:

Métodos e Análises. Centro Brasileiro de Pesquisas Científicas, Rio de Janeiro.

Disponível em: <http://www.cbpf.br/cat/download/publicacoes/pdf/

ProcessamentoImagens.PDF $>$

ARAÚJO, J. J. (2007) Estudo do Impacto de Veículos Pesados Sobre a Infra-Estrutura Rodoviária Através de Simulação Microscópica de Tráfego. 154 p. Tese (Doutorado) - Escola de Engenharia de São Carlos, Universidade de São Paulo, São Carlos. Disponível em: <http://www.teses.usp.br/teses/disponiveis/ 18/18137/tde06112007-172037>

BADENAS, J.; BOBER, M.; PLA, F. (2001) Segmenting Traffic Scenes from Grey Level and Motion Information. Pattern Analysis \& Application, v. 4, n. 1, p. 28-38. DOI: $10.1007 /$ s100440170022.

BATISTA, J.; PEIXOTO, P.; FERNANDES, C.; RIBEIRO, M. (2006) A Dual-Stage Robust Vehicle Detection and Tracking for Real-time Traffic Monitoring. IEEE Intelligent Transportation Systems Conference, p. 528-535. DOI: 10.1109/ITSC.2006.1706795.

BENEZETH, Y.; JODOIN, P. M.; EMILE, B.; LAURENT, H.; ROSENBERG, C. (2008) Review and Evaluation of Commonly-Implemented Background Subtraction Algorithms. International Conference on Pattern Recognition ICPR, p. 1-4. DOI: 10.1109/ICPR.2008.4760998.

BEZDEK, J. C. (2005) Fuzzy Models and Algorithms for Pattern Recognition and Image Processing. New York: Springer.

BOAVEnTURA, I. A. G. (2010) Números Fuzzy em Processamento de Imagens Digitais e Suas Aplicações na Detecção de Bordas. 218 p. Tese (doutorado) - Universidade de São Paulo, Escola de Engenharia de São Carlos, Departamento de Engenharia Elétrica. Disponível em: < http://www.teses.usp.br/teses/ disponiveis/18/18152/tde-06052010154227/pt-br.php $>$.

BOAVENTURA, I. A. G.; GONZAGA, A. (2007) Uma Abordagem Fuzzy para Detecção de Bordas em Imagens Digitais. Congresso Nacional de Matemática Aplicada e Computacional. Disponível em: < http://www.sbmac.org.br/eventos/ cnmac/Xxx_cnmac/PDF/259.pdf $>$

BRADSKI, G.; KAEHLER, A. (2008) Learning OpenCV. Sebastopol: O’Reilly Media Inc. 555 p. ISBN: 978-0-596-51613-0. 
BRUNO, O. M.; CARVALHO, L. A. V. (2008) Óptica e Fisiologia da Visão - Uma Abordagem Multidisciplinar. Editora Roca: São Paulo. ISBN 978-85-7241-711-2.

CHANDLER, R. E; HERMAN, R.; MONTROLL, E. W. (1958) Traffic Dynamics: Studies in Car Following. Operations Research, v. 6, p. 165-184. Disponível em <http://www. mathstat.dal.ca/ iron/math4190/Papers/traffic.pdf $>$.

CHEN, C. J.; CHIU, C. C. ; WU, B. F.; LIN, S. P.; HUANG, C. D. (2004) The moving object segmentation approach to vehicle extraction. Proceedings of IEEE International Conference on Networking, Sensing and Control, v. 1, p. 19-23.

CHEN, C.; ZHANG, X. (2012) Moving Vehicle Detection Based on Union of Three-Frame Difference. Advances in Electronic Engineering, Communication and Management vol. 2, p. 459-464. DOI: 10.1007/978-3-642-27296-7_71.

CHEN, J.; LIU, Q.; HUANG, J. (2011) A Traffic Parameter Detection Based on Computer Vision. $3^{\text {rd }}$ International Conference on Advanced Computer Control (ICACC). DOI: 10.1109/ICACC.2011.6016483.

CHIU, C.-C.; KU, M.-U. (2009) Robust Background Subtraction Algorithm in Intelligence Traffic System. Journal of Meiho Institute of Technology, vol. 28, n. 1, p. 55-76. Disponível em: < http://wr.meiho.edu.tw/course/file/04Robust\% 20Background\%20Subtraction\%20Algorithm\%20in\%20Intelligence\%20Traffic\%20Sys tem.pdf $>$.

CHIU, C.-C.; KU, M.-Y.; LIANG, L.-W. (2010) A Robust Object Segmentation System Using a Probability-Based Background Extraction Algorithm. IEEE Transaction on Circuits and Systems for Video Technology, v. 20, n. 4, p. 518-528. DOI: 10.1109/TCSVT.2009.2035843.

CHIU, C.-C.; KU, M.-Y.; WANG, C.-Y. (2010) Automatic Traffic Surveillance System for Vision-Based Vehicle Recognition and Tracking. Journal of Information Science and Engineering, n. 26, p. 611-629. Disponível em: < http://www.iis.sinica.edu.tw/page/jise /2010/201003_17.pdf $>$.

COIFMAN, B.; BEYMER, D.; MCLAUCHLAN, P.; MALIK, J. (1998) A real-time computer vision system for vehicle tracking and traffic surveillance. Transportation Research Part C: Emerging Technologies, v. 6, n. 4, p. 271-288. DOI: 10.1016/S0968-090X(98)00019-9.

CROWLEY, J. L.; CHRISTENSEN, H. I. (1995) Vision as Process: Basic Research on Computer Vision Systems. Verlag: Springer. 435 p.

CUNHA, A. L. B. N. (2007) Avaliação do Impacto da Medida de Desempenho no Equivalente Veicular de Caminhões. Dissertação (Mestrado) - Escola de Engenharia de São Carlos, Universidade de São Paulo, São Carlos. Disponível em: < http://www.teses.usp.br/teses/disponiveis/18/18144/tde-27112007-094400 >. 
CUNHA, A. L. B. N.; MODOTTI, M. M.; SETTI, J. R. (2008) Classificação de Caminhões através de Agrupamento por Análise de Cluster. Anais do Congresso em Pesquisa e Ensino em Transportes, ANPET, Florianópolis, SC.

DAGANZO, C. Fundamentals of Transportation and Traffic Operation. $1^{\text {a }}$ edição. Oxford: Pergamon-Elsevier. 339 p.

DNIT (2006) Manual de Estudos de Tráfego. Departamento Nacional de Infraestrutura de Transportes. Instituto de Pesquisas Rodoviárias. Rio de Janeiro, 384 p. Disponível em: $<$ http://ipr.dnit.gov.br/manuais/manual_estudos_trafego .pdf $>$.

DOURADO, D. A. F. (2007) Gerenciamento da Demanda de Tráfego em Tempo Real. Dissertação (mestrado). Instituto Militar de Engenharia (IME). Rio de Janeiro, 188 p.

EDIE, L. (1963) Discussion of Traffic Stream Measurements and Definitions. Proceedings of the Second International Symposium on the Theory of Traffic Flow, p. 139-154. Citado por Coifman et al. (1998).

EGAMI, C. Y. (2006) Adaptação do HCM-2000 para Determinação do Nível de Serviço em Rodovias de Pista Simples Sem Faixas Adicionais no Brasil. 233 p. Tese (Doutorado) - Escola de Engenharia de São Carlos, Universidade de São Paulo, São Carlos. Disponível em: < http://www.teses.usp.br/teses/disponiveis/ 18/18137/tde-1002 2011-105402 >

ELHABIN, S. Y; EL-SAYED, K. M; AHMED, S. H. (2008) Moving Objects Detection in Spatial Domain Using Background Removal Techniques - State-of-Art. Recent Patents on Computer Science, n. 1, p. 32-54. Disponível em: < http://www.benthamscience .com/cseng/samples/cseng1-1/Elhabian.pdf $>$.

FAWCETT, T. (2005) An Introduction to ROC Analysis. Pattern Recognition Letters, v. 27, n. 8, p. 861-874. DOI: 10.1016/j.patrec.2005.10.010

FERREIRA, M. A. L (2008) Vigilância e Monitoramento em Tempo Real de Veículos em Rodovias com Câmeras Não-Calibradas. 69 p. Dissertação (mestrado) - PUC-Rio, Departamento de Informática. Disponível em: < http://www.maxwell.lambda.ele.pucrio.br/Busca_etds.php?strSecao=resultado \&nrSeq=12971@1 >.

FHWA (1997) Field Test for Monitoring of Urban Vehicle Operations Using NonIntrusive Technologies: Final Report. Report No. FHWA-PL-97-018, Minnesota Department of Transportation and SRF Consulting Group, Minneapolis, MN, EUA. Disponível em < http://ntl.bts.gov/lib/jpodocs/repts_te/ 6665.pdf > .

FU, X.; WANG, Z.; LIANG, D.; JIANG, J. (2004) The Extraction of Moving Object in RealTime Web-Based Video Sequence. 8th International Conference on Computer Supported Cooperative Work in Design, v. 1, p. 187-190. DOI: 10.1109/CACWD. 2004.1349013.

FUNG, G. S. K.; YUNG, N. H. C.; PANG, G. K. H.; LAI, A. H. S. (2000) Effective Moving Cast Shadow Detection for Monocular Color Image Sequence. International Conference on Image Analysis and Processing, p. 404-409. DOI: 10.1109/ ICIAP.2001.957043. 
GANGODKAR, D.; KUMAR, P.; MITTAL, A. (2012) Robust Segmentation of Moving Vehicles Under Complex Outdoor Conditions. IEEE Transactions on Intelligent Transportation Systems, v. 13, n. 4, p. 1738-1752. DOI: 10.1109/TITS.2012.2206076.

GODBEHERE, A.; MATSUKAWA, A.; GOLDBERG, K. (2012). Visual Tracking of Human Visitors under Variable-Lighting Conditions for a Responsive Audio Art Installation. American Control Conference, Montreal. Disponível em: < http://goldberg.berkeley.edu/pubs/acc-2012-visual-tracking-final.pdf $>$.

GONZALEZ, R. C.; WOODS, R. E. (2007) Processamento de Imagens Digitais. Editora Blutcher: São Paulo. 509 p. ISBN: 85-212-0264-44.

GONZALEZ, R. C.; WOODS, R. E.; EDDDINS, S. L. (2004) Digital Image Processing Using Matlab. New Jersey: Person Prentice Hall. 609 p. ISBN: 0-13-008519-7.

GREENSHIELDS, B. D.; BIBBINS, J. R.; CHANNING, W. S.; MILLER, H. H. (1935) A Study of Traffic Capacity; Highway Research Board, v. 14, HRB, National Research Council, Washington, D.C., p. 448-477. Disponível em: <http://www.tft.pdx.edu/ greenshields/docs/greenshields_1935_1.pdf>.

HADID, A., PIETIKÄINEN,M. (2009) Combining Appearance and Motion for Face and Gender Recognition from Videos. Pattern Recognition, v. 42, n. 11, p. 2818-2827. DOI: 10.1016/j.patcog.2009.02.011.

HARALICK, R. M.; SHAPIRO, L. G. (1985) Image Segmentation Techniques. Computer Vision, Graphics, and Image Processing, v. 29, n. 1, p. 100-132. DOI: 10.1016/ S0734-189X(85)90153-7.

HARITAOGLU, I.; HARWOOD, D.; DAVIS, L. S. (2000) W4: Real-Time Surveillance of People and Their Activities. IEEE Transactions on Pattern Analysis and Machine Intelligence, v. 22, n. 8, p. 809-830. DOI: 10.1109/34.868683.

HE, D.-C.; WANG, L. (1990) Texture Unit, Texture Spectrum, and Texture Analysis. IEEE Transactions on Geoscience and Remote Sensing, v. 28, n.4, p. 509-512.

HE, X. C.; YUNG, N. H. C. (2007) A Novel Algorithm for Estimating Vehicle Speed from Two Consecutive Images. IEEE Workshop on Applications of Computer Vision. DOI: 10.1109/WACV.2007.7.

HEIKKILÄ, M.; PIETIKÄINEN, M. (2006) A Texture-Based Method for Modeling the Background and Detection Moving Objects. IEEE Transactions on Pattern Analysis and Machine Intelligence, vol. 28, n. 4. DOI: 10.1109/TPAMI.2006.68.

HEIKKILÄ, J.; SILVÉN, O. (1997) A Four-Step Camera Calibration Procedure with Implicit Image Correction. IEEE Conference on Computer Vision and Pattern Recognition, p. 1106-1112. DOI: 10.1109/CVPR.1997.609468.

HEIKKILÄ, J.; SILVÉN, O. (1999) A Real-Time System for Monitoring of Cyclists and Pedestrian. IEEE Workshop on Visual Surveillance, p. 74-81. DOI: 10.1109/VS.1999.780271. 
HU, Q.; LI, S.; HE, K.; LIN, H. (2010) A Robust Fusion Method for Vehicle Detection in Road Traffic Surveillance. Advanced Computing Theories and Applications (Lecture Notes in Computer Science 6216), p. 180-187. DOI: 10.1007/978-3-642-14932-0_23.

HU, W.; TAN, T.; WANG, L.; MAYBANK, S. (2004) A Survey on Visual Surveillance of Object Motion and Behaviors. IEEE Transactions on Systems, Man, and Cybernetics - Part C: Application and Review, v. 34, n. 3, p. 334-352. DOI: 10.1109/TSMCC. 2004.829274

HUNG, M.-H.; PAN, J.-S.; HSIEH, C.-H. (2010) Speed Up Temporal Median Filter for Background Subtraction. 2011 First International Conference on Pervasive Computing, Signal Processing and Applications. DOI: 10.1109/PCSPA.2010.79.

JAIN, A. K.; DUBES, R. C. (1988) Algorithms for Clustering Data. New Jersey: Pretince Hall. 334p.

JELAČA, V.; PIŽURICA, A.; PHILIPS, W. (2009) Computationally Efficient Algorithm for Tracking of Vehicles in Tunnels. Proceedings of the IEEE Benelux Workshop on Circuits, Systems and Signal Processing, p. 335-338.

JIN, C.; CHANG, G.; CHENG, W.; JIANG, H. (2011) Background Extraction and Update Method Based on Histogram in YCbCr Color Space. International Conference on EBussiness and E-Government (ICEE), p. 1-4. Shanghai, China. DOI: 10.1109/ICEBEG.2011.5882095.

JUNG, Y.-K.; HO, Y.-S. (1999) Traffic Parameter Extraction using Video-based Vehicle Tracking. IEEE International Conference on Intelligent Transportation Systems, p. 764-769. DOI: 10.1109/ITSC.1999.821157.

KANHERE, N. (2008) Vision-Based Detection, Tracking and Classification of Vehicles using Stable Features with Automatic Camera Calibration. Tese (doutorado), Clemson University, Clemson, SC, EUA. Disponível em <http://etd.lib.clemson.edu/ documents/1219861574/umi-clemson-1773.pdf>.

KAUFMAN, L.; ROUSSEEUW, P. J. (1990) Finding Groups in Data: An Introduction to Cluster Analysis. John Wiley \& Sons, Hoboken.

KHORRAMSHASHI, V.; BEHRAD, A.; KANHERE, N. K. (2008) Over-Height Vehicle Detection in Low Headroom Roads Using Digital Video Processing. International Journal of Computer, Information, and Systems Science, and Engineering, v. 2, n. 2, p. 82-86. Disponível em: < http://www.techrepublic.com/resource-

library/whitepapers/over-height-vehicle-detection-in-low-headroom-roads-using-digitalvideo-processing/ > .

KLEIN, L. A. (2001) Sensor Technologies and Data Requirements for ITS. Boston: Editora Artech House. 549 p.

KLEIN, L. A.; MILLS, M. K.; GIBSON, D. (2006) Traffic Detector Handbook. $3^{\mathrm{a}}$ edição, volume 1. Publication No. FHWA-HRT-06-108. Federal Highway Administration, Turner-Fairbank Highway Research Center, EUA, 288 p. Disponível em < http://www.fhwa.dot.gov/publications/research/operations/its/ 06108/06108.pdf > 
KNOOP, V. L.; HOOGENDOORN, S. P.; VAN ZUYLEN, H. J. (2009) Processing Traffic Data Collected by Remote Sensing. Transportation Research Record: Journal of Transportation Research Board, n. 2129, Washington, D.C., p. 55-61. DOI: 10.3141/ 2129-07.

KYTE, M.; KHAN, A.; KAGOLANU, K. (1993) Using Machine Vision (Video Imaging) Technology to Collect Transportation Data. Transportation Research Record, vol. 1412, p. 23-32.

LAGANIÉRE, R. (2011) OpenCV 2 Computer Vision Application Programming Cookbook. Packt Publishing Ltda. Birmingham, Inglaterra. 287p.

LAI, A. H. S.; FUNG, G. S. K.; YUNG, N. H. C. (2001) Vehicle Type Classification from Visual-Based Dimension Estimation. IEEE Intelligence Transportation Systems Conference, p. 201-206. DOI: 10.1109/ITSC.2001.948656.

LAI, A. H. S.; YUNG, N. H. C (1998) A Fast and Accurate Scoreboard Algorithm for Estimating Stationary Backgrounds in an Image Sequence. IEEE International Symposium on Circuits and Systems Proceedings. Monterey, California. DOI: 10.1109/ISCAS.1998.698804.

LAM, W. W. L.; PANG, C. C. C.; YUNG, N. H. C. (2003) Vehicle Feature Extraction by Patch-Based Sampling. Proceedings of Image and Video Communications and Processing, Electronic Imaging: Science and Technology, v. 5022, p. 921-932. DOI: 10.1117/12.476650.

LAM, W. W. L.; PANG, C. C. C.; YUNG, N. H. C. (2004) Highly Accurate Texture-Based Vehicle Segmentation Method. Optical Engineering, v. 43, n. 3, p. 591-563. DOI: 10.1117/1.1645849.

LEDUC, G. (2008) Road traffic data: collection methods and applications. JRC Technical Notes, 53 p. Disponível em: < http://ipts.jrc.ec.europa.eu/publications/ pub.cfm?id= $1839>$.

LI, M.; ZHU, Y.; HUANG, J. (2009) Video Background Extraction Based on Improved Mode Algorithm. 2009 Third International Conference on Genetic and Evolutionary Computing. DOI: 10.1109/WGEC.2009.51.

LIEN, C.-C.; TSAI, Y.-T.; TSAI, M.-H.; JANG, L. G. (2011) Vehicle Counting without Background Modeling. Advances in Multimedia Modeling (Lecture Notes in Computer Science 6523), p. 446-456. DOI: 10.1007/978-3-642-17832-0_42.

LOUREIRO, P. F. Q.; ROSSETTI, R. J. F.; BRAGA, R. A. M. (2009) Video Processing Techniques for Traffic Information Acquisition Using Uncontrolled Video Streams. IEEE Conference on Intelligent Transportation Systems, p. 1-7. DOI: 10.1109/ ITSC.2009.5309595.

MARTEKA, A.; STRZELECKI, M. Texture Analysis Methods: A Review. Technical report, University of Lodz. Disponível em: http://citeseerx.ist.psu.edu/viewdoc/ download?doi=10.1.1.97.4968\&rep=rep1\&type=pdf $>$. 
MARTIN, P. T.; FENG, Y.; WANG, X. (2003) Detector Technology Evaluation. 128 p. Department of Civil and Environmental Engineering, University of Utah Traffic Lab. Disponível em: <http://www.mountain-plains.org/pubs/pdf/MPC03-154.pdf>. Acesso em: 8/9/2013.

\section{MATHWORKS (2012) Matlab R2012a User's Guide.}

MEJIA-IÑIGO, R.; BARRILA-PÉREZ, M. E.; MONTES-VENEGAS, H. A. (2008) Colorbased Texture Image Segmentation for Vehicle Detection. International Conference on Electrical Engineering, Computing Science and Automatic Control, p. 1-6. DOI: 10.1109/ICEEE.2009.5393396.

METZ, C. E. (1978) Basic Principles of ROC Analysis. Seminars in Nuclear Medicine, vol. 3, n. 4, p. 283-298. Disponível em: < ftp://norbif.uio.no/pub/outgoing/runeho/KR/ Metz78SeminNuclMed8-283.pdf $>$.

MICHALOPOULOS, P. G. (1991) Vehicle Detection Video Through Image Processing: The AUTOSCOPE System. IEEE Transactions on Vehicular Technology, vol. 40, n. 1, p. 21-29. DOI:10.1109/25.69968.

MICHALOPOULOS, P. G.; FITCH, R.; WOLF B. (1989) Development and Evaluation of a Breadboard Video Imaging System for Wide Area Vehicle Detection. Transportation Research Record, v. 1225, p. 140-149.

MIDDLETON, D.; GOPALAKRISHNA, D.; RAMAN, M. (2002) Advances in Traffic Data Collection and Management - White Paper. Traffic Data Quality Workshop. FHWA, DOT, Washington, D.C. Disponível em < http://www.trpc.org/regionalplanning/transportation/projects/Documents/Smart\%20Corr idors/ advancestrafficdata.pdf $>$

MOEN, B. A.; KOLLBAUM, J. A.; BONNESON, J. A.; MCCOY, P. T. (2003) Traffic Data Collection Using a Computerized Data Acquisition System. Transportation Research Record, vol. 1412, p. 39-45.

MON-MA, M. L. (2009) Adaptação do HCM-2000 para Rodovias de Pista Simples com Faixas Adicionais Típicas do Estado de São Paulo. 179p. Tese (Doutorado) - Escola de Engenharia de São Carlos, Universidade de São Paulo, São Carlos.

MONTEIRO, G.; MARCOS, J.; RIBEIRO, M.; BATISTA, J. (2008) Robust Segmentation for Outdoor Traffic Surveillance. IEEE International Conference on Image Processing, p. 2652-2655. DOI: 10.1109/ICIP.2008.4712339.

NIXON, M.; AGUADO, A. S. (2012) Feature Extraction \& Image Processing for Computer Vision. Londres: Elsevier. 424 p. ISBN: 978-0-123-96549-3

OJALA, T.; PIETIKÄINEN, M.; HARWOOD, D. (1996) A Comparative Study Of Texture Measures With Classification Based on Feature Distributions. Pattern Recognition, v. 29, n. 1, p. 51-59. DOI: 10.1016/0031-3203(95)00067-4.

OLIVEIRA, A. B.; SCHARCANSKI, J. (2010) Vehicle Counting and Trajectory Detection Based on Particle Filtering. 23 ${ }^{\circ}$ SIBGRAPI Conference on Graphics, Patterns and Images, p. 376-383. DOI: 10.1109/SIBGRAPI.2010.57. 
PAL, N. R.; PAL, S. K. (1993) A Review on Image Segmentation Techniques. Pattern Recognition, v. 26, n. 9, p.1277-1294. DOI: 10.1016/0031-3203(93)90135-J.

PAN, J.; LIN, C.-W.; GU, C.; SUN, M.-T. (2002) A Robust Video Object Segmentation Scheme With Prestored Background Information. IEEE International Symposium on Circuits and Systems, v. 3, p. 803-806.

PARK, Y. (2001) Shape-resolving local thresholding for object detection. Pattern Recognition Letters, v. 22, n. 8, p. 883-890.

PARKER, J. R. (2010) Algorithms for Image Processing and Computer Vision. $2^{\text {nd }}$ edition. Indianapolis: Wyley Publishing, Inc. 480 p. ISBN: 9780470643853.

PIETIKÄINEN M.; A. HADID; G. ZHAO; T. AHONEN (2011) Computer Vision Using Local Binary Pattern. Londres: Ed. Springer. 207 p.

PORIKLI, F. (2005) Multiplicative Background-Foreground Estimation Under Uncontrolled Illumination using Intrinsic Images. IEEE Workshop on Motion and Video Computing, v. 2, n. 2, p. 20-27. Disponível em: < http://ieeexplore.ieee.org/stamp/ stamp.jsp?arnumber $=04129580>$.

SETCHELL, C. J. (1997) Applications of Computer Vision to Road Traffic Monitoring. Tese (doutorado) Universidade de Bristol. 170 p. Disponível em: < http://www.cs.bris.ac.uk/Publications/pub_master.jsp?id=1000217 >.

SETTI, J. R. A. (2002) Tecnologia de Transportes. Material didático, 214 p. Universidade de São Paulo, Escola de Engenharia de São Carlos.

SILVA, E. A.; GONZAGA, A. (2006) Detecção de Veículos em Movimento Usando Modelo de Misturas Gaussianas e RNAs. II Workshop de Visão Computacional (WVC), São Carlos, SP. Disponível em: < http://iris.sel.eesc.usp.br/lavi/pdf/wvc2006_0033.pdf >.

SKLANSKY, J. (1978) Image Segmentation and Feature Extraction. IEEE Transactions on Systems, Man and Cybernetics, v. 13, n. 5, p. 907-916. Disponível em: < http://ieeexplore.ieee.org/stamp/stamp.jsp?arnumber=04309944 >.

STROUSTRUP, B. (2000) A Linguagem de Programação C++. $3^{a}$ edição. São Paulo: Bookman Editora. 823 p.

SZELISKI, R. (2011) Computer Vision: Algorithms and Applications. Texts in Computer Science. Londres: Editora Springer. 812 p.

TANCREDI, P. R. (2012) Monitoramento do Acesso de Veículos de Carga em Vias Urbanas. 81 p. Dissertação (mestrado) - Escola de Engenharia de São Carlos, Universidade de São Paulo, São Carlos. Disponível em: < http://www.teses.usp.br/teses/disponiveis/18/18144/tde-20062013-161631/pt-br.php >.

TANG, Z.; MIAO, Z.; WAN, Y. (2007) Background Subtraction Using Running Gaussian Average and Frame Difference. Entertainment Computing - ICEC 2007 (Lecture 
Notes in Computer Science 4740), p. 411-414. International Federation for Information Processing. DOI: 10.1007/978-3-540-74873-1_50.

TOYAMA, K.; KRUMM, J.; BRUMITT, B.; MEYERS, B. (1999) Wallflower: Principles and Pratice of Background Maintenance. IEEE International Conference on Computer Vision, v.1, p. 255-261. DOI: 10.1109/ICCV.1999.791228.

TSAI, R. Y. (1987) A Versatile Camera Calibration Technique for High Accuracy 3D Machine Vision Metrology using Off-The-Shelf TV Cameras and Lenses. IEEE Journal of Robotics and Automation, v. 3, n. 4, p. 323-344. Disponível em: < http://www. vision.caltech.edu/bouguetj/calib_doc/papers/Tsai.pdf >.

VERSAVEL, J.; LEMAIRE, F.; VAN DER STEDE, D. (1989) Camera and Computer-aided Traffic Sensor. $2^{\text {nd }}$ International Conference on Road Traffic Monitoring, Londres, p. 66-70.

VIEIRA, R. T. (2013) Análise de Micropadrões em Imagens Digitais Baseada em Números Fuzzy. 155 p. Dissertação (mestrado) - Universidade de São Paulo, Escola de Engenharia de São Carlos, Departamento de Engenharia Elétrica. Disponível em: < http://www.teses.usp.br/teses/disponiveis/18/18152/tde-29042013-154729/pt-br.php >.

VIEIRA, R. T.; CHIERICI, C. E. O.; FERRAZ, C. T.; GONZAGA, A. (2012) Local Fuzzy Pattern: A New Way for Micro-pattern Analysis. Intelligent Data Engineering and Automated Learning - IDEAL 2012 (Lecture Notes in Computer Science 7435), p. 602-611. DOI: 10.1007/978-3-642-32639-4_73.

WANG, C.; SONG, Z. (2011) Vehicle Detection Based on Spatial-Temporal Connection Background Subtraction. IEEE Conference on Information and Automation, p. 320323. DOI: 10.1109/ICINFA.2011.5949009.

WANG, G.; XIAO, D.; GU, J. (2008) Review on Vehicle Detection Based on Video for Traffic Surveillance. IEEE International Conference on Automation and Logistics, p. 2961-2966. DOI:10.1109/ICAL.2008.4636684.

WEISS, Y. (2001) Deriving intrinsic images from image sequences. IEEE International Conference on Computer Vision, v. 2, p. 68-75. DOI: 10.1109/ICCV.2001.937606.

WORRALL, A. D.; SULLIVAN, G. D.; BAKER, K. D. (1994) A Simple, Intuitive Camera Calibration Tool for Natural Images. Proceedings of the Conference on British Machine Vision, v. 2, p. 781-790. Disponível em: < http://citeseerx.ist.psu.edu/viewdoc/download?doi=10.1.1.57.3568\&rep=rep1\&type=pdf $>$.

XIA, Y.; JIN, B.; GAN, Y.; HUANG, M.; CHEN, X. (2009) A Simple Vehicle Segmentation Approach for Intelligent Transportation System. Proceedings of the International Conference on Digital Image Processing, p. 225-228. DOI: 10.1109/ICDIP.2009.40.

XU, F.; SUN, L. (2013) An Efficient Video-Based Vehicle Trajectory Processing Approach. Proceedings of International Conference on Transportation and Safety (ICTIS 2013), ASCE, p. 1001-1007. DOI: 10.1061/9780784413036.135. 
YEN, J. C.; CHANG, F. J.; CHANG, S. (1995) A New Criterion for Automatic Multilevel Thresholding. IEEE Transactions on Image Processing, vol. 4, n. 3, p.370-378.

YONEYAMA, A.; YEH, C.-H.; KUO, C.-C. J. (2005) Robust Vehicle and Traffic Information Extraction for Highway Surveillance. EURASIP Journal on Applied Signal Processing, p. 2305-2321. DOI: 10.1155/ASP.2005.2305.

YU, Y.; YU, M.; YAN, G.; ZHAI, Y. (2011) Length-Based Vehicle Classification in Multilane Traffic Flow. Transactions on Tianjin University, v. 17, n. 5, p. 362-368. DOI: 10.1007/s12209-011-1598-0.

ZADEH, L. A. (1965) Fuzzy Sets. Information and Control, v. 8, p. 338-353.

ZHAO, G.; PIETIKÄINEN, M. (2007) Dynamic Texture Recognition Using Volume Local Binary Pattern. IEEE Transactions on Pattern Analysis and Machine Intelligence, v. 29, n. 6, p. 915-928. DOI: 10.1109/TPAMI.2007.1110.

ZHENG, J.; WANG, Y.; NIHAN, N. L.; HALLENBECK, M. E. (2006) Extracting Roadway Background Image. Transportation Research Record, v. 1944, p. 82-88. DOI: 10.3141/1944-11.

ZHONG, Q.; GUANGTING, S.; DONGHUI, L. YU, M.; YIWEI, H.; QINGSEN, C. (2011) Vehicle Segmentation Approach based on the Space-time and Self-similarity of Background. Advanced Materials Research, v. 179, p. 115-121. DOI: 10.4028/www. scientific.net/AMR.179-180.115.

ZIVKOVIC, Z. (2004) Improved Adaptive Gaussian Mixture Model for Background Subtraction. In: Proceedings of the $17^{\text {th }}$ International Conference on Pattern Recognition (ICPR 2004), v. 2, p. 28-31. DOI: 10.1109/ICPR.2004.1333992. 